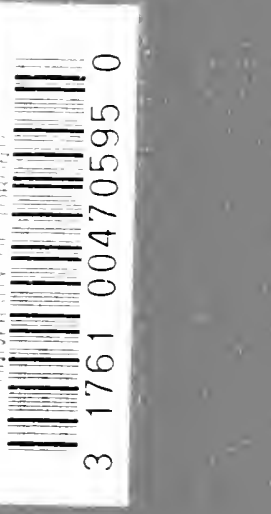

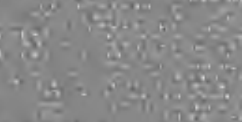

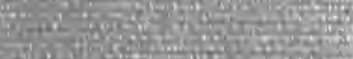

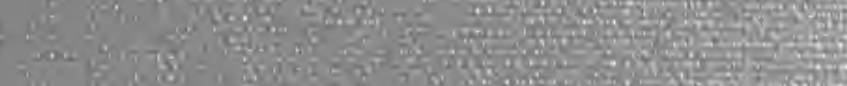

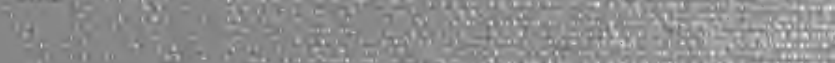

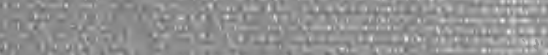

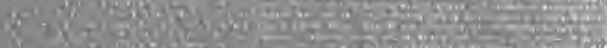

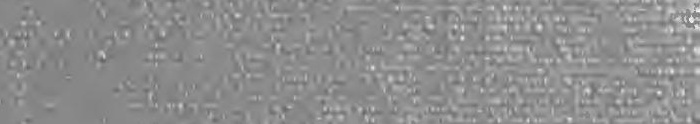

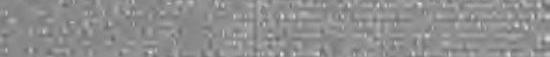

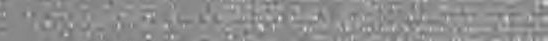

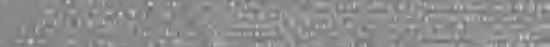

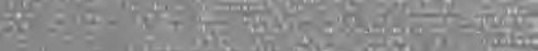

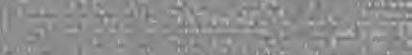

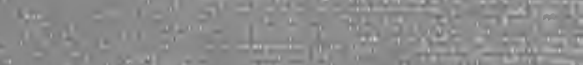

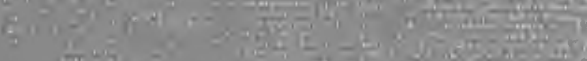

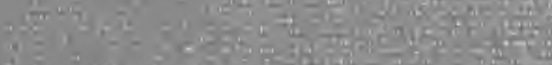

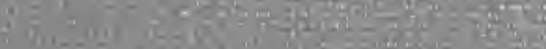

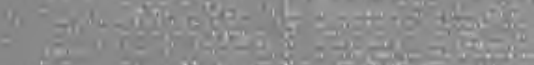

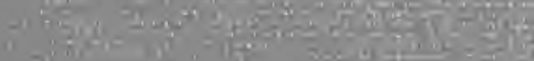

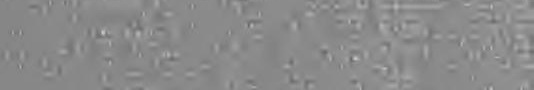

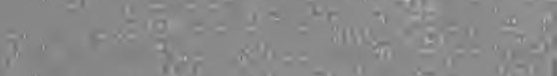
$a^{2}=7^{2}(x=98$

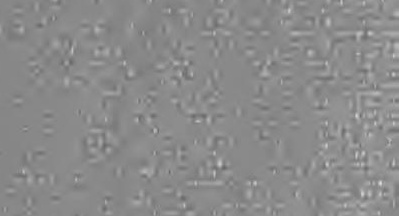

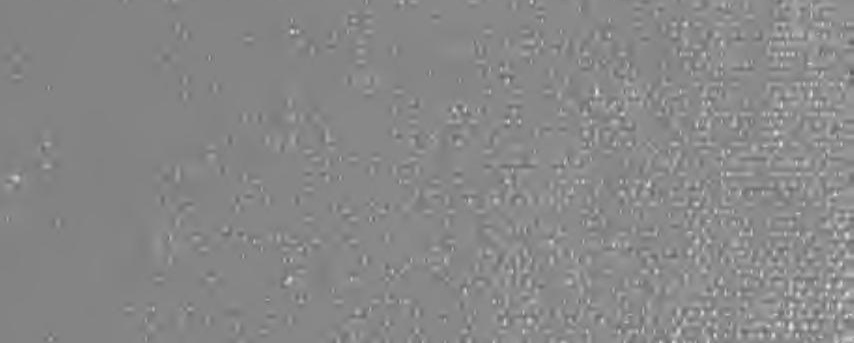


Digitized by the Internet Archive in 2008 with funding from Microsoft Corporation 


LANDMARKS AND SURFACE MARKINGS OF THE HUMAN BODY 




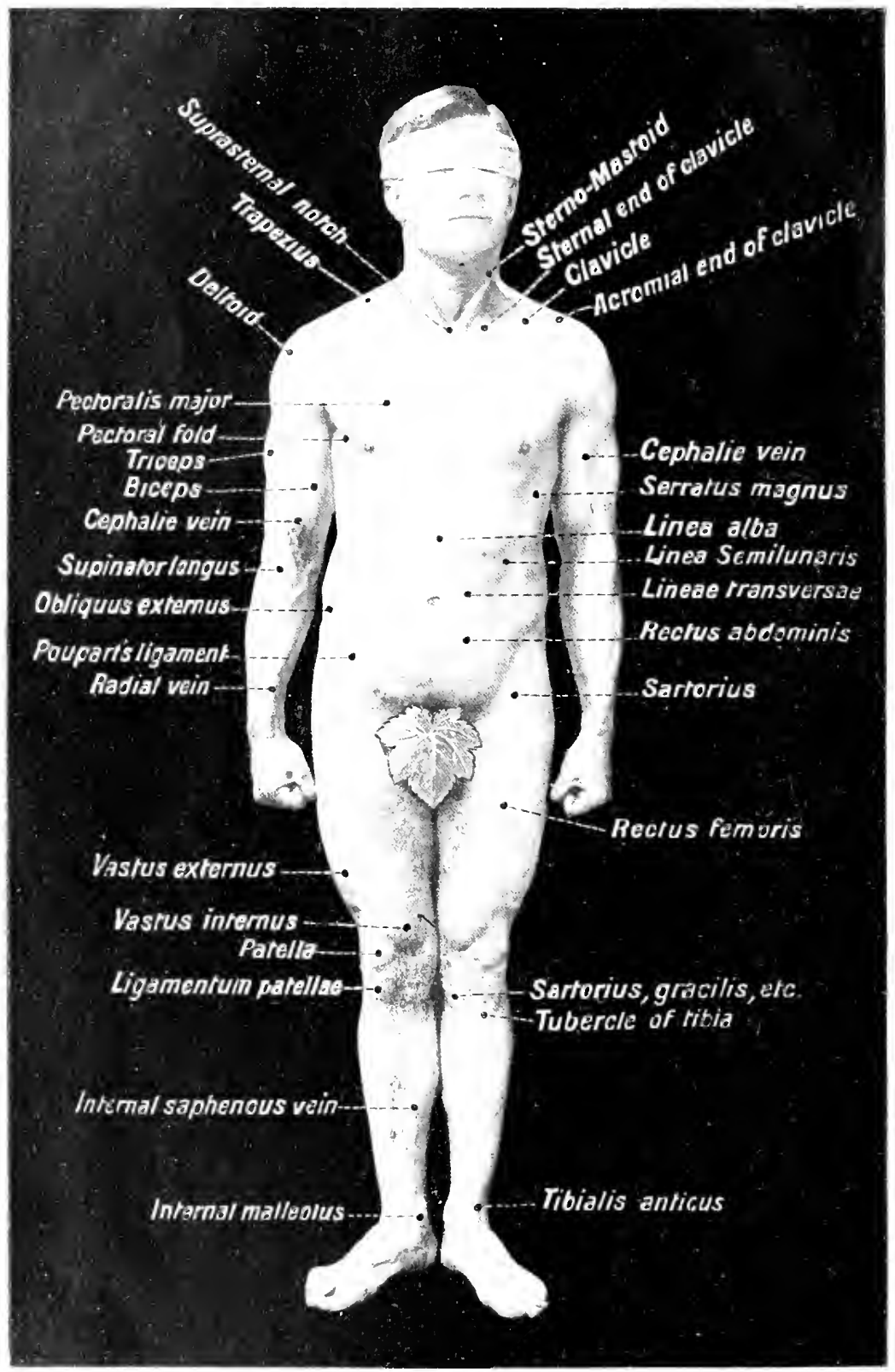




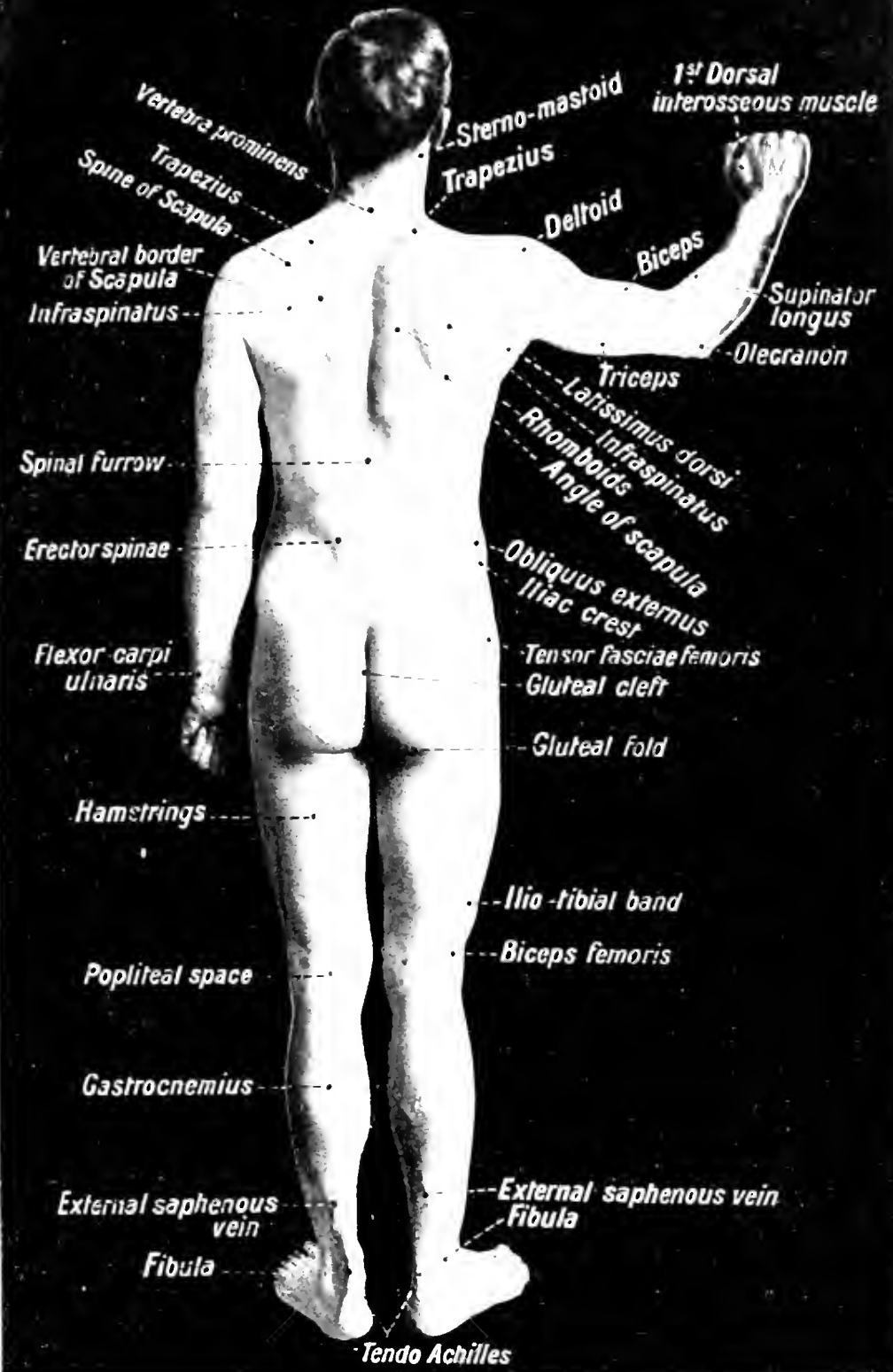





\title{
LANDMARKS AND
}

\section{SURFACE MARKINGS OF}

\section{THE HUMAN BODY}

\author{
BY \\ L. BATIE RAIVLING \\ M.L., B.C. (CANT.), F.R.C.S. \\ Surgeon, Senior Demonstrator of Operative Surgery, late Senior \\ Demonstrator of Anatom, Sr. Baktholomew's Hosittal; \\ hXaminek in SURgert at Cambridgr UniverstTy
}

WITH THILTY-ONE HLLUSTRATIONS

\section{FIFTH EDITION}

(LEVENTH REPRINT)

\section{TORONTO}

THE MACMILLAN COMPANY OF CANADA, LTD. 


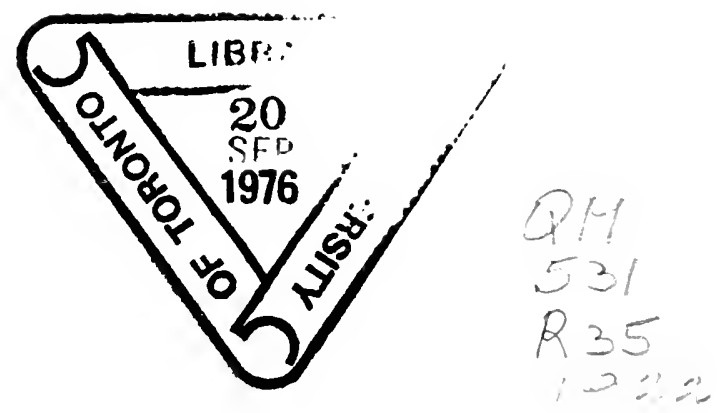

Cofyright.

Printal in England. 


\section{PREFACE \\ TO THE SIXTH REPRINT OF THE FIFTH EDITION}

DURING the War the Fifth Edition was reprinted five times. Now that the War is over one is tempted to reconstruct, to enlarge the scope of this work. But many reasons have decided me to refrain. "Landmarks and Surface Markings" was first published in 1904. It has met the demand, criticisms have been most kindly, and the sales continue to increase. In view of these facts, and in further consideration of the great increase in cost of production, I decided to leave the work as it is, in the anticipation that it will continue to meet with the approval of all those who are interested in the surface markings of the human body.

L. BATHE RAWLING.

August, 1920. 



\section{CONTENTS}

\section{CHAPTER ।}

\section{THE HEAD AND NECK \\ CHAPTER II}

THE UPPER EXTREMITY

CHAPTER III

THE THORAX

THE ABDOMEN

CHAPTER IV

CHAPTER V

THE LOWER EXTREMITY .

\section{APPENDIX}

THE Length of Various Passages, tUbes, Etc. - $\quad$ - 86

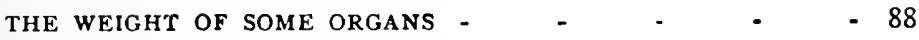
THE OSSIFICATION AND EPIPHYSES OF THE BONES OF THE UPPER AND LOWER EXTREMITIES $\quad$ - $\quad \cdot \quad \cdot \quad \cdot 89$

INDEX 


\section{ILLUSTRATIONS}

\begin{tabular}{|c|c|c|c|c|c|}
\hline \multicolumn{2}{|c|}{ I and 2. Cranio-cerebral Topography } & \multirow{2}{*}{$\cdot$} & \multirow[t]{2}{*}{ - } & \multirow{2}{*}{$\begin{array}{c}\text { To face } p . \\
\text { " }\end{array}$} & \multirow{2}{*}{$\begin{array}{r}4 \\
14,5\end{array}$} \\
\hline 3 and 4. The Side of the Neck & - & & & & \\
\hline 5. Tlie Front of the Neck & $\cdot$ & $\cdot$ & - & $"$ & 18 \\
\hline 6. The Front of the Arm and For & rin & - & - & ", & 2 \\
\hline 7. The Elbow and Back Region & $\cdot$ & $\cdot$ & 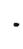 & ", & 23 \\
\hline 8. The Elbow Region - & - & - & - & ", & 24 \\
\hline 9. The Veins of the Arm and For & rint & $\cdot$ & & ", & 24 \\
\hline Io and II. The Palm of the Hand & $\cdot$ & $\cdot$ & • & ", & 26 \\
\hline I2. The Back of the Wrist & $\cdot$ & $\cdot$ & - & " & 28 \\
\hline I3. The Back of the Arm and For & & - & & $"$, & 30 \\
\hline I4. The Slioulder and Arm & - & $\cdot$ & & , & $3 \mathbf{I}$ \\
\hline I5. The Heart, Great Vessels, Kid & 7 , an & Ureter & r & $"$ & 36 \\
\hline I6 and I7. The Plenral Sacs, Lung & etc. & $\cdot$ & & $"$ & $4 \mathrm{I}, 4^{2}$ \\
\hline 18. The Abdominal and Thoracic & anes & $\cdot$ & & $"$ & 50 \\
\hline 19. The Alimentary Canal & - & - & & " & 56 \\
\hline 20. The Liver, Anterior Abdomin & Vall, & & & $"$ & 62 \\
\hline 21 to 24 . The Thigh and Leg . & $\cdot$ & $\cdot$ & 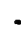 & " & 70,74 \\
\hline 25 and 29. The Region of the An & nd & & $\bullet$ & $"$ & $77-80$ \\
\hline
\end{tabular}




\title{
LANDMARKS AND SURFACE MARKINGS OF THE HUMAN BODY
}

\author{
CHAPTER I \\ THE HEAD AND NECK \\ Cranio-cerebral Topography
}

ONLY those surface markings will be given which are of practical value, and, as far as possible, each landmark will be rendered independent of any other, as by such means any given structure can be rapidly depicted on the surface, the important question of time and of space rendering the more complicated systems, in which it is necessary to map out a network of intersecting lines in order to fix the position of any single structure, of little surgical value. It is necessary, however, to recognize first certain important bony points, etc.

The nasion, situated at the base of the nose at the Fig. i., 1. central point of the naso-frontal suture.

The inion, or external occipital protuberance, Fig. i., 2. a projection, variable in size, which can be readily felt on the occipital bone, immediately above the nuchal furrow.

A line uniting these two points over the vertex of the skull corresponds in direction to the mesial longitudinal fissure of the brain, to the upper attached margin of the 
falx cerebri, and to the superior longitudinal venous sinus. This sinus originates in the region of the foramen crecum, just anterior to the crista galli, and broadens out rapidly as it passes backwards towards the internal occipital protuberance, which lies at the same level as the previously mentioned external protuberance. It then turns sharply to the right, forming the right lateral simus. The left lateral sinus derives its blood mainly from the straight simus, which receives, at the anterior margin of the tentorium cerebelli, the great vein of Galen, the main efferent trunk of the deep nuclear cerebral veins. The line drawn as above from the nasion to the inion also corresponds in direction to the occasionally persistent metopic suture between the two halves of the frontal bone, and to the sagittal suture between the two parietal bones.

The frontal bone is separated off from the two parietal bones by the coronal suture, and the point of junction of the coronal and sagittal sutures is known as the bregma, the site of the fœtal anterior fontanelle, an opening which is normally closed by the end of the second year. Between the parietal and occipital bones the lambdoid suture lies; and at the junction of the sagittal and lambdoid sutures the posterior fontanelle is situated, closed at or soon after Fig. i., 13. birth. The point of junction of the last two sutures is known as the lambda. This point lies about $2 \frac{1}{2}$ inches above the inion or external occipital protuberance. About $I$ inch from its posterior superior angle, and close to the sagittal suture, the parietal bone is perforated by a small foramen, and a line uniting the two foramina crosses the sagittal suture at a point known as the obelion. The parietal bone is outwardly bulged at Fig. i., 11. a point rather above its centre, forming the parietal eminence, especially marked in the fotal 
skull, and indicating the point at which the single ossific nucleus makes its appearance.

Turning now one's attention to the lateral aspect of the Fig. i., 6. skull, the inferior temporal crest should be examined. This crest crosses the parietal bone rather below the junction of the middle and lower thirds, cutting off the vault proper above from the temporal fossa below. The ridge is often so fecbly developed in this region that it may be necessary to verify its position by tracing it backwards from the region of the external angular frontal process, at which level the crest is always well marked. The temporal muscle arises from the inferior temporal crest and from the temporal fossa below, whilst Fig. i., 5. the overlying fascia, the temporal fascia, gains fecbly developed ridge which runs above and parallel to the inferior crest. To avoid confusion, it is perhaps necessary to add that the inferior temporal crest is quite distinct from the infratemporal crest, which forms the lower margin of the temporal fossa, and separates off that fossa from the zygomatic fossa.

The external angular frontal process articulates with Fig. ii., 16. the frontal process of the malar bone, and the articulation between the two processes is easily felt at the upper and outer border of the orbital cavity.

The malar tubercle, a small prominence to be felt Fig. i., 12. along the poscerior border of the frontal process of the malar bone, a short distance below the fronto-malar suture.

The zygomatic process of the temporal bone should be traced backwards towards the ear, and an examination of the skull will show that this process divides in front of the 
ear into three roots, the anterior merging into the eminentia articularis, the middle helping in the formation of the post-glenoid process, whilst the posterior or upper root Fig. ii.,13,14 sweeps backwards above the external auditory Fig. i., 17. meatus to become continuous with the suprameatal and supramastoid crests, and to blend with the posterior curved end of the temporal crest. The suprameatal crest is of special surgical importance, as it forms the upper boundary of Macewen's suprameatal triangle, and also indicates fairly accurately the lower level of the cerebrum in this situation.

The lateral sinus describes a gentle curve from the Fig. i., 16. external occipital protuberance to the upper Fig. ii., 9. and posterior part of the base of the mastoid process, finally curving downwards towards, though not reaching to, the apex of that process. The degree of upward curve is subject to a good deal of variation, and the sinus frequently presents a lesser upward convexity than was the case in the specimen from which the illustration was taken.

The lower limit of the cerebrum can, with sufficient Fig. i., 17, accuracy, be mapped out in the following 17, 17. manner: A point is taken in the median antero-postcrior line about $\frac{1}{2}$ inch above the nasion, and from this point a line is drawn outwards which lies about $\frac{1}{2}$ inch above, and follows the curve of the upper border of the orbit. This line is carried backwards as far as the level of the external angular frontal process, then curving upwards and backwards towards the Sylvian point (see next page). The temporo-sphenoidal lobe sweeps now downwards and forwards towards the posterior border of the malar bone, and then lies practically on a level with the upper border of the zygoma. At and behind the ear 



\section{FIG. 1}

t. The nasion.

2. The inion.

3. The mid-point between nasion and inion.

4. The Rolandic fissure.

5. The superior temporal crest.

6. The inferior temporal crest.

7. The Sylvian point.

๖. The anterior horizontal limb of the Sylvian fissure.

9. The vertical limb of the Sylvian fissure.

Io. The posterior horizontal limb of the Sylvian fissure

IJ. The parietal prominence.

12. The malar tubercle.

I3. The lambda.

14. The first temporo-splienoidal sulcus.

I5. The external parieto-occipital sulcus.

I6. The lateral sinus.

17, I7, 17. The level of the base of the cerebrum.

IS. The external auditory meatus.

I9. I9. Reid's base line. 


\section{CRANR_CERELRAL TOHOCRAIIL}
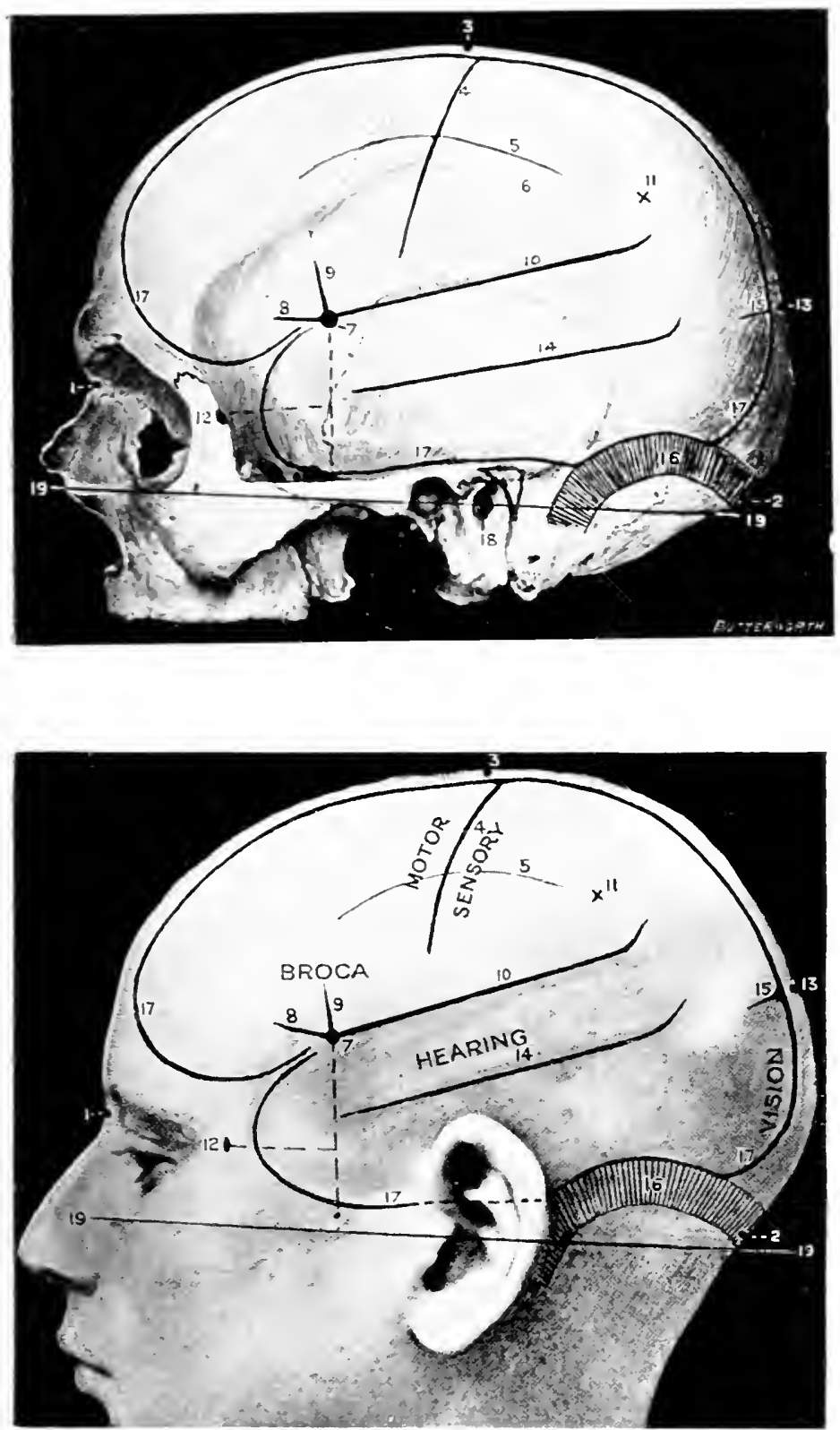

FIf. I. 


FIG. II.

1, I. Reid's base line.

2, 2. A line parallel to the above at the level of the supra. orbital margin.

3. The middle meningeal artery.

4. The anterior branch.

$5,5,5$. The three sites for trephination.

6. The posterior branch.

7. The site for trephination.

8 . The point for trephining to reach the descending horn of the lateral ventricle.

g. The lateral sinus.

.o. The inion.

II. The mastoid process.

12. Macewen's suprameatal triangle.

12a. The mastoid antrum.

12b. The facial nerve.

13. The suprameatal and supramastoid crests

14, 14. The temporal crest.

I5. The temporal fossa.

16. The external angular frontai procese.

17. The tendo-oculi attachment.

I8. The lachrywal groove. 


\section{CR.ANOCERELR.II, TOPOCRALHY}
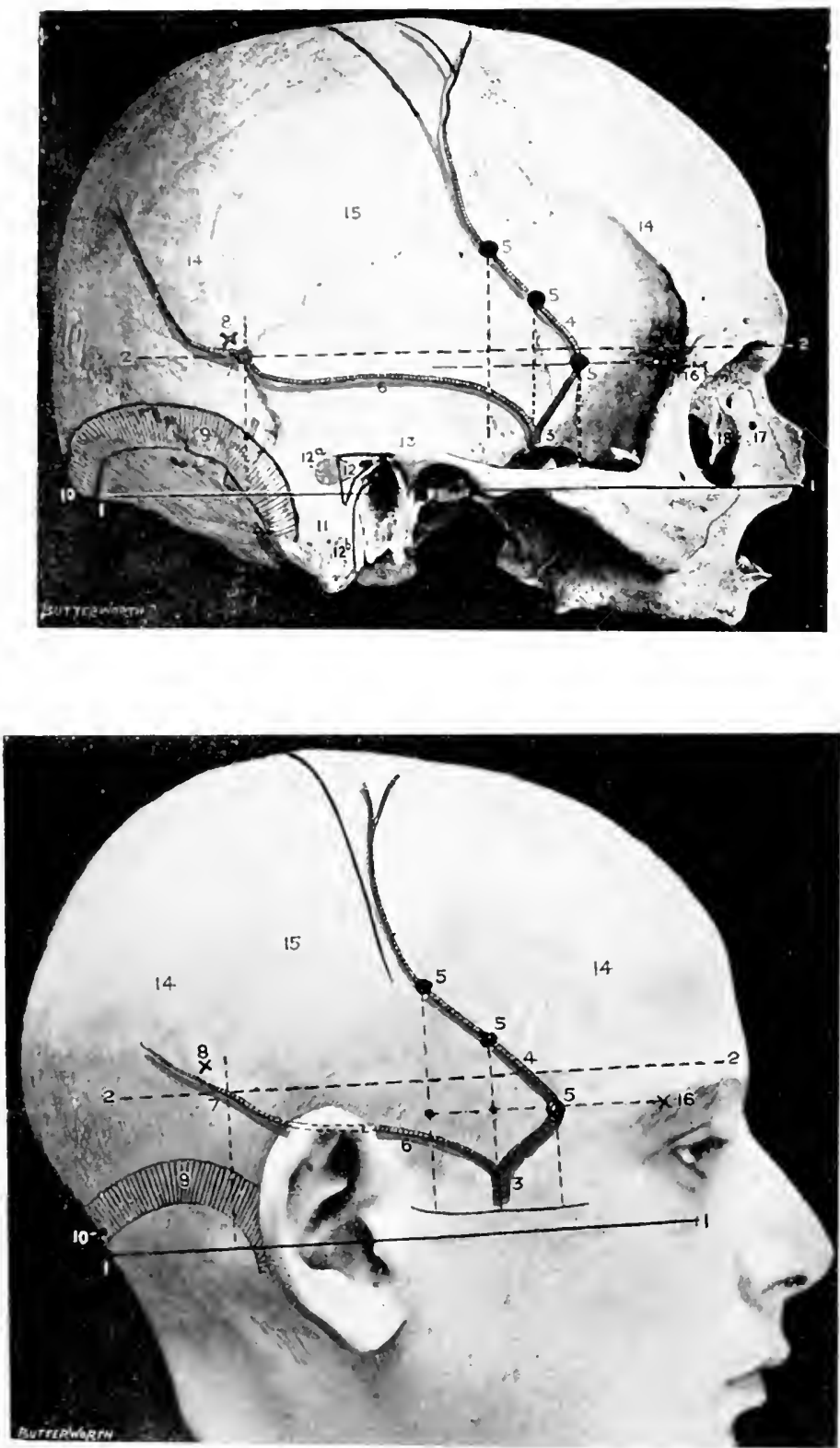

IIIG. II. 

the cerebrum lies flush with the suprameatal and supramastoid crests, and subsequently follows the curve of the lateral sinus from the base of the mastoid process to the external occipital protuberance.

The lateral sinus is, to a large extent, walled in by the tentorium cerebelli, a membrane separating the cerebrum and cerebellum one from the other. The simus curve, therefore, corresponds not only to the position of the lateral sinus, but also represents the outer attachment of the tentorium cerebelli, and the interval between the cerebrum above and the cerebellum below.

Reid's base line is drawn backwards from the lower Fig. i., 19, border of the orbit to the middle of the external 19. auditory meatus, and, when further produced, Fig. ii., 1, 1. the line will be found to fall just below the level of the inion, and to lie almost entirely below the level of the lateral sinus. This line is utilized by some surgeons in trephining the skull, distances being measured along this line and points taken above or below, according to the seat of the lesion.

The Sylvian point represents the site of divergence of Fig. i., 7. the three limbs of the Sylvian fissure. It lies I $\frac{1}{4}$ inches behind the external angular frontal process, and $I \frac{1}{2}$ inches above the upper border of the zygoma. The main posterior horizontal limb of the Fig. i., 10, Sylvian fissure passes backwards and upwards 11. from the Sylvian point to a second point situated $\frac{3}{4}$ inch below the most prominent part of the parietal bone.

The vertical limb is directed upwards for about $\frac{3}{4}$ inch, Fig. i., 8, 9. whilst the anterior horizontal limb passes forwards for about the same distance.

The Sylvian point corresponds also to the anterior pole 
of the island of Reil and to the middle cerebral artery, as that vessel lies deeply embedded in the anterior part of the Sylvian fissure.

To mark out the external parieto-occipital fissure and the Fig. i., 12- first temporo-sphenoidal or parallel sulcus, it is

15. necessary to find two bony points-the malar tubercle and the lambda. A line uniting these two points corresponds in its posterior part to the external parieto-occipital sulcus, and in its middle third to the first temporo-sphenoidal sulcus.

The Rolandic fissure.-Take a point $\frac{1}{2}$ inch behind the Fig. i., 4. centre of a line drawn across the vertex of the skull from the nasion to the inion, and from this point draw a line downwards and forwards for $3 \frac{1}{2}$ to 4 inches, at an angle of $67 \frac{1}{2}^{\circ}$ (three-quarters of a rightangle) to the median antero-posterior line. In front of this sulcus is the precentral or ascending frontal convolution, an area better known as the Rolandic or motor area. The main centres here situated correspond, from above downwards, to the movements of the lower extremity, upper extremity and face of the opposite side of the body.

The superior temporal crest cuts across the Rolandic line Fig. i., 5. at the junction of its lower and middle thirds. between the upper extremity area above and the face area below.

On the left side of the head, that part of the brain which is included in the obtuse angle between the anterior and Fig. i. posterior horizontal limbs of the Sylvian fissure is known as Broca's area (the motor speech centre).

The middle meningeal artery, a branch of the internal maxillary, enters the skull through the foramen spinosum, and divides, after a short and variable course across the 
middle fossa of the skull, into two main trunks. The seat Fig. ii., 3. of bifurcation usually corresponds to a point just above the centre of the zygoma.

The anterior branch is not only the larger of the two, Fig. ii., 4. but it is also more liable to injury, since it is protected in the temporal region by a comparatively thin osseous barrier.

Fig. ii., 5, The danger zone in the course of this branch 6, 5. may be mapped out by taking three points :

(I) I inch behind the external angular frontal process, and $I$ inch above the zygoma.

(2) I $\frac{1}{2}$ inches behind the external angular frontal process, and $\mathrm{I} \frac{1}{2}$ inches above the zygoma.

(3) 2 inches behind the external angular frontal process, and 2 inches above the zygoma.

A line uniting these three points indicates, therefore, that part of the anterior division of the middle meningeal artery which is most liable to injury.

The anterior division of the vessel will be exposed by trephining over any of these three points, but it is generally preferable to choose the highest point, as by such means the posterior border of the great wing of the sphenoid is avoided; $*$ and, as an additional reason, it should be added that, in the position of points I and 2, the artery frequently runs in an osseous canal. After trephining over the upper point, the bone can be chipped away in a downward and forward direction, if such an exposure of the artery is deemed necessary.

Fig. ii., 6. The posterior branch of the artery passes almost horizontally backwards, parallel to the zygoma and to the supramastoid crest, and it can be exposed

* N.B.-This point will be better understood by reference to the base of the skull. 
by trephining over a point where a vertical line drawn Fig. ii, 7. upwards from the posterior border of the mastoid process cuts another line drawn backwards from the supra-orbital margin parallel to Reid's base line.

The lateral ventricles.-The descending cornu of the Fig. ii., 8. lateral ventricle may be tapped by trephining behind the external auditory meatus. The trocar should be directed towards the summit of the opposite ear, the ventricle being reached within 2 inches from the surface (Keen).

The basic fosse.- "There is no external sign to indicate the situation of the fossæe of the skull. In general, however, it may be said that the anterior fossa extends as far back as the anterior end of the zygoma; that the middle fossa lies between this and the mastoid process, and the posterior includes all the base behind the process" (Eisendrath).

The mastoid antram may be exposed by trephining Fig. ii., 12a. in Macewen's suprameatal triangle, a space which Fig. ii., 12. is bounded above by the backward continuation of the upper root of the zygoma (the supramastoid crest), behind by a vertical line drawn upwards from the posterior border of the external auditory meatus, and below and in front by the suprameatal spine, a prominent bony process which assists in the formation of the posterior superior quadrant of the external auditory meatus. In this triangle there is usually a well-marked depression, the suprameatal fossa. The supramastoid crest not only indicates the uppermost possible limit of the mastoid antrum, but, as has already been stated it corresponds also to the level of the base of brain in 
this situation. The crest, therefore, represents the level of the tegmen antri, and, in mastoid cxploraFig. ii., 13. tions, the scene of operation must be confined to an area below this crest. In the adult the antrum usually lies at a depth of $\frac{1}{2}$ to $\frac{3}{4}$ inch from the surface.

The lateral simus lies posterior and nearer to the surface, Fig. ii., 9. whilst the facial nerve pursues its course in frort Fig. ii., 12b. and on a deeper plane.

The parotid gland occupies the space which is bounded Fig. iii., 5 . above by the zygomatic arch, behind by the
auricle and the mastoid process, and below by a line drawn from the angle of the jaw to the apex of the mastoid process. In front, the gland extends a variable distance over the anterior surface of the masseter muscle. This muscle passes downwards and backwards from the lower border of the zygomatic arch to be attached to the outer surface of the descending ramus and angle of the lower jaw. When the teeth are clenched, the anterior border of the muscle is easily defined, a well-marked line of demarcation being so formed between the masseter muscle behind and the buccinator in front.

Stensen's duct, the duct of the parotid gland, corresponds Fig. iii., 7. lower border of the tragus of the ear to a point situated half-way between the ala of the nose and the red line of the upper lip. At the anterior border of the masseter muscle the duct dips inwards, through the buccinator muscle, to open on the buccal mucous membrane, opposite the second molar tooth of the upper jaw.

The transverse facial artery, a branch of the superficial temporal, runs inwards parallel to and immeFig. iii., 6. diately below the zygoma, lying above the level of Stensen's duct. 
The facial nerve, after emerging from the stylo-mastoid Fig. iii., 8. foramen, curls round the condyle of the jaw, and traverses the substance of the parotid gland, in which part of its course it divides into numerous branches. The general transparotid course of the nerve and the direction of its buccal branch may be indicated by a line drawn forwards parallel to and below Stenson's duct from the lobule of the ear.

The inferior dental nevve may be exposed by trephining Fig. iv., 2. over the ascending ramus of the lower jaw,
midway between the anterior and posterior borders, and on a level with the last molar tooth. In this manner, the nerve, accompanied by the corresponding artery, is exposed as it enters the inferior dental canal.

The tonsil corresponds in position to a point situated Fig. iv., 3. just above

The borders of the bony orbit. - The following bones assist in the formation of the orbital margin :

Above, the frontal bone.

Externally, the external angular frontal process and the malar bone.

Below, the malar bone and the superior maxilla.

Internally, the nasal process of the superior maxilla and the internal angular frontal process.

The tendo oculi and nasal duct.-By alternate forcible closure and opening of the lids, the internal
tarsal ligament, or tendo oculi, can be felt passing to its insertion into the nasal process of the superior maxilla. Immediately below the tendon, at the Fig. ii., 18. junction of the inner and lower walls of the Fig. ii., 18. orbital cavity, is the depression for the lachrymal sac, which sac narrows below into the nasal duct. 
The duct passes downwards, backwards and slightly outwards, to open into the anterior part of the inferior meatus of the nose under cover of the inferior turbinated bone. The duct is about $\frac{1}{2}$ inch long.

The supra-orbital, infra-orbital, and mental foramina.Figs. iii., At the junction of the inner and middle thirds v., 1.3. of the supra-orbital margin, the supra-orbital notch or foramen may be felt, and a line drawn downwards from this foramen through the interval between the two lower bicuspid teeth will pass through both infraorbital and mental foramina. The former foramen lies $\frac{1}{4}$ to $\frac{1}{2}$ inch below the orbital margin, whilst the latter (in the adult) lies midway between the alveolar and inferior borders of the lower jaw.

The frontal sinuses are very variable in extent. They occupy the space between the inner and outer tables of the frontal bone, above the base of the nose and above the inner half of the supra-orbital margin. The sinus communicates with the nasal cavity by means of a narrow channel, the infundibulum, which opens into the middle meatus of the nose under cover of the middle turbinated bone, on a level with the inner margin of the palpebral fissure.

The antrum of Highmore usually occupies the greater part of the interior of the superior maxilla, and opens into the hiatus semilunaris, a depression which lies under cover of the middle turbinated bone. The opening is, however, situated at so high a level that pus only escapes into the nose when the antrum is practically full. Two teeth are, on the other hand, closely related to the antrum-namely, the second bicuspid and the first molar-the sinus usually extending downwards in the interval between the two labial and single palatal fangs of the latter 
tooth. The removal of either of these teeth, followed up by any necessary upward boring, will efficiently drain the sinus.

The sinus may also be drained by everting the upper lip and puncturing the outer wall through the canine fossa, a depression lying above the canine tooth.

The sphenoidal sinus occupies the greater part of the body of the sphenoid, and opens into the spheno-ethmoidal recess, a space lying above and behind the superior turbinated bone.

The simuses of the nose and their efferent channels:

The sphenoidal sinus $=$ spheno-ethmoidal recess.

The posterior ethmoidal cells = superior meatus.

The anterior ethmoidal cells

The middle ethmoidal cells

The frontal sinus

$=$ middle meatus.

The antrum of Highmore

The nasal duct $=$ inferior meatus.

The Triangles of the Neck.

The lateral aspect of the neck is divided by the sternomastoid muscle into two triangles-anterior and posterior.

The anterior triangle is bounded in front by the middle Fig. iv. line of the neck, behind by the anterior border lower border of the ramus of the jaw.

The space so marked out is divided into three smaller triangles by the digastric muscle and by the anterior belly of the omo-hyoid :

Fig. iv., 17.

(I) The submaxillary triangle, above the digas- . tric muscle, containing the submaxillary gland.

Fig. iv., 19.

(2) The muscular triangle, anterior to the omo-hyoid muscle. 
(3) The carotid triangle, bounded above by the posterior belly of the digastric, behind by the anterior Fig. iv., 16. border of the sterno-mastoid muscle, and in front by the anterior belly of the omo-hyoid. In this triangle the common carotid bifurcates, and the cxternal carotid gives off most of its branches.

The posterior triangle is bounded in front by the posterior border of the sterno-mastoid, behind by the Fig. iv., 15, anterior border of the trapezius, and below by

18. the middle third or fourth of the clavicle. The triangle is subdivided by the posterior belly of the omohyoid, which cuts off the small subclaitin triangle below from the more extensive occipital triangle above.

\section{The Vessels and Nerves.}

The carotid arteries correspond in direction to a line Fig. iii., 9 . between the angle of the jaw and the mastoid process. The common carotid usually bifurcates at the level of the upper border of the thyroid cartilage (fourth Fig. iii., 10, cervical vertebra), the external carotid subse11. quently lying superficial to and slightly to the inner side of the internal carotid. The omo-lnyoid muscle (upper belly) crosses the common carotid at the level of the cricoid cartilage, and in this situation the artery may be compressed against the prominent anterior tubercle of the transverse process of the sixth cervical vertebra (Chassaignac's tubercle).

The superior thyroid artery arises from the external carotid in the carotid triangle, immediately above the level of the upper border of the thyroid cartiFig. iii., 12. lage, and, turning downwards under cover of the anterior belly of the omo-hyoid muscle, is directed 
towards the apex of the lateral lobe of the thyroid gland.

The lingual artery arises midway between the level of the upper border of the thyroid cartilage and the great Fig. iii., 13. cornu of the hyoid bone, and enters the subFig. v., 7. maxillary triangle by passing deep to the posterior belly of the digastric muscle. The artery so gains the upper border of the hyoid bone, and runs inwards for a short distance parallel to that bone under cover of the hyo-glossus muscle.

The facial artery arises opposite the great cornu of the hyoid bone, and also enters the submaxillary triangle by

Fig. iii., 14 passing deep to the posterior belly of the digastric. In this triangle the artery lies deeply embedded in the substance of the submaxillary salivary gland, and then enters on its facial course by curling round the inferior border of the lower jaw immediately anterior to the masseter muscle, about $I_{\frac{1}{2}}$ inches in front of the angle of the jaw. The vessel then passes upwards towards the inner canthus of the eye, there terminating as the "angular artery."

The occipital artcry arises from the outer side of the external carotid artery in the upper part of the carotid

Fig. iv. triangle, and passes upwards and backwards, tric muscle, towards the interval between the mastoid process and the transverse process of the atlas. At the apex of the posterior triangle the artery is joined by the great occipital nerve (posterior primary division of the second cervical nerve), the two structures then passing upwards on to the vault of the skull.

The posterior auricular artery arises from the external carotid, immediately above the posterior belly of the 



\section{THE SIDE OF THE FACE AND NECK}

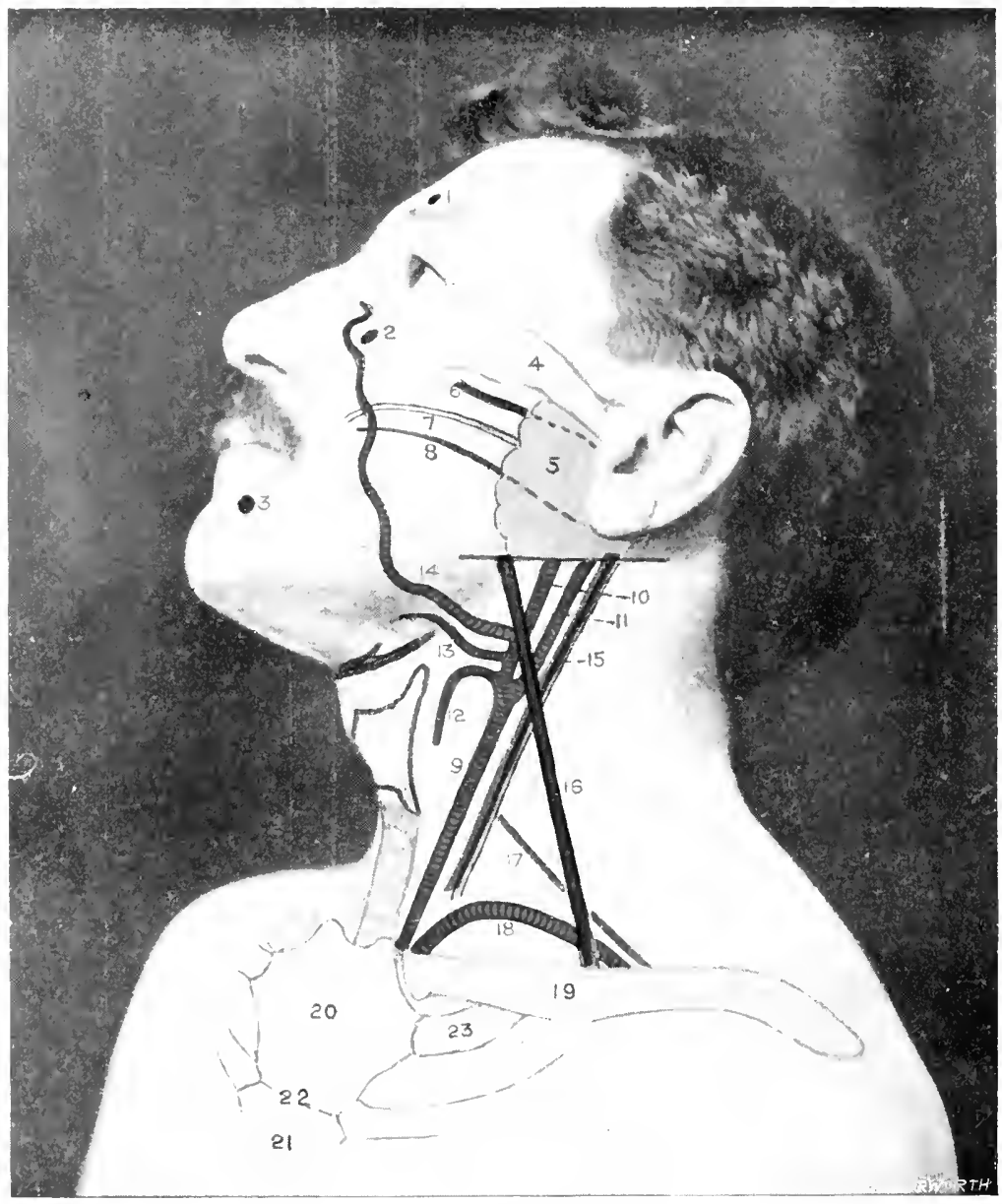

IIIF. III.

1. The supra-orbital formen.

2. The infra-orlital foramen.

3. Tlie mental formen.

4. The zyenoma.

5. "lle parotid glamel.

6. The transwerse facial artery.

7. Sitensen's luet.

S. "Tle fitcial nerve.

9. The common carotil artery.

Io. The external carotid artery.

11. Tle internal carotid arters.

12. lihe superior thyorid artery.
13. The lingual artery.

14. 'Tle facial artery.

5. 'Tlue internal jugnlar vein.

16. The external jugular vein.

17. The nuper limit of the brachial plexis.

IS. "Ilie sulclavian artery.

19. 'The clavicte.

2). 'The manulurium sterni.

2I. 'The glatliolns sterni.

22. 'l'he angle of I, mlwig.

23. 'lne first costal cartilage.

To face Fis. IV, pp, 14, 15 . 


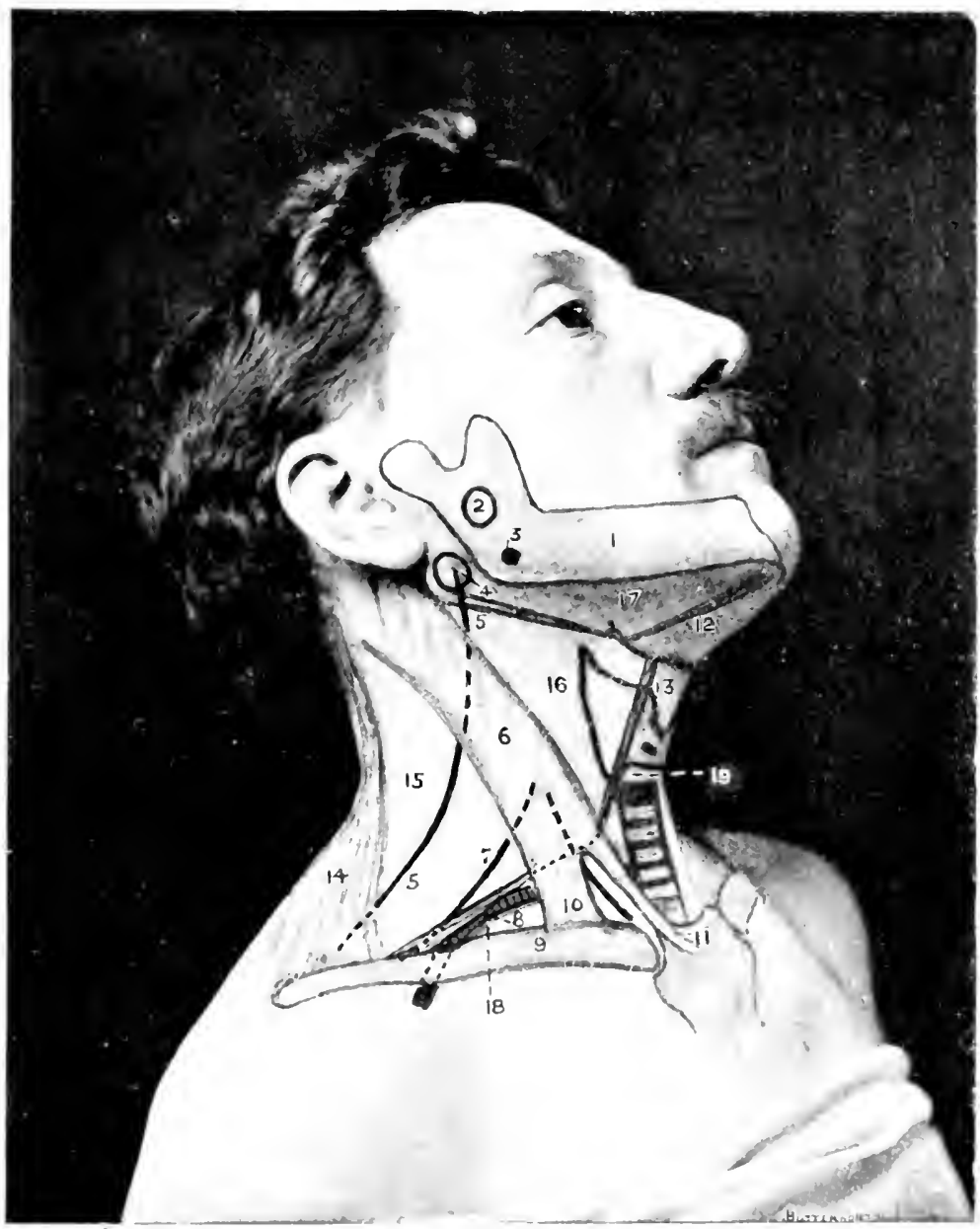

IVI: IV.

I. The inferior maxilla.

2. The inferior dental nerre.

3. ']he [1, 1 <1].

4. The thanswerse process of the atlats.

5, 5. The spinal aceessory nerve.

6. The stermo mastoisl muscle.

7. The upler limit of the liratial plexus.

s. The thoml part of the sulclavian artery.

9. The clavicle.
10. The elatriculat leant of the

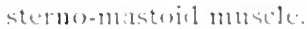

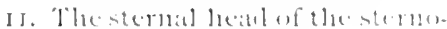
mantoit muncle.

12. The digatsie muscle.

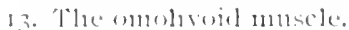

3. Tlac \{rapezius musede.

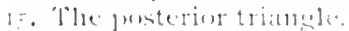

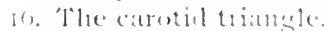

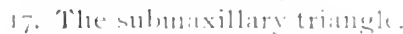

1.s. The suixlavian triangle.

Ig. The muscular trianerle. 

digastric muscle, and passes backwards parallel to the Fig. iv. upper border of that muscle, through the lower part of the parotid gland, to the depression between the cartilage of the concha of the ear and the mastoid process. Here the artery is joined by the posterior auricular nerve- a branch of the facial.

The superficial temporal artery arises in the substance of the parotid gland as one of the two terminal branches of the external carotid. It crosses the base of the zygomatic process of the tcmporal bone, immediately in front of the tragus of the ear, and is accompanied by the auriculotemporal nerve, a sensory branch of the third division of the fifth cranial nerve.

The subclavian artery (cervical course) is represented by Fig. iii., 18. a curved line from the sterno-clavicular joint Fig. iv., 8. to the mid-point of the corresponding clavicle, the convexity of the line extending upwards into the supraclavicular fossa about $\frac{3}{4}$ to $I$ inch above the clavicle. In marking out this vessel, the shoulders should be well depressed.

The artery passes behind the scalenus anticus muscle, the second part of the artery being covered by that muscle. The outer border of the scalene muscle usually corresponds to the outer border of the sterno-mastoid muscle, and consequently the third part of the subclavian artery is mastoid muscle and the mid-point of the clavicle.

The subclavian artery ends anatomically at the outer border of the first rib.

The external jugular vein is formed just behind the angle of the jaw by the junction of the posterior division of the temporo-maxillary trunk with the posterior auricular vein. 
The vessel so formed passes downwards and backwards, Fig. iii. 16. superficial to the sterno-mastoid muscle, toFin. wards the middle of the clavicle, above which bone the vein pierces the deep fascia to join the subclavian vein.

The internal jugular vein runs parallel and external to the internal and common carotid arteries, and Fig. iii., 15. therefore presents a similar surface marking to that already given for those arteries.

The vagus rorve passes downwards in the carotid sheath, behind and between the carotid arteries and the internal jugular vein.

The cervical sympathetic trunk also lies in the line of the carotid arteries, being placed behind the carotid sheath. The superior cervical ganglion is situated in front of the transverse processes of the second and third cervical vertebræ; the middle ganglion overlies the corresponding process of the sixth vertebra; whilst the inferior ganglion, which is frequently fused with the first thoracic, lies behind the first part of the subclavian artery, between the transverse process of the seventh cervical vertebra and the neck of the first rib.

The phrenic nerve is formed below the level of the hyoid Fig. iv. (un. bone by branches from the anterior primary numbered, divisions of the third, fourth and fifth cervical 10 and 11). nerves, and passes downwards and slightly inwards towards the sternal end of the clavicle. At the level of the cricoid cartilage the nerve lies midway between the anterior and posterior borders of the sterno-mastoid muscle.

The spinal accessory nevve crosses the transverse process of the atlas, a bony prominence to be felt immediately below and in front of the apex of the mastoid process. 
The nerve enters the substance of the sterno-mastoid Fig. iv., 4, at the junction of the upper and second quar. 5. 5. ters along the anterior border of the muscle, emerging from the posterior border of the muscle at the junction of the upper and middle thirds. The point of emergence is, however, subject to some variation, and the nerve may enter the posterior triangle of the neck at a somewhat lower level, pursuing subsequently a downward and backward course towards the anterior border of the trapezius muscle, beneath which muscle it sinks.*

The superficial cervical plexus. - Take a point midway along the posterior border of the sterno-mastoid muscle, and from this point draw three lines:

I. Upwards towards the lobe of the ear $=$ the great auricular nerve ( 2 and $3 \mathrm{C}$.).

2. Upwards along the posterior border of the sternomastoid muscle $=$ small occipital nerve $(2 \mathrm{C}$.).

3. Forwards towards the middle line of the neck $=$ the transverse cervical nerve ( 2 and 3 C.).

By producing these three lines in a downward direction, the descending branches of the plexus are roughly indicated.

Thus the great auricular produced = the supraclavicular nerve; the small occipital produced=the suprasternal nerve; the transverse cervical produced $=$ the supraacromial nerve. The three descending trunks are derived from the third and fourth cervical nerves, and all the branches of this plexus arise from the anterior primary divisions of their respective nerves.

* Another surface-marking for the spinal accessory nerve.-Draw a line from a point midway between the tip of the mastoid process and the angle of the jaw to the niddle of the posterior border of the sterno-mastoid muscle, and thence across the posterior triangle to the anterior border of trepezius. 
The brachial plexus.-The upper limit of the nerveFig. iii., 17. trunks which form this plexus is represented Fig. iv., 7 . by a line drawn from the mid-point between the anterior and posterior borders of the sterno-mastoid muscle at the level of the cricoid cartilage to a second point situated just external to the mid-point of the clavicle. The lowest cord lies behind the third part of the sub. clavian artery.

The rima glottidis, which in its front part is laterally Fig. v., 10. bounded by the true vocal cords, lies opposite thyroid cartilage.

The epiglottis, though fixed below to the thyroid angle Fig. v., 9. immediately above the point of attachment of
the true vocal cords, extends upwards to above the level of the body of the hyoid bone.

A suicidal cut-throat frequently involves the thyro-hyoid space, and the epiglottis may be severed from its thyroid attachment.

The isthmus of the thyroid gland crosses the trachea Fig. v., 12. about $\frac{1}{2}$ to $\frac{3}{4}$ inch below the cricoid cartilage. Fig. v. The structures in the middle line of the neck:

(I) Passing down from the jaw to the body of the hyoid bone, the two genio-hyoid muscles lie each side of the middle line. They are placed, however, deep to the mylohyoid muscles, which are directed downwards and inwards to the median raphe and to the body of the hyoid bone. (2) The body of the hyoid bone. (3) The thyro-hyoid space. (4) The thyroid cartilage. (5) The crico-thyroid space. (6) The cricoid cartilage. (7) The upper two or three tracheal rings. (8) The isthmus of the thyroid gland (g) The trachea. (Io) The suprasternal notch. 


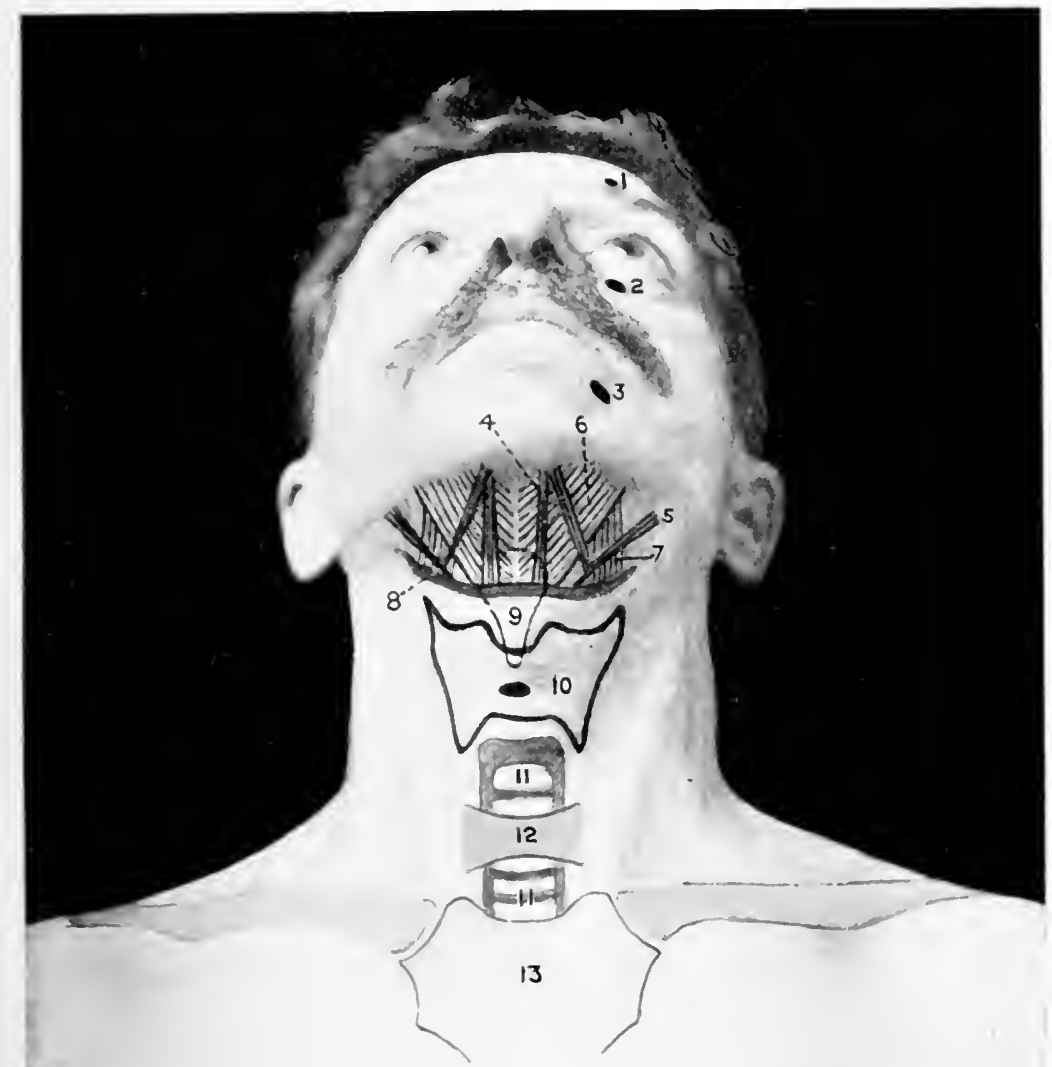

IF. 1

1. The supra-orbital formuen.

2. The infra-orfital foramen.

3. The mental foranen.

4. The genio-hyoirl muscle (deeg) to the mylo-hyoin muscle).

5. The digastric muscle.

6. The mylo-lyoil muscle.
7. The hyo-glossus musele.

s. The hyoil bone.

9. The epiglottis.

10. The thyroil cartilage.

I 1 , I. The tracliea.

12. The thyroid istlimus.

13. The sternum. 



\section{CHAPTER II}

\section{THE UPPER EXTREMITY}

In this chapter, and in that on the lower extremity, the reader's attention is mainly directed to those bony prominences and muscular or tendinous elevations which lie in the region of the joints, since these form the more important landmarks which aid in the representation of the arteries, nerves, etc., of the limbs. The muscular masses, which complete the symmetry of the arm or leg between the joints, are only mentioned where necessary, a fair general knowledge of the anatomical structure of the body being assumed.

The shoulder region.-The acromial process, the spine of the scapula and the clavicle, being subcutaneous throughout their whole length, can readily be palpated from end to end. The clavicle should first be examined from its blunted sternal extremity to the acromio-clavicular joint. The inner third of the shaft is rounded and presents a marked forward convexity, whilst the outer third of the bone is flattened from before backwards and shows a concave anterior border. At the outer end of the bone a slight elevation can usually be felt on the superior surface, and immediately external to this is the acromioclavicular joint, the long axis of which lies in the anteroposterior direction. 
The acromial spine is narrow at about its centre, broadening out towards the vertebral border of the Fig. xiii., 1. scapula, and forming there a smooth triangular surface, over which glides the tendinous part of the trapezius. Externally, the spine terminates in the Fig. xiii., 2. border of which an oval facet is situated for articulation with the clavicle. The supra- and infraspinatus muscles fill up the depressions or fossæ which lie in relation to the spine of the acromion.

The clavicle is also bounded above and below by depressions, little evident in fat subjects, but most marked when, as the result of pathological or physiological condiFig. iv., 18.
clavicular or subclavian triangle is dealt with in the first chapter. The infraclavicular space is bounded above by the clavicle, below by the clavicular head of the pectoralis major muscle, internally by the costal cartilage of the first rib, and externally by the anterior border of the deltoid muscle. The floor is formed by the subclavius muscle and the costo-coracoid membrane. In the outer Fig. vi., 3. fart of the space the coracoid process may be
felt, the apex of the process lying under cover of the anterior border of the deltoid muscle. In favourable cases, the pulsation of the axillary artery (Part I.) may be detected below the clavicle, as this vessel runs downwards from the outer border of the first rib. The bulky Fig. xiv., 5. deltoid muscle, arising from the clavicle and from the acromial process and spine, is, so to speak, pushed outwards by the underlying head and great tuberosity of the humerus, so producing the normal rounded appearance of the shoulder. This outward displacement of the muscle is taken advantage of by Hamilton in the diag. 


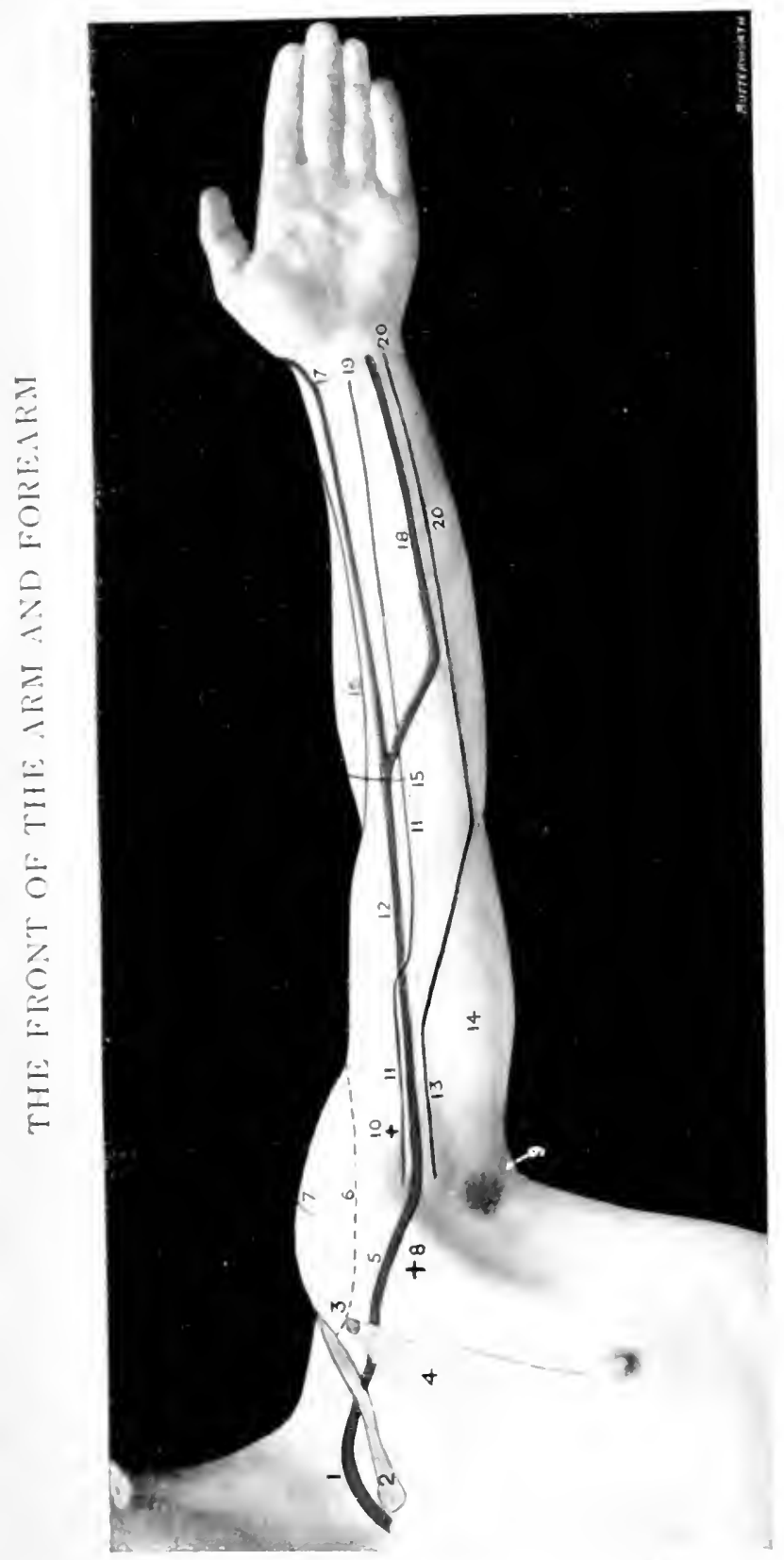

$$
\begin{aligned}
& \begin{array}{ll}
\stackrel{\dot{\Xi}}{\Xi} & \dot{\Xi} \\
\Xi & \doteq \\
\Xi & \doteq \\
\dot{\Xi} & \Xi
\end{array} \\
& \therefore \quad \equiv \\
& \exists \\
& \Xi \text { 可 }
\end{aligned}
$$

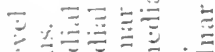

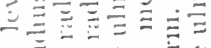

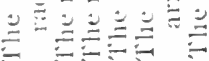

$$
\begin{aligned}
& \dot{y} \doteq \dot{\theta} \dot{0}
\end{aligned}
$$

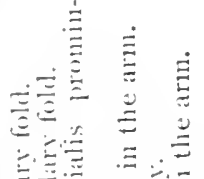$$
\therefore \text { ن }
$$

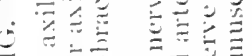$$
-\div \overline{-}
$$$$
-\ldots
$$

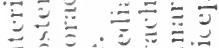

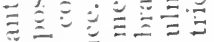

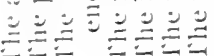

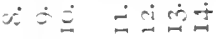

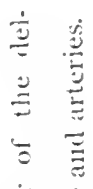

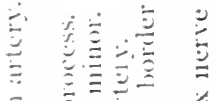

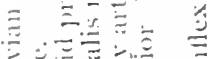

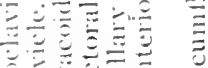

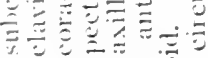

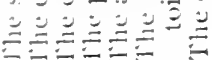

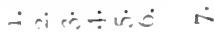



nosis of a dislocation of the shoulder-joint, as, after such an injury, the humerus is drawn inwards by the pectoralis major, latissimus dorsi and other muscles to such a degree that a ruler placed along the outer side of the arm will be in contact with the acromion process and the external humeral condyle at one and the same time. In the normal condition, this is not possibie.

To measure the length of the humerus, the tape-measure Fig. xiv., 4, should be carried from the lower margin of the

4. acromial process to the external condyle of the humerus. The lesser tuberosity of the humerus is always difficult to identify, but it can usually be distinguished lying rather below the mid-point of a line uniting the coracoid process and the great tuberosity of the humerus, the arm being well everted and the elbow in contact with the side of the body.

Between the two tuberosities is the bicipital groove, in which runs the long tendon of the biceps muscle. The groove may be represented by a line, about 2 inches long, which runs downwards from the tip of the acromial process, parallel to the long axis of the humerus.

The upper cpiphysis of the humerus includes the head and both tuberosities, and the epiphysial line runs transversely, at right angles to the long axis of the humerus, at the lower border of the great tuberosity.

The axilla.-To examine this spare, the elbow should be supported, and the patient instructed to relax all muscles. The anterior wall is formed by the major and minor pectoral muscles, and by the costo-coracoid membrane. The pectoralis major alone forms the anterior fold of the axilla, and does not extend as far Fig. vi, 8 . downwards as the posterior fold, whilst its rounded appearance results from the twisting of the fibres 
of the pectoral muscle before their insertion into the outer bicipital ridge. The posterior wall is formed mainly by the subscapularis muscle overlying the ventral surface of the scapula, the axillary border of which bone can be made out by deep palpation from the inferior angle below to the head above. The rounded posterior fold of the axilla results from the fact that the latissimus dorsi curls round the Fig. vi., 9. teres major muscle from behind forwards in Fig. xiii., 7. order to reach its insertion into the floor of the bicipital groove. The narrow outer boundary of the axilla corresponds to the upper part of the shaft and to the head of the humerus, and in this situation, in a well-developed Fig. vi., 10. arm, two prominent longitudinal folds are seen, the anterior of which corresponds to the coracobrachialis and biceps (short head) muscles, whilst the Fig. vi., 11. more posterior fold results from the projection 13. of the neuro-vascular bundle. The head of the humerus and of the scapula can be felt at the upper and posterior part of the axilla, the second rib on the inner side, and the coracoid process in front. The head of the humerus looks in the same direction as the internal condyle of the humerus. The inner wall of the axilla is formed by the upper part of the lateral wall of the thorax, which is here clothed by the serrations of the serratus magnus muscle.

The axillary lymphatic glands are arranged in three main groups, all converging towards the apex of the axilla :

(a) The pectoral set, running upwards and outwards under cover of the outer border of the pectoral muscles, and draining the anterior and lateral aspects of the chestwall and the abdomen above the level of the umbilicus.

(b) The subscapular set, running upwards along the axillary border of the subscapularis muscle, and draining 



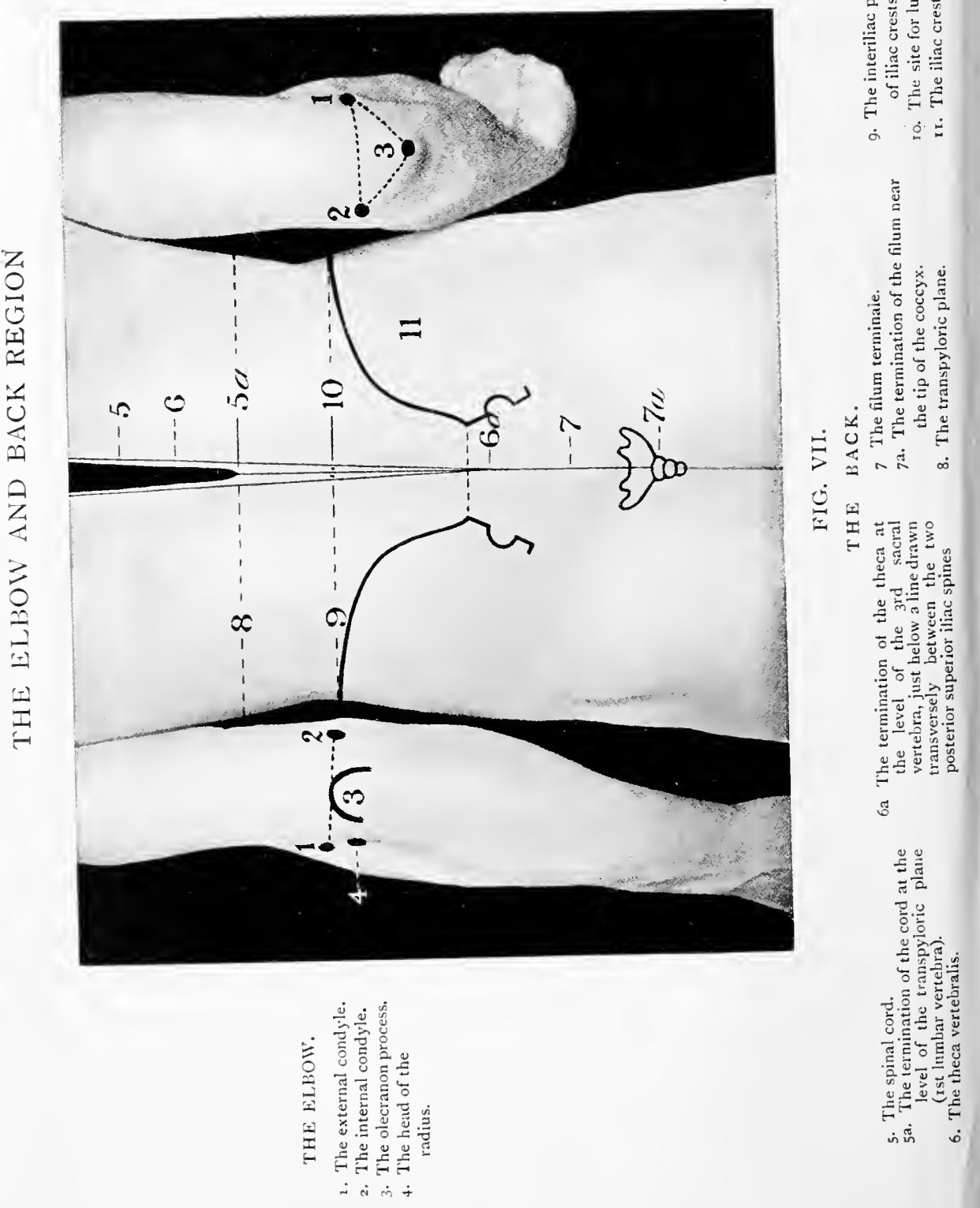


the lateral and posterior aspect of the chest above the level of the umbilicus.

(c) The brachial and axillary set, running upwards in the line of the axillary vessels, and draining the whole of the upper extremity.

The elbow region. - When the forearm is extended, a Fig. vii,, line joining the internal and external condyles 1.3. of the humerus cuts across the tip of the olecranon process, which bony prominence lies well to the inner side of the mid-point of the intercondyloid line. When the forearm is flexed, the olecranon moves downwards, and by uniting the three bony points a triangle is Fig. xiii, formed. Immediately below the external con5. 8. dyle the head of the radius is felt "lying in the valley behind the supinator longus" (Holden). The humero-radial articulation is transverse, but the humeroulnar articulation slopes obliquely downwards and inwards, and consequently, whilst the external condyle is about $\frac{3}{4}$ inch above the humero-radial joint, the internal condyle lies rather more than I inch above the line of the humero-ulnar articulation.

The junction of the draplyysis and lower cpiphysis of the humerus corresponds to a transverse line drawn across the humerus immediately above the tips of the condyles. The bony points on the outer side of the joint are generally obscured in those cases where there is considerable effusion into the elbow-joint, the synovial membrane bulging outwards below the external condyle of the humerus and between that process and the olecranon process. Under similar conditions, there is also an outward projection of the synovial membrane between the olecranon and the internal condyle of the humerus, obscuring the deep depression that normally exists in that situation-a de- 
pression at the base of which the ulnar nerve can be rolled beneath the finger.

In front of the elbow is the antccubital triangle, the base of which corresponds to a line drawn across the Fig. viii., 1. front of the elbow between the two humeral condyles, whilst the inner and outer boundaries are formed Fig. viii., respectively by the pronator radii teres and 2, 3. supinator longus muscles. This triangular space is vertically subdivided by the biceps Fig. viii., 5. tendon, on either side of which a depression exists, the inner and outer bicipital sulci. In the outer Fig. viii., 4. two terminal branches, radial and posterior interosseous, whilst the median nerve and the brachial Fig. viii., artery lie in the inner sulcus, the artery inter7, 8. mediate between the tendon and the nerve. The artery and nerve are, however, obscured in the lower Fig. viii, 6. part of the inner sulcus by the overlying bito the pronator region, whilst its upper free margin presents a well-marked crescentic edge which looks upwards and inwards.

The superficial veins in front of the bend of the elbow Fig. ix. are arranged in the form of a letter $\mathbf{M}$, the from below, whilst two main efferent vessels, the cephalic and the basilic, carry the blood upwards, The Fig. ix., 9. basilic vein passes upwards in the superficial fascia, along the inner side of the arm, and pierces the deep fascia about half-way between the axilla and the internal condyle, and at the foramen so proFig. ix., 10. duced in the deep fascia the internal cutaneous nerve emerges to become superficial. The epitrochlear 


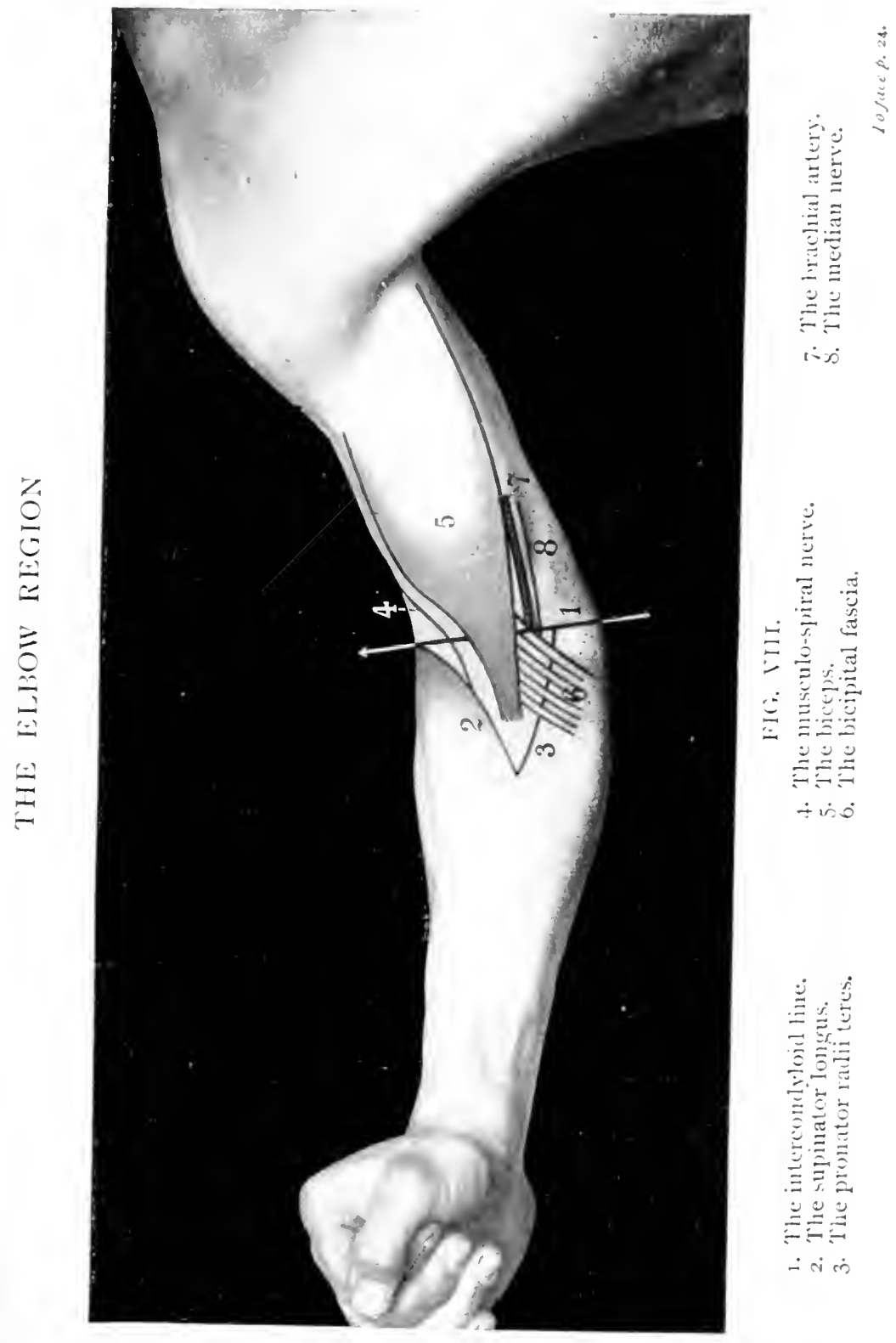





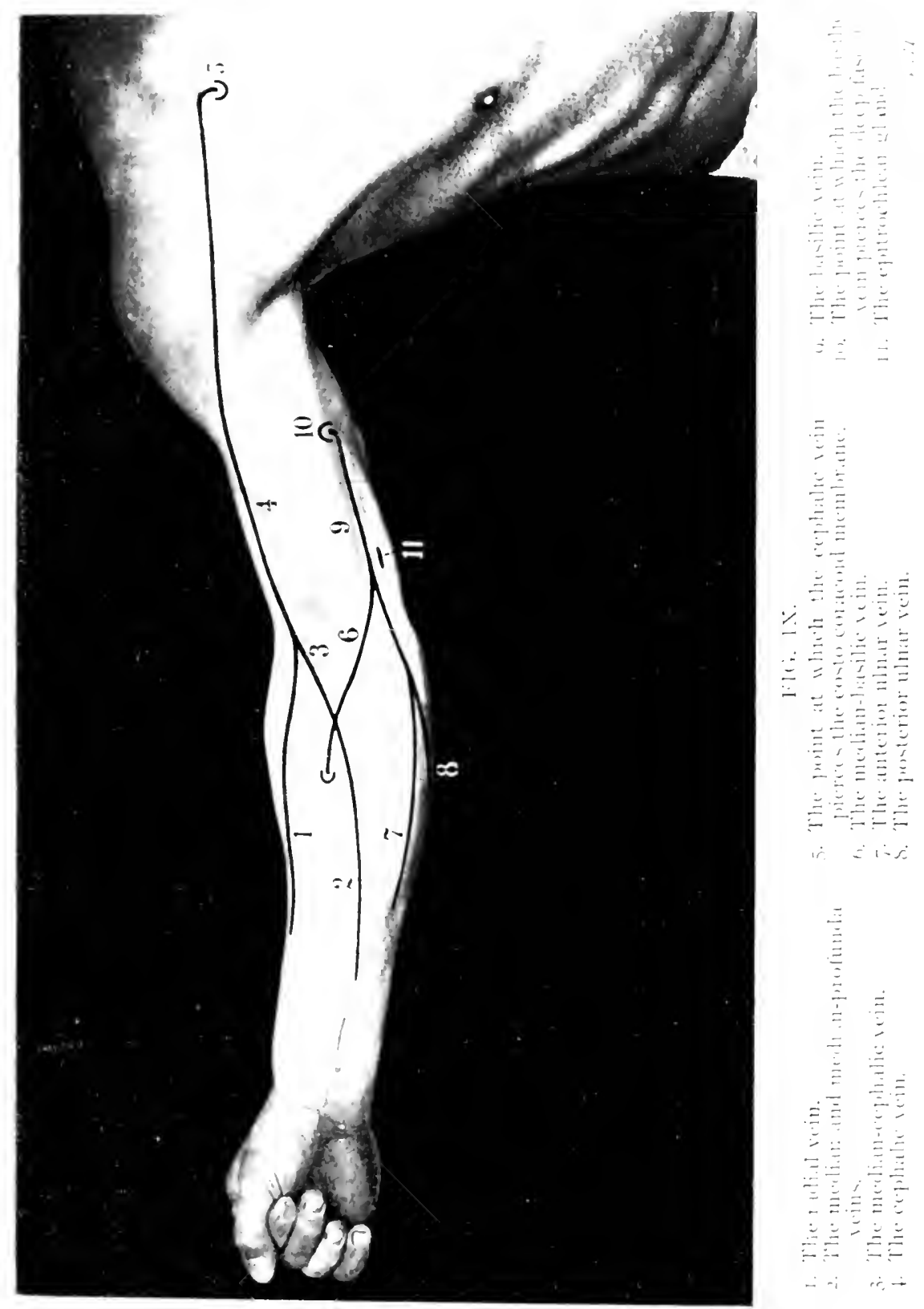



gland lies in close connection with the median basilic or Fig. ix., 11 . condyle.

basilic veins above and in front of the internal

The cephalic vein can be traced upwards along the outer

Fig. ix., 4. the deltoid and pectoralis major muscles. In the interval between these two muscles the vein lies Fig. ix., 5 . coracoid membrane in the infraclavicular region to open into the axillary vein.

\section{The Region of the IVRISt and Hand.}

Two tendons only are conspicuous at the front of the Fig. x., wrist-the palmaris longus in the middle line, 2,1 . and the flexor carpi radialis to the outer side of the palmaris longus. The flexor carpi ulnaris can, however, be distinguished by palpation along the ulnar Fig. x., border of the forearm, and can be traced down4. 5. wards to its insertion into the pisiform bone. Between the palmaris longus and the flexor carpi ulnaris the main mass of the flexor sublimis digitorum lies. Two

transverse creases are seen in this situation, the

Fig. x., 6. upper of which roughly corresponds to the level of the radio-carpal joint, whilst the lower represents almost exactly the upper limit of the anterior annular ligament.

Just external to where the flexor carpi radialis tendon cuts across the two transverse creases there is a Fig. xi., 4. depression, in the floor of which the lower end of the radius and the tubcrcle of the scaphoid bone may be felt. The radial artery crosses this space in a downward and outward direction. The trapezium Flg. xi., 3. lies at the lower limit of the depression, immediately below and external to the scaphoid tuberosity. 
The prominent pisiform bone can be distinguished by Fig. xi., 1. tracing downwards the tendon of the flexor both cuneiform and unciform bones are situated. A finger's Fig. xi., 2. breadth below and external to the pisiform the hook of the unciform bone.

The anterior anmular ligament is attached to four bony Fig. xi., 5. points, two on the radial side, the scaphoid tubercle and the ridge on the trapezium, and two on the ulnar side, the pisiform and the hook of the unciform. The upper limit of the ligament corresponds

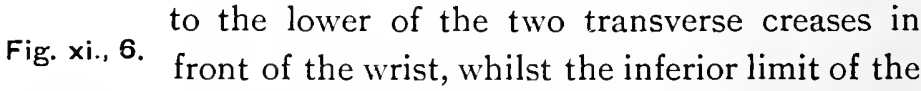
ligament lies about $\frac{3}{4}$ inch below.

The flexor synovial sheaths.-The flexor longus pollicis, the flexor sublimis and the flexor profundus Fig. xi. digitorum all pass beneath the anterior annular ligament. In this situation the flexor sublimis consists of four tendons, of which the medius and annularis lie superficial to the tendons which pass to the index and little fingers. The profundus consists of two parts only, the tendon to the index-finger being alone differentiated off from the main mass. Beneath the ligament these tendons are surrounded by two synovial sheaths, one for the flexor longus pollicis and one for the remaining tendons plus the median nerve. The sheaths extend upwards about $I$ inch above the upper limit of the ligament, and therefore the same distance above the lower transverse Fig. xi., crease in front of the wrist. The flexor longus 6, 6. pollicis sheath is continued downwards to the insertion of the tendon into the distal phalanx of the thumb. The main sheath broadens out below the liga- 


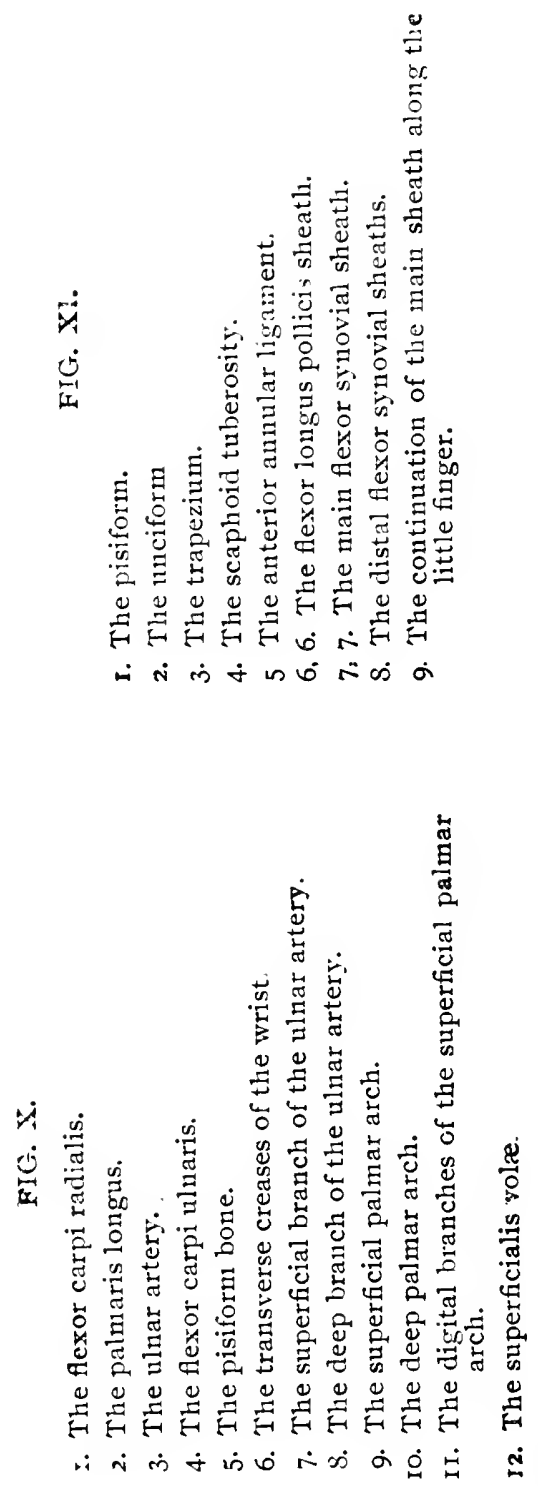


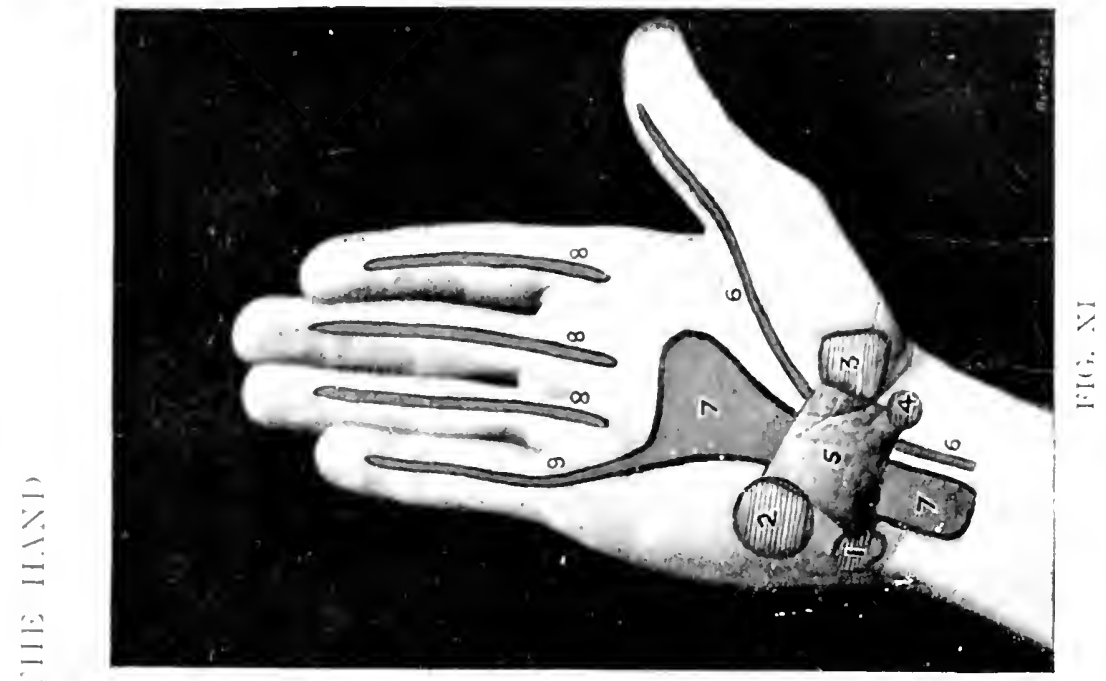

$=$
$=$
$=$
$=$

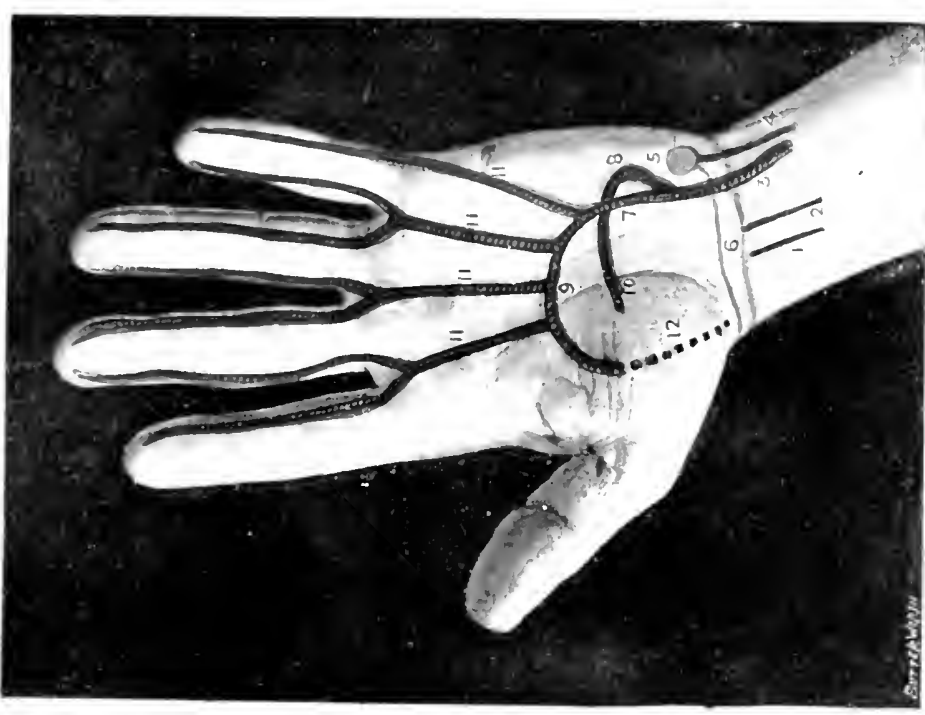



ment, and though generally continued onwards to the end Fig $x i ., 7$, of the little finger, the major portion terminates $\mathbf{7}, \mathbf{9}$. at the level of the upper transverse crease of the palm. The flexor tendons to the fore, middle and ring fingers also possess more distally distinct synovial sheaths, Fig. xi., 8, which extend from the terminal phalanges 8. 8. of the fingers upwards to the necks of the metacarpal bones, a level corresponding roughly to the lower transverse crease of the palm.

$A$ distance of $\frac{1}{2}$ inch separates the main synovial slicatl. above from the more distal segments below.

On the outer side of the wrist the most marked feature is the "anatomical snuff-box," a space bounded on the radial side by the tendons of the extensor ossis metacarpi and primi internodii pollicis muscles, and on the ulnar side by the tendon of the extensor sccundi internodii pollicis.

In the floor of the space the styloid process of the radius is felt, this prominence lying fully $\frac{1}{2}$ inch below the level of the corresponding process of the ulna, and also on a slightly more anterior plane. Immediately below the radial styloid process the scaphoid bone lies, most prominent when the hand is well adducted. Below this, again, the trapezium and the bases of the first and second metacarpals are to be felt.

On the dorsum of the hand there is a well-marked elevation, most noticeable when the wrist is fully flexed, due to the projection of the bases of the second and third metacarpal bones, the styloid process of the latter bone being especially prominent.

Immediately above this elevation there is a depression where the tendons of the extensor carpi radialis longior and brevior are felt as they pass to their insertion into the bases of the second and third metacarpal bones. 
Near the middle of the posterior aspect of the lower end Fig. xii., 4. of the radius a tubercle can generally be disextensor secundi internodii pollicis on the inner side from the tendon of the extensor carpi radialis brevior, which lies more external.

The posterior anmular ligament, about $\frac{3}{4}$ inch broad, Fig. xii. 1. extends from the lower part of the outer border and the carpal bones below the ulna. The ligament has, therefore, a downward and inward direction, and beneath it pass the extensor tendons. These occupy distinct compartments, and possess synovial sheaths as under:

I. One compartment and synovial sheath for the Fig. xii., 2. extensor ossis metacarpi and extensor primi internodii pollicis.

Fig. xii., 3. 2. Ond brevior.

Fig. xii., 5. pollicis.

3. One for the extensor secundi internodii Fig. xii., 6. 4. One for the ext

Fig. xii., 7. 5. One for the extensor minimi digiti. Fig. xii, 8. 6. One for the extensor carpi ulnaris.

The extent of the synovial sheaths is indicated in the diagram, where the radial artery is also depicted as it Fig. xii., crosses the "anatomical snuff-box" towards 9, 10. the base of the first interosseous space, at which level the vessel dips down between the two heads of the first dorsal interosseous muscle to complete the deep palmar arch. 
THE B.ICK OF THE WRIST

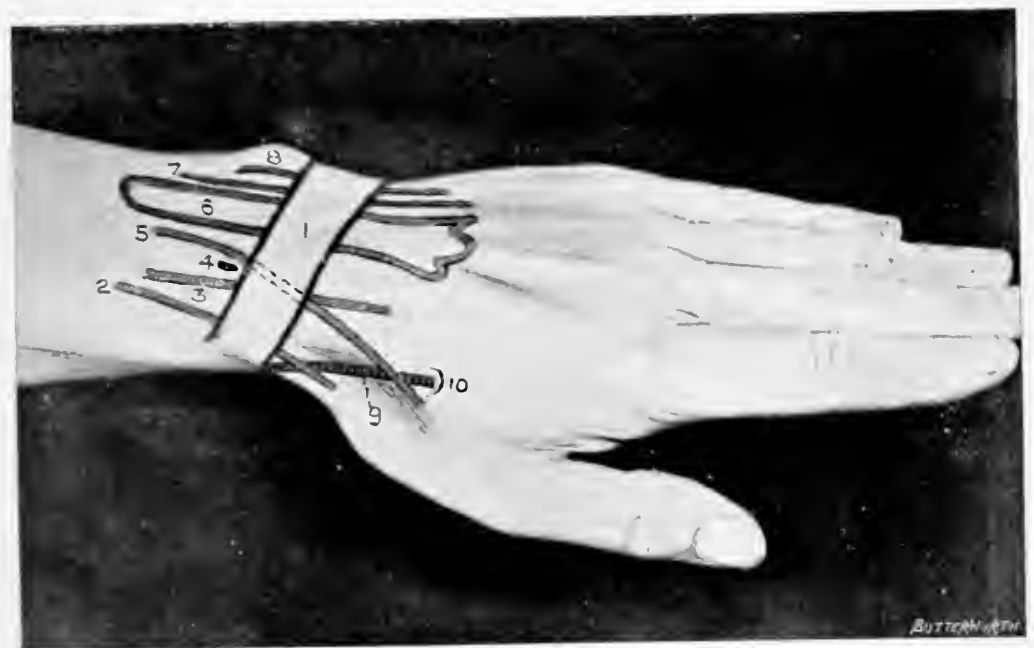

III. XII.

I. The posterior annular lisanent.

4. Tlue rarljal tulercle.

2. $3,5-8$. The compartuents anel synovial sleatlis of the extensor temilons (see text).

9. 'The radial artery, crossing the " anatomical sumff-box." 10. "1he base of the first interosscous space. 

Vessels, etc., of the Upper Extremity.

The axillary artery extends from the outer border of Fig. vi., 5. the first rib to the lower margin of the
teres major muscle. When the arm is held out at right angles to the long axis of the body, and the palmar surface of the hand turned upwards, the artery corresponds in direction to a line drawn from the middle of the clavicle to the junction of the anterior and middle thirds of the outer axillary wall at the outlet of that space. At its termination the artery and the accomFig. vi., panying nerves-the neuro-vascular bundle-

10.13. form a projection which lies behind that due to the coraco-brachialis and biceps (short head) muscles. Fig. vi., 4. The artery is divided into three parts by the pectoralis minor muscle, which muscle can be represented by a triangle, the base corresponding to the anterior extremities of the third, fourth and fifth ribs, whilst the apex is situated at the end of the coracoid process.

The brachial artery. - The arm and forearm being held Fig. vi., 12. in order to map out the axillary artery, the brachial artery corresponds to a line drawn from the outer wall of the axillary outlet at the junction of its anterior and middle thirds to the mid-point in front of the bend of the elbow at the level of the head of the radius. Fig. vi., 15 At the last point the artery bifurcates into radial and ulnar arteries.

The radial artery extends from the middle of the bend Fig. vi., 17. of the elbow at the level of the head of the Fig. xii.,
9, 10 . radius to the radial side of the tendon of the 9, 10. flexor carpi radialis muscle just above the base of the thumb. The artery then crosses the "anatonical 
snuff-box" towards the base of the first interosseous space.

The unar artery in the lower two-thirds of its course Fig accompanies and lics to the radial side of the Fig. vi., 18. ulnar nerve (see "ulnar nerve in the forearm," p. 32). The upper third of its course is represented by a line which passes obliquely upwards and outwards to the middlc of the bend of the elbow at the level of the head of the radius.

The superficial palmar arch is formed by the anastomosis Fig. $x ., 7$, of the superficial division of the ulnar artery 9, 12. with the superficialis volæ, or with some other branch of the radial artery. The convexity of the arch looks towards the fingers, and lies on a level with the lower border of the outstretched thumb. Occasionally the arch extends lower down, reaching as far as the upper of the two transverse creases on the palmar aspect of the hand.

The deep palmar arch, formed by the anastomosis of the Fig. x., 8, radial artery with the deep branch of the ulnar,

10. lies about one finger's breadth above the level of the superficial palmar arch.

The digital branches of the superficial palmar arch pass downwards in the intervals between the metaFig. x., 11. carpal bones to within $\frac{1}{2}$ inch of the digital clefts, where the vessels bifurcate to run along the adjacent sides of the fingers.

The circumflex nerve and the posterior circumflex artery Fig. xiii., 3. both pass backwards through the quadrilateral Fig. vi., 7. muscular space, and curl round the surgical neck of the humerus towards the outer and front aspect of the shoulder region. The artery anastomoses with the anterior circumflex artery, and the level of the arterial 


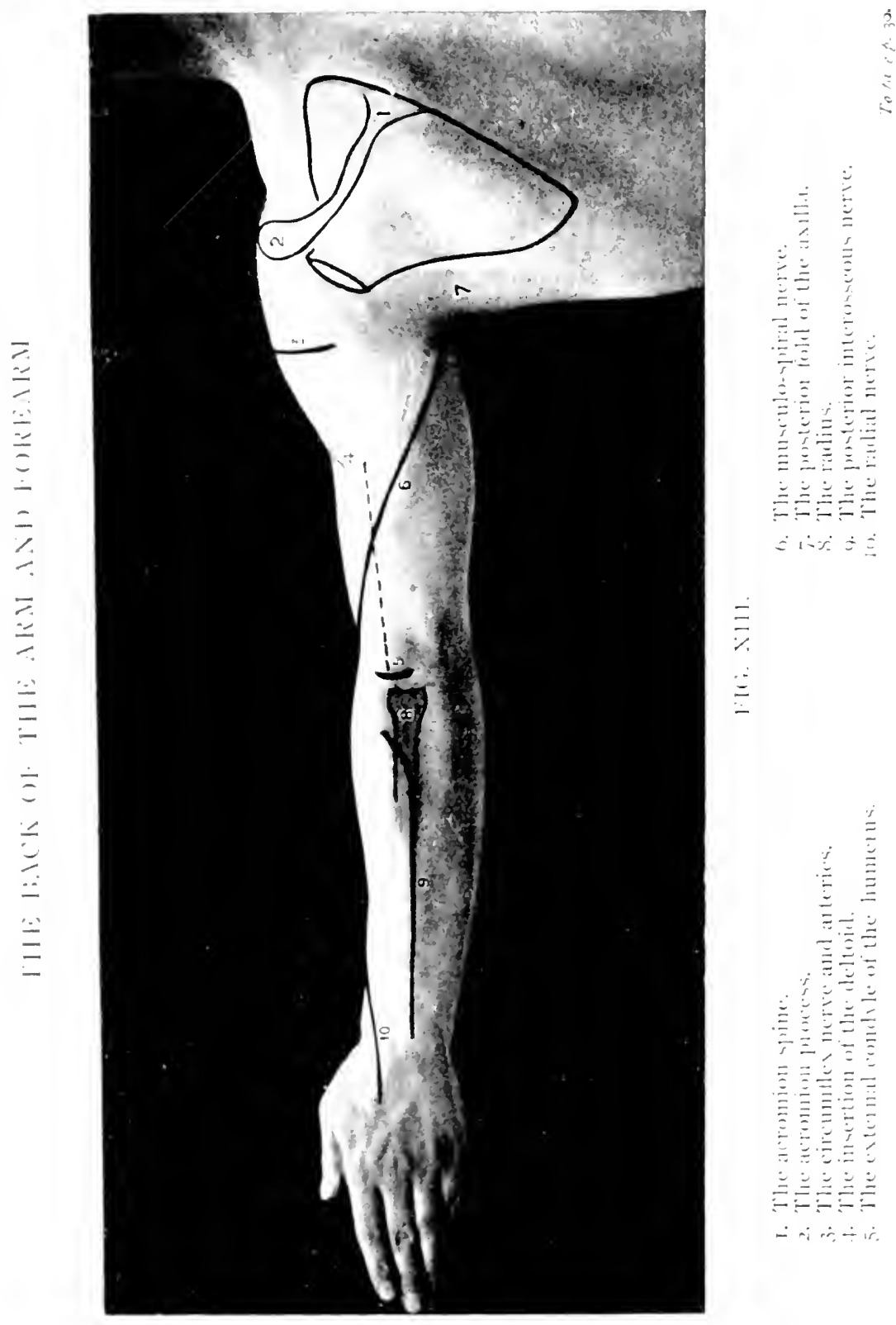


<smiles>[SiH3]</smiles> 
U 
THE SHOULDER AND ARM

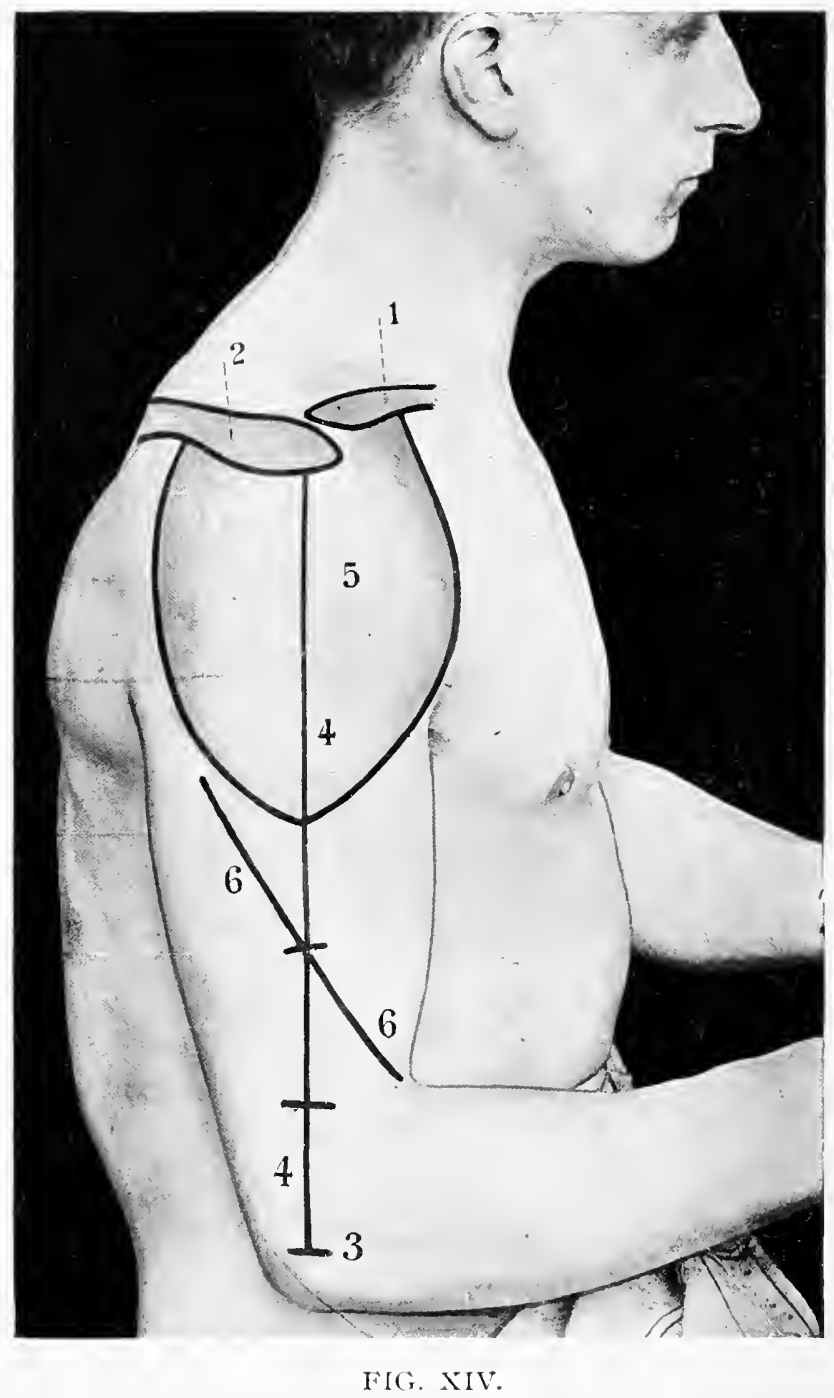

I. The clavicle.

2. The acromion process.

3. The external comble of the humerus.

4, 4. Hamilton's line.

5. The deltoid muscle.

6. 6. The nusculo-spiral nerve. 
circle so formed, and of the posterior circumflex nerve, may be represented by a line drawn at right angles to the shaft of the humerus from a point just above the centre of the deltoid muscle.

The musculo-cutancous nerve usually pierces the inner aspect of the coraco-brachialis muscle about I to 2 inches below the coracoid process. It then runs downwards and outwards, deep to the biceps muscle, towards the outel bicipital sulcus, at which level it becomes cutaneous. The course of the nerve in the arm can, therefore, be roughly indicated by a line from the coracoid process above to the outer bicipital sulcus below.

The musculo-spiral nerve, accompanied by the anterior Fig. xiii, 6 . branch of the superior profunda artery, pierces Fig. xiv. 6, the external intermuscular septum of the arm, 6.

from bchind forwards, at the junction of the upper and middle thirds of a line drawn from the insertion of the deltoid muscle to the external condyle of the humerus. Below this point the nerve passes downwards and inwards to the outer bicipital sulcus, where it bifurcates into its two terminal branches. Above the point at which the nerve pierces the external intermuscular septum, the course of the nerve may be represented by a curved line drawn upwards and inwards to the junction of the upper arm with the posterior fold of the axilla.

The radial nerve, a branch of the musculo-spiral, arises Fig. vi., 16 in the outer bicipital sulcus, and passes vertically Fig. xiii., 10. down the forearm, accompanying, and lying to the outer side of, the radial artery in its middle third. At the junction of the middle and lower thirds of the forearm, the nerve turns round the outer border of the radius under cover of the supinator longus tendon, to be distributed to the back of the wrist and hand. 
The posterior interosseous nerve arises from the musculoFig. xiii, 9. spiral in the outer bicipital sulcus, and curls round the neck of the radius in the substance of the supinator brevis muscle, emerging from the posterior border of that muscle 2 inches below the head of the radius. It then passes vertically down the posterior aspect of the forearm, lying about midway between the inner and outer borders, and terminating in a gangliform enlargement at the posterior aspect of the wrist.

The median nerve in the arm.-This nerve accompanies Fig. vi., 11, the brachial artery, and therefore presents a 11. similar surface marking. It is necessary, however, to bear in mind that the nerve crosses the artery superficially from above downwards and from without inwards.

The median nerve in the forearm passes vertically downFig. vi., 19. front of the wrist, there lying to the ulnar side of the flexor carpi radialis and under cover of the palmaris longus tendon. The nerve then passes under the anterior annular ligament to the palm.

The ulnar nerve in the upper third of the arm lies along the inner side of the brachial artery. It then Fig. vi., 13. leaves that vessel, and, accompanied by the inferior profunda artery, passes downwards and backwards to reach the hollow between the internal condyle and the olecranon process.

The ulnar nerve in the forearm corresponds in direction to a line drawn from the internal condyle of the
Fig. vi., 20. humerus to the radial side of the pisiform bone. In front of the wrist the nerve lies to the radial side of the tendon of the flexor carpi ulnaris muscle, and subsequently passes superficial to the anterior annular ligament to its palmar distribution. 
The palmar fascia is triangular in shape, the apex being attached to the anterior annular ligament between the thenar and hypothenar eminences, whilst the base corresponds to the proximal ends of the four inner fingers.

The Creases of the Palm and Fingers.

The upper transverse crease on the palmar aspect of the hand lies just below the normal limit of the superficial palmar arch, but at the level of the lower limit of the main flexor synovial sheath. The lower crease crosses the necks of the metacarpal bones, and corresponds to the upper limit of the distal flexor synovial sheaths.

The metacarpo-phalangeal joints lie about half-way between the distal crease of the palm and the proximal crease of the fingers. The middle and distal creases on the palmar aspect of the fingers correspond fairly accurately to the respective interphalangeal joints. The "knuckles" are formed by the heads of metacarpal bones. 


\section{THE THORAX}

THE majority of the thoracic viscera are depicted on the surface in relation to the costal cartilages, ribs and intercostal spaces, and it is therefore necessary to lay stress on certain important points :

I. That the twelve ribs are divided into two groups: (a) True ribs, seven in number, articulating by means of their costal cartilages with the mesial sterno-xiphoid bone; (b) False ribs, five in number, all falling short of the middle line, the upper three attached to the costal cartilage of the rib above, the lower two not articulating with the transverse process of the corresponding vertebra, and the anterior extremities not attached to the costal cartilage of the rib above. These last two ribs are therefore known as "floating ribs."

2. That the first rib lies mainly under cover of the Fig. iii., 23. clavicle, but that its costal cartilage can generFig. iii., 23. ally be palpated with ease as it lies below the sternal end of the clavicle.

3. That the first interspace which can be felt to the outer side of the sternum is the first interspace. This axiom may appear at first sight to be quite unnecessary, but it is in reality not uncommon for students to regard the first space which can be felt as the second interspace. 
4. That the second costal cartilage articulates in front Fig. iii., at the angle of Ludwig with the adjoining parts 2022 . of the manubrium and gladiolus.

5. Tha the seventh costal cartilage articulates with Fig. xvii. the adjoining parts of the giadiolus and xiphoid cartilage.

6. That the anterior extremity of the ninth costal cartilage corresponds almost exactly to the Fig. $x x$. costal arch. point where the linea semilunaris cuts the

7. That the twelfth rib is liable to great variation in size, frequently bcing so insignificant that it cannot be felt at all. It is, therefore, often advisable to count from above in fixing any particular rib.

$S$. That the intercostal spaces, in consequence of the downward and forward obliquity of the ribs, are wider in front than behind.

The female mamma, when well developed, extends upwards to the second rib, inwards to the outer border of the sternum, downwards to the sixth or seventh rib, and outwards to the mid-axillary line. The true glandular substance is, however, less regular in disposition, pro longations passing in various directions. Of these, the most important is the so-called "axillary prolongation," which is directed upwards and outwards along the anterior fold of the axilla.

The nipple usually corresponds to the fourth interspace It is variable in position, and not infrequently Fig. xv. overlies the fourth rib. In the female the nipple lics just below, and external to, the apex or central point of the breast.

Fig. $x v$.,

The heart lies opposite the middle four dorsal 1.4 . vertebræ, and the projection of its anterior 
surface upon the front of the chest wall may be indicated in the following manner.

Take the following four points:

I. The lower border of the second left costal cartilage about $\mathrm{I}$ inch from the left border of the sternum.

2. The upper border of the third right costal cartilage $\frac{1}{4}$ to $\frac{1}{2}$ inch from the right border of the sternum.

3. The lower border of the sixth right costal cartilage $\frac{3}{4}$ inch from the right border of the sternum.

4. The fifth left interspace $I \frac{1}{2}$ inches below and just internal to a line drawn vertically downwards from the nipple. If any abnormality exists with regard to the position of the nipple, this last point may be fixed with greater accuracy by taking a point in the fifth left interspace nearly 4 inches from the middle line.

The apex beat-the point of maximum impulse of the left ventricle against the chest wall-lies in the Fig. $x$ v., 8. fifth left interspace $I \frac{1}{2}$ inches below and $\frac{1}{2}$ inch internal to the nipple, or $3 \frac{1}{2}$ inches from the middle line. The position of the apex beat, therefore, does not exactly represent the outermost limit of the left ventricle. The above four points should now be joined in the following manner :

Points $I$ and 2 by a straight line.

Points 2 and 3 by a curved line, the heart reaching the greatest distance from the middle line, $I_{2} \frac{1}{2}$ inches, in the fourth interspace.

Points 3 and 4 by a line presenting a slight downward convexity, and cutting across the middle line in close relation to the xiphisternal junction.

Points I and 4 by a line presenting a fairly well marked convexity to the left. In the illustration this line is drawn rather too straight. 

FIG. XV.

N.B. - In this and in other figures in which the costal cartilages are depicted the numbered references do not refer to the corresponding cartilages. These are numbered for general convenieuce only.

I-4. The four points of the heart.

5. The auricular area.

6. The ventricular area.

7. The left ventricle.

8. The apex beat.

9. The pulmonary valve.

I0. The pulmouary artery.

II. The aortic valve.

I2. The mitral valve.

I3. The tricuspid valve.

14. The ascending aorta.

I5. The aortic arch.

16. The in nominate artery.

17. The riglit and left common carotid arteries

18. The right and left subclavian arteries.

19. The right and left subclavian veins.

20. The right and left interual jugular vein ${ }^{*}$

2 I. The right and left innominate veins.

22. The superior vena cava.

23. The inferior vella cava.

24. The abdominal aorta.

25. The cœliac axis.

26. The superior mesenteric artery.

27. The renal arteries.

28. The inferior mesenteric artery.

29. The common iliac arteries.

3o. The internal iliac arteries.

3r. The external iliac arteries.

32. The kidney.

3.3. The ureters.

34. Tlie ovaty. 
THE IIE.TRT, (IREAT VISSELS, KIDNEY, AND l'RETER

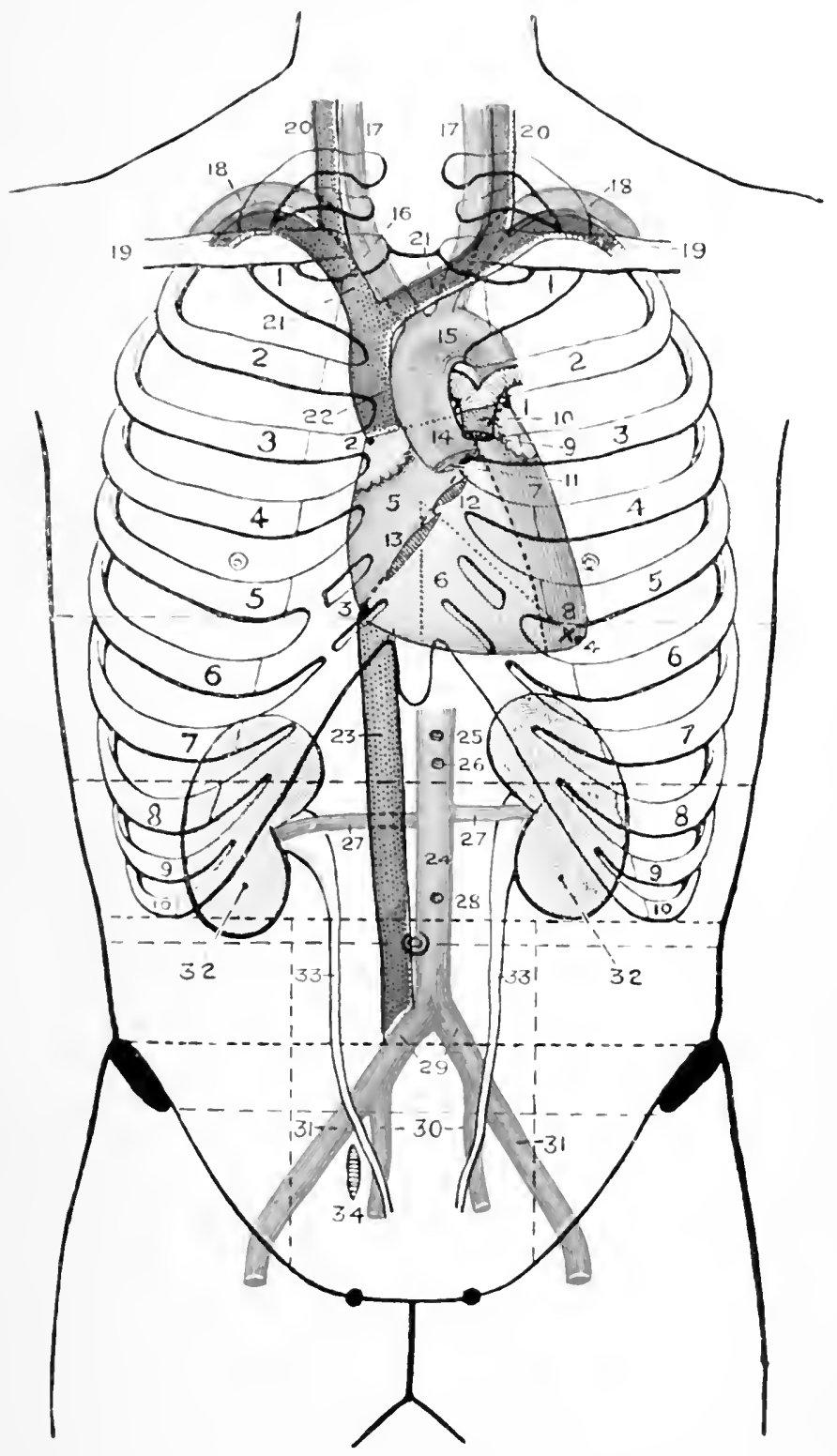

III ( .25 . 

A line joining Points $I$ and 3 divides this cardiac area Fig. xv., 5. into two parts, which roughly correspond to Fig. $x v ., 6$. the auricular area above and to the right, and the ventricular area below and to the left. This ventricular area is occupied mainly by the right ventricle, whilst a narrow strip along Fig. xv., 7. the left border represents that part of the left ventricle which comes to the surface.

The four points given above for marking out the projection of the heart on the anterior thoracic wall may be simplified by taking and joining the following four points:

I. The upper border of the third right chondro-sternal junction.

2. The lower border of the second left chondro-sternal junction.

3. The lower border of the sixth right chondro-sternal junction.

4. The position of the apex beat.

By uniting these four points, the heart is mapped out for most practical purposes with suflicient accuracy.

\section{The Valves of the Heart.}

I. The pulmonary valve is situated at the highest level, and lies opposite the upper border of the third Fig. xv., 9. left costal cartilage, close to its junction with the sternum.

2. The aortic valve lies just below and internal to the Fig. xv., 11. pulmonary valve at the lower border of the
third left costal cartilage at its junction with the sternum.

3. The mitral or left auriculo-ventricular valve is situated behind the left half of the sternum at the level

Fig. xv., 12. of the fourth chondro-sternal junction. 
4. The tricuspid or right auriculo-ventricular valve lies Fig. xv., very obliquely behind the sternum at the level

13. of the fourth interspace and the anterior extremities of the fifth costal cartilages, extending downwards and to the right almost as far as the sixth chondro-sternal junction.

The Aorta and other Vessels, etc.

The ascending aorta, 2 to $2 \frac{1}{2}$ inches long, arises behind Fig. xv., the left border of the sternum at the level of

14. the third costal cartilage, and passes upwards and to the right towards the right border of the sternum at the level of the second costal cartilage.

The aortic arch is directed backwards and to the left, Fig. xv., the upper limit lying about I inch below the 15. suprasternal notch, or half-way between that notch and the angle of Ludwig. The arch becomes the descending aorta at the left side of the lower part of the body of the fourth dorsal vertebra.

The descending thoracic aorta, 7 to 8 inches long, passes onwards through the posterior mediastinum, and pierces the diaphragm at the level of the twelfth dorsal vertebra. The site of diaphragmatic perforation is represented on the surface by a point situated just to the left of the middle line, two fingers' breadth above the transpyloric plane.*

The innominate artery, $\mathrm{I} \frac{1}{2}$ to 2 inches long, arises from Fig. $x v$., the aortic arch in the middle line $\mathbf{I}$ inch below 16. the suprasternal notch, and passes upwards and to the right to the right sterno-clavicular articulation, at which level it bifurcates into its two terminal branches.

The left common carotid (thoracic course) arises from

* Any "planes" mentioned in this chapter will be explained in thr chapter on the abdomen. 
the aortic arch on a posterior plane to, and slightly to Fig. $\times v^{\prime}$., the left of, the trunk of the innominate artery, 17. and passes upwards and to the left to the left sterno-clavicular articulation.

The left subclavian artery (thoracic course) arises from Fig. $x v$., the aortic arch on a posterior plane to, and 18. slightly to the left of, the thoracic part of the left common carotid artery, and passes almost vertically upwards behind the left border of the sternum to the left sterno-clavicular joint.

The superior mediastimum is bounded above by the plane of the thoracic inlet and below by a plane which Fig. xviii. passes backwards from the angle of Ludwig in front to the lower border of the fourth dorsal vertebra behind (Ludwig's plane).

The pulmonary artery arises opposite the upper border Fig. xv., of the third left costal cartilage at its junctior: 10. with the sternum, and passes backwards and slightly upwards to its bifurcation, which takes place opposite the second left costal cartilage.

The internal mammary artery arises from the first part Fig. xx., 8. of the cervical course of the subclavian behind the corresponding sterno-clavicular joint. In its further thoracic course, the artery lies $\frac{1}{2}$ inch external to the outer border of the sternum, bifurcating opposite Fig. $x$ x., the sixth costal cartilage or the sixth interspace 9, 10. into the musculo-phrenic and superior epigastric arteries. The former vessel curves outwards, following the line of the costal arch, whilst the latter passes onwards to enter the sheath of the rectus abdominis muscle.

The left innominate vein, 3 inches long, is formed opposite the left sterno-clavicular joint, and passes to the 
right, slightly overlapping the upper part of the aortic Fig. xv., arch, and occupying the greater part of the

21. space between the summit of the arch below and the suprasternal notch above.

The right innominate vein is formed at the right sternoFig. xv, clavicular joint, and passes obliquely down-

21. wards and inwards to meet the corresponding vein of the opposite side at the lower border of the first right costal cartilage close to its junction with the sternum.

The superior vena cava, formed by the junction of the Fig. xv., above two veins, is directed almost vertically 22. downwards from the lower border of the first right costal cartilage close to its junction with the sternum, to open into the right auricle of the heart at the level of the upper border of the third right chondrosternal junction.

The inferior vena cava enters upon its short intrathoracic Fig. $x v$., course by passing through the quadrate opening 23. of the diaphragm at the level of the eighth dorsal vertebra, opening into the right auricle of the heart opposite the fifth right interspace and the adjoining part of the sternum.

The vena azygos major drains the whole thoracic wall, except the first space on the right side and the upper three spaces on the left. It opens into the superior vena cava at the level of the lower part of the second right interspace, curling round the root of the right lung in order to reach its destination.

The main aortic intercostal vessels occupy the subcostal groove of a rib as they pass round the chest wall, lying between the corresponding vein above and the nerve below. 

THE PLEURAL SACS, LUNGS, ETC.

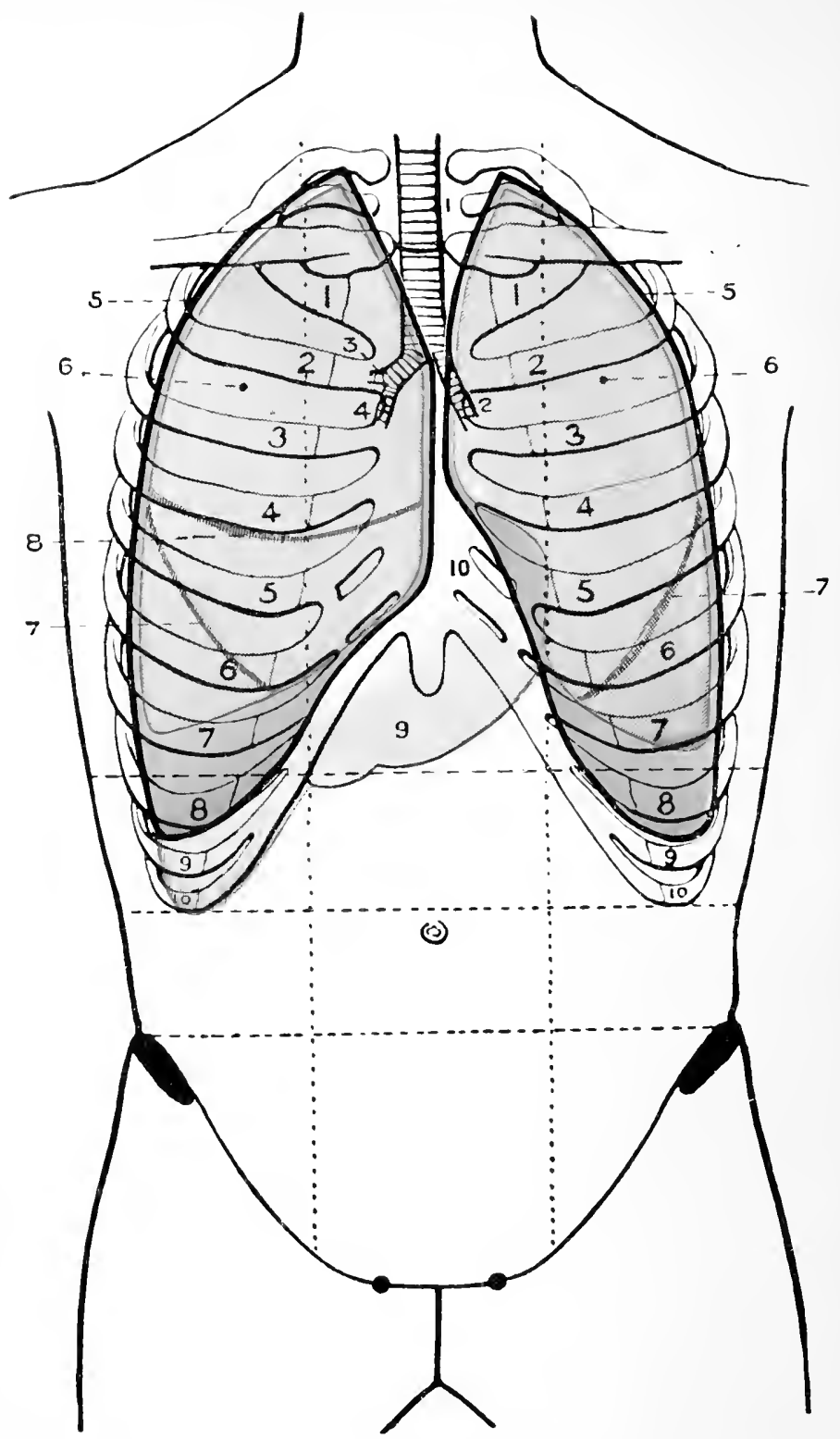

IIG. XVI.

1. The trachea.

2. The left lironclius.

3. The eparterial broncluss.

4. The hyparterial bronchis.

5, 5. The pleura.

6,6 . The lungs.
7,7. The main oblique fissure of the lungs.

s. The small transverse fissure of the right ling.

9. The liver.

Io. Area of superficial cardiac dul. ness. 


\section{Tiie Pleura and Lungs.}

. The pleural sacs.--When the shoulders are depressed, Fig. xvi., 5. the two clavicles lie practically at right angles Fig. xvii., 4. to the long axis of the body, and in this position the apices of the pleural sacs extend into the supraclavicular region, lying about $\mathrm{r} \frac{1}{2}$ inches above the clavicle under cover of the clavicular head of the sterno-cleidomastoid muscle.

The anterior margin of each sac sweeps downwards and inwards behind the corresponding sterno-clavicular joint, the two sacs converging towards the angle of Ludwig, at which level they meet one another just to the left of the middle line. They then pass vertically downwards parallel to one another as far as the level of the fourth chondrosternal junction.

The right sac passes onwards in the same straight line to the sixth or seventh chondro-sternal articulation, and then sweeps round the anterior, lateral, and posterior aspects of the chest wall, cutting across-

(I) The upper part of the eighth costal cartilage in the lateral vertical line;

(2) The tenth rib in the mid-axillary line;

(3) The eleventh rib in the line of the inferior angle of the scapula;

(4) The twelfth rib at the outer border of the erector spinæ muscle.

The obliquity of the twelfth rib causes the pleura to fall below the level of the inner half of the rib, the pleura in this last part of its course being directed inwards towards the spine of the twelfth dorsal vertebra.

The left plcura, from the level of the fourth left chondro. sternal articulation, sweeps obliquely outwards and down. 
wards behind the costal cartilages of the fifth, sixth and seventh ribs to the eighth costal cartilage in the lateral vertical plane. Beyond this point the left pleura follows the same general direction as the right sac, descending, however, to a slightly lower level.

The lowest limit reached by the two pleural sacs is situated in the mid-axillary line, the sacs there cutting across the tenth rib about 2 inches above the costal margin, which is in this situation usually represented by the tip of the eleventh rib.

Difficulty is sometimes experienced in endeavouring to verify the position of the twelfth dorsal spine, and in such cases the pleural reflection behind the mid-axillary region may be represented by a line which passes almost trans. versely backwards toward the median posterior line from the tenth rib in the mid-axillary line.

The two sacs are for the most part separated from one another by the width of the vertebral bodiesFig. xvii., 4. about $I \frac{1}{2}$ inches. In the lower part of the posterior mediastinum, however, the right sac approaches the median line.

2. The lungs may be mapped out in part by lines similar to those given for the pleural sacs. The apex of the Fig. xvi., 6. upper lobe of each lung extends into the supraFig. xvi.,
Fig.

converge towards the angle of Ludwig, cutting obliquely across the corresponding sterno-clavicular joint.

The two anterior borders do not, however, meet at the angle of Ludwig, for the right lung on reaching the middle line passes vertically downwards as far as the level of the sixth or seventh chondro-sternal junction, whilst the left lung runs down behind the left border of the sternum to the junction of the fourth costal cartilage with the sternum. 
THE PLEURII, SACS, IUNGS, ETC.

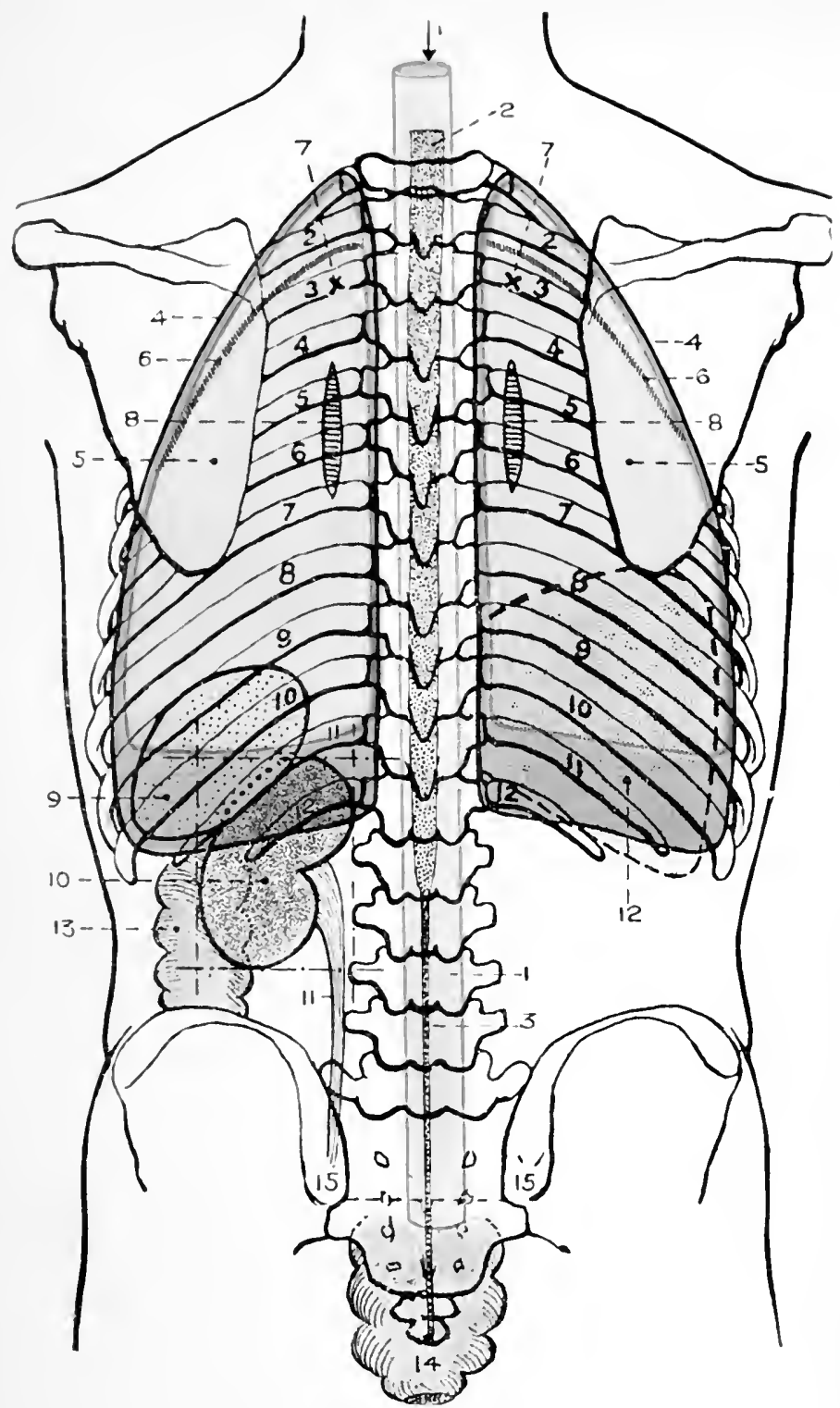

FIG. NIII.

I, I. The spinal dural sheath.

2. The spinal cort.

3. The filum terminale.

4 , 4. The pleurie.

5. 5. The lungs.

6, 6. The main ollique fissures of the fungs.

7,7. The apex of the lower lohe of the lungs.
9. The spleen.

ro. 'The left killney in Morris's guadrilateral.*

II. The ureter.

12. 'The liver.

13. The descending colon.

1.4. The rectum.

15. The pósterior superior iliac spine.

s, s. The roots of the lungs. 

The right lung, from the level of the sixth or seventh chondro-sternal junction, sweeps outwards, cutting across-

(I) The sixth costal cartilage in the lateral vertical line

(2) The eighth rib in the mid-axillary line;

(3) The tenth rib in the line of the inferior angle of the scapula, and finally passing inwards towards the tenth dorsal spine.

The left lung, from the outer border of the sternum at the level of the fourth chondro-sternal articulation, passes outwards for a short distance along the lower border of the fourth costal cartilage, and then iurns downwards and inwards in a curved direction to the sixth costal cartilage in the lateral vertical plane. The lung then sweeps round the chest wall, following a course similar to that already indicated as pursued by the right lung, the left lung lying, however, at a slightly lower level.

Stress should, perhaps, be laid on the fact that, as the lower border of each lung sweeps round the antero-lateral, lateral, and posterior aspects of the chest wall, from the sixth costal cartilage in front to the tenth dorsal spine behind, the course pursued is practically transverse to the long axis of the body.

It will be convenient to here put in a tabulated manner the comparative lower levels of the right pleura and lung. Starting in each case at the right chondro-sternal junction, the pleura and lung may be represented by lines which traverse the chest wall, cutting across the

(I) Lateral vertical line at the eighth costal cartilage (pleura)-sixth costal cartilage (lung).

(2) Mid-axillary line at the tenth rib (pleura)-eighth rib (lung).

(3) Scapular line at the eleventh rib (pleura)-tenth rib (lung). 
(4) And sweeping in towards the twelfth dorsal spine (pleura)-tenth dorsal spine (lung).

The numbers to be remembered are, therefore, 6, 8, ro, II, and I2 for the pleura, and 6, 6, 8, Io, ro for the lung.

On the left side, the levels are similar with two main exceptions- $-(a)$ the lung and pleura sweep outwards so as to leave a part of the heart uncovered (see "superficial cardiac dulncss"), (b) both lung and pleura descend to a slightly lower level.

The Lower Limit of the Lung, the Pleura, and the Liver in the Right Mid-axillary Line.

(I) The lung corresponds to the eighth rib.

(2) " pleura ," , tenth rib.

(3) " liver costal margin, or even lower.

The fissures of the lungs. - The main fissure of each lung Fig. xvi., 7. is indicated by a curved line which starts behind Fig. xvii., 6 . at the level of the second dorsal spine, the apex of the main lower lobe of each lung, therefore, being situated immediately below and external to this dorsal spine. When the arms fall naturally to the side of the body, the line representing the main fissure cuts across the infraspinous surface of the scapula, and crossing then the fifth rib in the mid-axillary line, terminates in front at the inferior border of the lung at the level of the sixth chondro-costal junction. When the arms are extended above the head, the inferior angle of the scapula slides upwards and outwards on the chest wall. In this position the main fissure is represented by a line from the second dorsal spine which passes downwards and outwards to the inferior angle of the scapula, and then forwards to the termination of the fissure at the inferior border of the lung. 
The smaller or upper fissure of the right lung separates off from the main fissure in the mid-axillary line, and passes Fig. xvi., 8. almost transversely forwards along the lower border of the fourth rib and costal cartilage to the anterior border of the lung. It is thus manifest that the anterior aspect of the chest, above the level of the sixth costal cartilage, corresponds to the upper two iobes of the right lung and to the upper lobe of the left lung, whilst the posterior aspect of the chest below the level of the second dorsal spine corresponds to the right and left main lower lobes.

The apices of the upper and lower lobes.-It will be here In place to again lay stress on the fact that the apex of the upper main lobe lies about I inch above the clavicle in the supraclavicular fossa, under cover of the clavicular head of a well-developed sterno-cleido-mastoid muscle, and Fig. xvi. that the apex of the lower lobe lies immediately Fig. xvii., 7. below and external to the spine of the second dorsal vertebra.

The roots of the lungs lie opposite the spines of the fourth, Fig. xvii., 8 . of the fifth, sixth, and seventh vertebræ. They
may be so represented, lying also midway between the may be so represented, lying also midway between the
median posterior line and the vertebral border of the scapula, the arms hanging loosely from the shoulders.

The areas of deep and superficial cardiac dulness.I. The area of deep cordiac dulness, quadrate in form, Fig. xv., corresponds to the complete area already 1.4. mapped out as representing the projection ${ }_{2}$ of the heart on to the anterior aspect of the chest wall.

2. The area of superficial cardiac dulness, more or less triangular in shape, corresponds to that part of the heart which is not covered by the thin anterior margin of the 
lung. This area can, with sufficient accuracy, be defined Fig. xvi., 10. as a triangular space, the left border being Fig. $x v$. formed by a line from the fourth left chondrosternal articulation to the apex beat of the heart in the fifth left interspace, the right border by a line which passes downwards along the middle of the sternum from the level of the anterior extremities of the fourth to the seventh costal cartilages, and the base by a line which passes outwards from the level of the seventh costal cartilage to the position of the apex beat.

A reference to Figs. xiv. and xv, will make it evident that paracentesis of the pericardium can be performed, without injury to pleura or lung, in the fifth left intercostal space. The internal mammary artery runs vertically downwards about $\frac{1}{2}$ inch from the outer border of the sternum, and the needle should, therefore, be inserted through the fifth intercostal space about I inch from the outer border of the sternum.

The trachea and bronchi.-The trachea, $4 \frac{1}{2}$ inches long, Fig. xvi., 1. commences immediately below the cricoid cartilage, on a level with the sixth cervical vertebra, and passing downwards through the superior mediastinum, bifurcates opposite the level of the lower part of the body of the fourth dorsal vertebra (Ludwig's plane).

The two bronchi diverge, the left being the longer Fig. xvi., 2, and the narrower. The tendency of foreign 3,4 . bodies to pass more frequently into the right bronchus is explained by the fact that the septum between the two bronchi is placed to the left of the middle line of the trachea. The right bronchus, previous to the givingoff of the eparterial bronchus, is less obliquely inclined than the left bronchus, though subsequently it follows much the same course. 
The greater obliquity of the left bronchus accounts also for the fact that the left pulmonary artery tends to lie at the higher level, whilst the right pulmonary artery lies below the level of the corresponding bronclius.

The asophagus, 9 inches long, also commences at the Fig.xix., level of the cricoid cartilage, and passing i, 1. downwards through the superior and posterior mediastina, pierces the diaphragm at the level of the tenth dorsal vertebra, entering the stomach at the level of the eleventh vertebra.

The entrance of the cesophagus into the stomach may be indicated by taking a point on the seventh left costal cartilage $\frac{1}{2}$ inch away from the left side of the xiphisternal junction.

The thoracic duct, I5 to is inches long, commences as the receptaculum chyli, a spindle-shaped sac which lies Fig. xx., 5. Opposite the bodies of the first and second lumbar vertebræ, and between the thoracic aorta on the left and the vena azygos major on the right. It may be represented on the surface by an oval enlargement placed just to the right of the middle line, occupying the upper two-thirds of the space between the transpyloric (first lumbar) and subcostal (third lumbar) planes.

The efferent duct pierces the diaphragm through the Fig. xx., 6. aortic orifice opposite the twelfth dorsal vertebra, and passes almost vertically upwards through the posterior mediastinum, just to the right of the middle line, as far as the lower part of the fourth dorsal vertebra (Ludwig's plane). The duct now crosses behind the œsophagus to the left of the middle line, and then agair passes vertically upwards through the superior mediastinum and into the neck as far as the level of the transverse process of the seventh cervical vertebra. 
Finally, the duct curls outwards and downwards to open Fig. xx., 7. into the angle between the internal jugular and
subclavian veins of the left side. The duct drains the whole of the lymphatic area of the body, excepl the right side of the head and neck, the right arm, the right side of the thorax and the convexity of the liver, he lymphatics from these regions draining into a smaller ducl which opens into the angle between the right internal jugular and subclavian veins. 


\section{CHAPTER IV}

\section{THE ABDOMEN}

THE anterior aspect of the trunk (i.e.; thorax and abdomen) Fig. xviii., is divisible into right and left halves by a modian

3, 3. vertical plane from the middle point at the suprasternal notch above to the symphysis pubis below. Each half is again divided by a lateral vertical plane which Fig. xviii., is drawn parallel to the median plane, half-way $4,4$.

between that plane and the anterior superior iliac spine. Prolonged downwards, this lateral plane crosses Poupart's ligament rather nearer to the inner than to the outer end. Prolonged upwards, it crosses the clavicle about midway between the median point at the suprasternal notch and the acromio-clavicular joint.

That part of the lateral vertical plane which traverses the mammary region is sometimes calied the "mammary plane," that part which crosses the clavicle the "clavicular plane," and the downward prolongation which cuts across Poupart's ligament the "Poupart plane."

The clavicular, mammary, and Poupart planes are, however, continuous, and they together form the lateral vertical plane, which is chosen in preference to the midPoupart plane of many anatomists, since it is measured from the median plane to a fixed bony point. Two vertical planes only will be consequently retained in the subdivision of the anterior aspect of the trunk, the median and latcral vertical pinus's. 
The median plane can be bisected by a horizontal plane which is on the same level as the body of the first lumbar vertebra. This plane so constantly cuts across the pyloric end of the stomach that it is called the transpyloric plane, Fig. xviii. and it will be found that not only does this plane lie half-way between the suprasternal notch and the symphysis pubis, but that it also lies midway between the umbilicus and the sterno-xiphoid junction. It is, therefore, not necessary to expose the whole of the anterior aspect of the trunk in order to verify the position of the transpyloric plane, a plane of the greatest value in defining the position of several abdominal viscera.*

The point at which the median vertical and transpyloric Fig. xviii., 1.

plares intersect has been suitably called the "central point," and the point of intersection of the lateral vertical and transpyloric planes may be Fig. xviii., 2. "tentatively called the "lateral central" or "paracentral" point. This latter point usually corresponds to the anterior extremity of the ninth costal cartilage.

The distance between the "central point" and the top of the symphysis pubis is bisected by a horizontal plane Fig. xviii. which passes through the tubercles of the iliac crests, the intertubercular plane, a plane corresponding to the level of the body of the fifth lumbar vertebra. It has also been suggested that the distance between the "central point" and the suprasternal notch should likewise be bisected by a plane, the thoracic plane, which crosses the gladiolus at the level of some part of

* N.B.-Most of the "planes" mentioned in the text were first put forward by Dr. C. Addison, Lecturer and Senior Demonstrator of Anatomy, St. Bartholomew's Hospital, to whom the credit is due. 
THE ABHOMINL ANH THORACIC PLANDS.

Level of harel palate = lis cervical.

l.evel of free margin os upler teeth $=$ secomt ecrvical.

Lerel of hroid lume = secund to thiril cervicial.

level of upper part of thyrofil carthlige formt cervical.

lovel of cricuil eartilage = siath ecrvical.

1.urwigrs

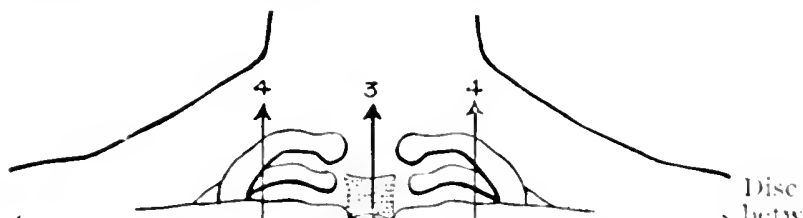

stcrual

plane

pline

Iranspyloric

plane

Thoracic plane

Sterno. xiphoid plane

Subcosta!

plane

Iinlilical

Intertuber

cular plane

spinous plane

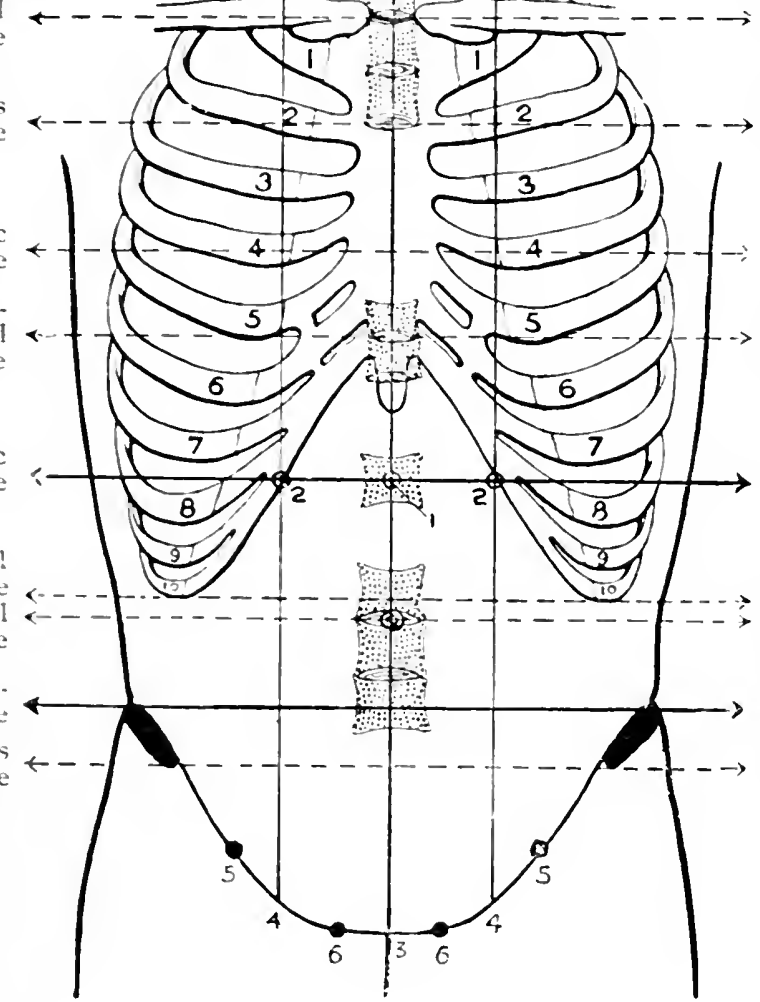

2 atil 3 I)

between

4 atmis 51 .

I).

I)isc

letween

$y$ and :O I).

Fig. Filis.

1. The central point.

2,2 The lateral central or puratentral point.

3. 3. The metlian vertical plane

4. - The laterat vertical plane

5. 5. The mul-I'oupart point.

6. 6. The julic spuns. 

the anterior extremities of the fourth costal cartilages. Fig. xviii. This plane is, however, of little value, and is merely mentioned as completing the symmetrical subdivision of the median vertical plane into four equal parts.

The following planes are, therefore, chosen as the most scientific in the subdivision of the anterior aspect of the trunk:

Two vertical planes-(I) The median; (2) the lateral.

Three transverse planes-(I) The intertubercular; (2) the transpyloric; (3) the thoracic.

Two important points are also named-(I) The central point; (2) the lateral central point.

The abdominal regions mapped out by the intersection of the transpyloric and intertubercular planes with the lateral vertical planes receive the same nomenclature as in the older methods of regional subdivision of the abdomen. These regions are nine in number :

r. Right hypochondriac. 2. Epigastric. 3. Left hypoFig. xviii. chondrinc. 4. Right lumbar. 5. Umbilical. 6. Left lumbar. 7. Right iliac. 8. Hypogastric. 9. Left iliac.

Other Transverse Planes, with their Correspond. ing Vertebral Levels.

(a) The suprasternal plane, on a level with the disc Fig. xviii. between the second and third dorsal vertebræ.

(b) Ludwig's plane (junction of manubrium and gladiolus), on a level with the disc between the fourth and fifth dorsal vertebræ.

(c) The sterno-xiphoid plane (junction of sternum and xiphoid cartilage), on a level with the disc between the ninth and tenth dorsal vertebra. 
(d) The subcostal plane, on a level with the lower part of the third lumbar vertebra.

(e) The umbilical plane, on a level with the disc between the third and fourth lumbar vertebræ.

(f) The spinous plane, drawn between the two anterior superior iliac spines, and usually falling below the level of the sacral promontory.

The linea semilunares correspond to the outer border Fig. xx., of the rectus abdominis muscle, and extend, 12. with a slight outward convexity, from the pubic spine below to the tip of the ninth costal cartilage above (the lateral central point).

The linece transverse result from the tendinous interFig. xx., 13, sections in the rectus abdominis muscle. They 13, 13. are three in number, and are situated-(I) at the level of the umbilicus; (2) midway between the umbilicus and the xiphoid cartilage; (3) immediately below the xiphoid cartilage.

The scmilunar fold of Douglas, representing the lower Fig. xx., 14. limit of the posterior lamella of the rectus sheath, lies about half-way between the umbilicus and the upper border of the pubic symphysis.

The umbilicus usually lies $I$ to $I \frac{1}{2}$ inches above the Fig. xviii intertubercular plane, and corresponds to the level of the disc between the third and fourth lumbar vertebræ. The umbilicus is, however, so inconstant in position that the umbilical plane is rejected as often as possible in favour of a more definite and scientific plane.

The iliac spines and crest.-When the body is in the Figs. xxii., dorsal recumbent position, the anterior superior xxiii. iliac spine is usually visible to the eye, and no palpation is needful in order to fix its position. In the 
obese, however, it is generally necessary to trace forward the iliac crest to its anterior termination. By tracing the iliac crests in a backward direction the "iliac tubercles" will be found, lying about 2 to $2 \frac{1}{2}$ inches behind the anterior superior spines, and a line uniting these two tubercles (the intertubercular plane) corresponds to the level of the fifth lumbar vertebra. Still further backward, the posterior superior iliac spines will be found at the Fig. xvii,, posterior termination of the iliac crest. A line 15, 16. which joins the posterior superior iliac spines cuts across the spine of the second sacral rertebra.

The pubic spine lies at the outer limit of the pubic crest. Fig. xviii., In the male, it is advisable to invaginate the Fig. 6 . 2, 2. spine; whilst in the female, owing to the prominence of the mons veneris, it is usually necessary to abduct the thigh, to feel for the rounded tendon of the adductor longus muscle, and to trace this tendon up to its origin from a depression on the pubic bone, which is situated immediately below and internal to the pubic spine.

In the erect position of the body the symphysis pubis is nearly horizontal, the inner or pelvic surface looking upwards and only slightly backwards, whilst the external surface faces downwards and a little forwards. The pubic crest is therefore practically directed forwards and the pubic arch backwards. A knife inserted horizontally backwards immediately above the pubic symphysis would pass above the upper limit of the prostate gland and below the promontory of the sacrum; whilst if directed horizontally backwards below the symphysis pubis, it would pierce the prostate near its centre and pass below the level of the tip of the coccyx. 
The inguinal canal.-In the adult this canal is about Fig. xx., 19, I $\frac{1}{2}$ inches long, and extends from the internal Fig. ${ }^{19}$., 17, to the external abdominal rings. The internal

17. abdominal ring, a funnel-shaped prolongation of the transversalis fascia, is situated $\frac{1}{2}$ inch above the midpoint of Poupart's ligament. The external abdominal ring, Fig. xx., 18, formed by the splitting of the aponeurosis of 18. the external oblique muscle, is triangular in shape, the base directed downwards and inwards and opening up immediately above the pubic spine, whilst the apex is directed upwards and outwards.

Petit's triangle.-This triangle is bounded in front by the posterior border of the external oblique, and behind by the anterior border of the latissimus dorsi muscle, whilst the base is formed by part of the iliac crest. The external oblique is inserted into the anterior half of the iliac crest, and the base of the triangle corresponds to I to 2 inches of the bone behind the mid-point of the crest. The triangle is subject to great variation in size, the two bounding muscles converging rapidly above to form the apex of the triangle. The floor is formed by the internal oblique muscle.

\section{The Alimentary Canal.}

The stomach.-Capacity about 2 pints. The cardiac Fig. xix., 2. and is situated about 4 inches away from the surface. It corresponds in position to a point on the seventh costal cartilage $\frac{1}{2}$ inch away from the outer border of the sterno-xiphoid junction. The seventh costal cartilage is the lowest of the series of cartilages which articulate in front with the mesial sterno-xiphoid bar, and forms, therefore, the upper lateral boundary of 
the epigastric triangle. The pyloric orifice lies opposite Fig. xix., 3. the first lumbar vertebra, and corresponds in just to the right of the middle line.

The lesser curvature is represented by a curved line, convexity to the left, uniting the above two points. The greater curature, in the moderately distended condition of the stomach, ascends to the lower border of the left fifth costal cartilage and rib, lying immediately above and behind the apex of the heart. Sweeping then downwards, the greater curvature usually cuts the left costal margin at some part of the ninth costal cartilage, and finally curves Fig. xx., 1. upwards and inwards to the pylorus. The sponds to the level of the left dome of the diaphragm.

The duodenum.- Total length, about ro inches. Part I Fig. xix., 4, $=2$ inches; part $2=3$ to 4 inches; part $3=4$ to 4,4 . 5 inches.

The pyloric orifice of the stomach lies opposite the first lumbar vertebra, and the first part of the duodenum is directed backwards, with a slight inclination upwards, to the right side of the body of the first lumbar vertebra.

Part 2 descends, on the right side of the median vertical plane, from the lcvel of the first lumbar vertebra (transpyloric plane) to the level of the third lumbar vertebra (subcostal plane). The third part of the duodenum passes almost transversely across the middle line at the level of the subcostal plane, and having reached the left Fig. xix., side of the middle line, ascends sharply to

5. the duodeno-jejunal flexure, which is placed on a level with the second lumbar vertebra, just below the transpyloric plane, and $I$ to $I_{2} \frac{1}{2}$ inches to the left of the middle line. The duodenum is subject to great variation 
in position, and the description given merely represents the average situation of this loop of the small gut. The pyloric orifice of the stomach and the duodeno-jejunal flexure are both fairly constant in position, and between these two more or less fixed points the gut describes a loop which varies both in shape and in extent.

The pancreas. - The head of the pancreas occupies the Fig. xix., concavity of the duodenal loop, the body cross-

4. ing the middle line at the level of the first and second lumbar vertebræ, and occupying, therefore, the upper two-thirds of the space between the transpyloric (first lumbar) and subcostal (third lumbar) planes. The tail of the pancreas extends to the left as far as the hilum of the spleen.

The small intestine is about 23 fect in length, the upper two-fifths being known as the jejunum, the lower threefifths as the ileum.

The mescnteric attachment of the small gut extends from Fig. xix., a point $I$ to $I \frac{1}{2}$ inches to the left of the middle 6. line, and just below the transpyloric plane (duodeno-jejunal flexure), to the junction of the right lateral vertical and intertubercular planes. The line drawn between these two points should pass at first obliquely outwards and downwards to the right iliac fossa, curving finally outwards to the region of the ileo-cæcal valve.

The ileo-cacal valve is placed opposite the junction of Fig. xix., the right lateral vertical and intertubercular $7 . \quad$ planes.

The cacum is about $2 \frac{1}{2}$ inches long, and the long axis of Fig. xix., the sac is directed downwards, forwards, and 8. inwards. This blind end of the large gut lies below the level of the intertubercular plane, and occupies the right iliac fossa and part of the right half of the hypogastric region. 



\section{FIG. XIX}

I, I. The œsophagus.

2. The stomach.

3. The pylorus.

$4,4,4$. The three parts of the duodenum. 4. The pancreas

5. The duodeno-jejunal flexure.

6. The attachment of the nesentery of the small intestine.

7. The ileo-cæcal valve.

8. The cæcum.

9. The vermiform appendix.

I0. The ascending colon.

I1. The hepatic flexure.

12. The splenic flexure.

I3. The descending colon.

14. The iliac colon.

I5. The ileo-pelvic colon.

I6. The gastro-hepatic omentum.

17. The foramen of Winslow.

I8. The common bile-duct.

N.B.-The transverse colon has been omitted intentionally.

X-ray pictures of the stomach filled with Barium show almost constantly a stomach of very different shape to that depicted in Fig. xix. This figure has, therefore, been criticised. I have, however, had the opportunity of seeing many normal stomachs, both in the anatomical department and in surgery. The cardiac and pyloric orifices, under normal conditions, are more or less fixed points. The stomach itself varies in shape and position from hour to hour, according to the period of digestion. Some average, however, has to be taken, and I submit that the normal stomach is represented with sufficient accuracy. 
THE ALIMENTARY CANAL

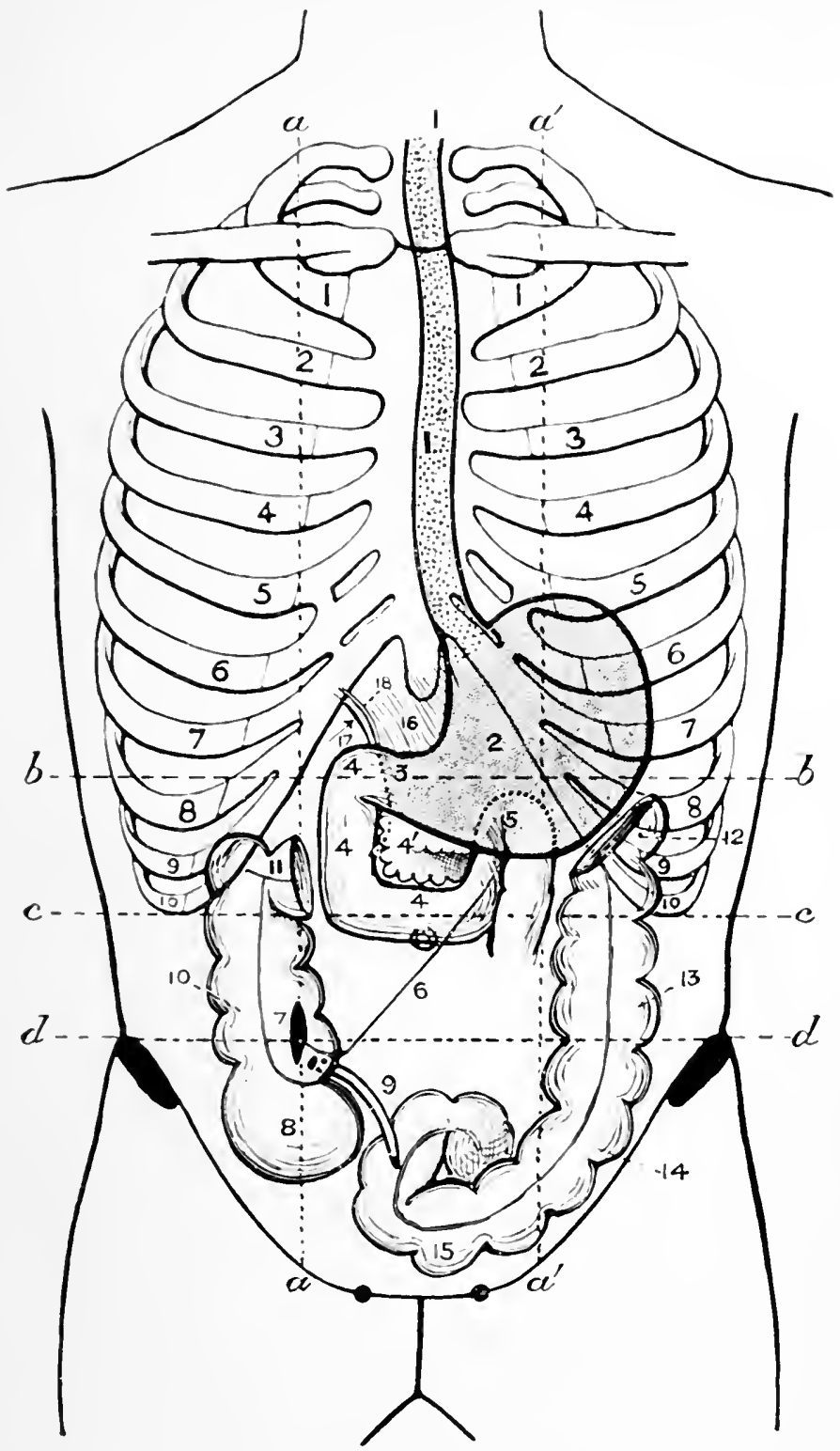

IFIG. XIX.

$a, a$, and $a^{\prime}, a^{\prime}=$ the lateral vertical planes.

$b, b$. The transprloric plane.

$c$ c. The subcostal plane.

$d, d$. The intertubercular plane. 

The vermiform appendix.-The opening of the appendix Fig. xix., into the crcum is situated just below and 9. internal to the junction of the right lateral vertical and intertubercular planes, at the top right-hand corner of the hypogastric region. The surface marking of the cæcal orifice of the appendix does not coincide with McBurney's point, which is situated at the junction of the outer and middle thirds of a line drawn from the right anterior superior iliac spine to the umbilicus. This point represents the usual seat of maximum pain on palpation in an attack of appendicitis. The appendix is usually 3 to 4 inches long, and, according to Testut, is in 40 per cent. of cases directed downwards and inwards, overhanging the pelvic brim, whilst in 26 per cent. of cases only is it directed upwards and inwards (towards the spleen). Stress should be laid on the fact that the ileo-cæcal valve and the cæcal orifice of the appendix are both situated on the postero-internal aspect of the cæcum.

The ascending colon passes upwards from the level of Fig. xix., the intertubercular plane to the upper part of 10. the ninth right costal cartilage, the gut there turning on itself to form the hepatic flexure. In its upward course the ascending colon lies almost entirely to the right of the right lateral vertical plane.

The transuerse colon extends from the hepatic flexure on Fig. xix., the right to the splenic flexure on the left. The ii. former flexure corresponds to the ninth costal cartilage, whilst the latter reaches upwards as high as the eighth. In between these two points the gut varies greatly in direction in different subjects. Most commonly the gut passes almost transversely from one side to the other, crossing the middle line at about the level of the second 
lumbar vertebra. It also crosses the second part of the Fig. xix., duodenum, and lies, therefore, usually above 12.

the umbilical plane. In the diagram the two flexures are dep cted, but the intervening portion of the gut has been intentionally omitted.

The descending colon passes almost vertically downwards Fig. xix., from the region of the splenic flexure to the 13.

level of the posterior part of the iliac crest, below which level it becomes known as the iliac colon. The descending colon lies wholly to the left of the left lateral vertical plane.

The operation of lumbar colotomy is now seldom Fig. xvii., performed, but it is nevertheless necessary to 13. indicate the position of the descending colon on the posterior aspect of the trunk. It corresponds in direction to a line drawn vertically upwards to the tip of the last rib, from a point situated $\frac{1}{2}$ inch behind the midpoint along the iliac crest between the anterior and posterior superior iliac spines.

The iliac and pelvic colon.-Between the termination of the descending colon at the level of the iliac crest, and the beginning of the rectum proper at the level of the third piece of the sacrum, the large gut describes so varied a course that no definite detailed account can be given of its surface marking. It may, however, be briefly described Fig. xix., as passing downwards and inwards from the 14. level of the iliac crest, parallel to Poupart's ligament, as far as the left side of the pelvic brim (the iliac colon). The gut then forms a great loop (the pelvic Fig.xix., colon), which sweeps over to the right side of 15. the pelvic brim, turning on itself to become the rectum at the level of the third sacral vertebra.

The rectum.-A line which unites the two posterior 
superior iliac spines crosses the spinous process of the Fig. xvii., second sacral vertebra. The rectum begins at 14. the level of the third sacral vertebra, and may be indicated on the surface by drawing in the gut as starting about $\frac{1}{2}$ to $\frac{3}{4}$ inch below the above-mentioned line, and extending downwards, following the curves of the sacrum and coccyx, to the anal orifice, which is placed about 2 inches below the level of the tip of the coccyx.

The dura mater enclosing the spinal cord (see "spinal cord") reaches downwards to the level of the Fig. xvii. third sacral vertebra. The spinal dura, therefore, terminates at the same level as the rectum begins, a point to be borne in mind in those operations carried out in the sacral region for the exposure of a growth involving the gut in the neighbourhood of the ilio-pelvic and rectal junction.

\section{ThE Kidney}

(Length, $4 \frac{1}{2}$ inches; breadth, $2 \frac{1}{2}$ inches; thickness,

I $\frac{1}{2}$ inches; weight, $4 \frac{1}{2}$ ounces).

(a) Anterior surface marking.- The two kidneys are Fig. xv., obliquely placed in such a manner that the 32. superior poles lie $I \frac{1}{2}$ to 2 inches, and the inferior poles $2 \frac{1}{2}$ to 3 inches, distant from the middle line. The left kidney lies at a slightly higher level than its fellow, and the hilum is placed just below and internal to the junction of the transpyloric and left lateral vertical planes; or, in other words, the hilum of the left kidney lies just internal to the anterior extremity of the ninth costal cartilage. The upper pole lies half-way between the sternoxiphoid and transpyloric planes, whilst the lower pole corresponds to the subcostal plane. The right kidney does not ascend to quite such a high level, and the inferior pole 
lies opposite the umbilical plane. The hilum of this kidney also lies just below the level of the hilum of the opposite kidney.

(b) Posterior surface marking-Morris's quadrilateral.Fig. xvii., Two vertical lines are drawn at a distance of 10. I inch and $3 \frac{1}{2}$ inches respectively from the median posterior line, and two horizontal lines are drawn outwards at the level of the spinous processes of the eleventh dorsal and third lumbar vertebræ. In the quadrilateral so marked out, the kidneys are drawn, care beirg taken to place the long axis of each kidney in the required oblique direction.

\section{The URETERS \\ (Length, Io inches).}

(a) Anterior surface marking.-The ureter passes nearly Fig. $x v$., vertically downwards from the hilum of the 33. kidney (just below and internal to the junction of the transpyloric and lateral vertical planes), and dips into the true pelvis in close relation to the bifurcation of the common iliac artery. This vessel bifurcates into internal and external iliacs at the junction of the upper and middle thirds of a line drawn from a point $\frac{1}{2}$ inch below and to the left of the umbilicus (the aortic bifurcation) to a second point situated half-way between the anterior superior iliac spine and the symphysis pubis. This apparently complicated surface marking for the ureter will be rendered more easy by a reference to the diagram. The right ureter generally dips into the pelvis just below the bifurcation of the common iliac artery.

(b) Posterior surface marking.-The course of the ureter Fig. xvii., on the posterior aspect of the trunk can be i1. represented by a line drawn vertically upwards 
from the posterior superior iliac spine to the level of the spinous process of the second lumbar vertebra.

The ovary lies in the angle between the internal and Fig.xv., external iliac arteries, immediately below the pelvic brim and anterior to the ureter.

The urachus is directed upwards from the apex of the Fig. xx., bladder, at the upper border of the pubic 16. symphysis, to the umbilicus.

\section{Abdominal Vessels.}

The abdominal aorta.-The thoracic aorta enters the Fig. xv., abdominal cavity by passing beneath the middle 24. arcuate ligament of the diaphragm at the level of the twelfth dorsal vertebra. The vessel then changes its name, and the abdominal aorta passes vertically downwards as far as the left side of the body of the fourth lumbar vertebra, at which level it bifurcates into the two common iliac arteries. The course of the vessel may be mapped out on the surface by taking a point about two fingers' breadth above the transpyloric plane and slightly to the left of the middle line, and by drawing a line vertically downwards to a second point situated $\frac{1}{2}$ inch below and to the left of the umbilicus.

The first large vessel which arises from the abdominal Fig. xv., aorta is the caliac axis. This trunk is given off 25. at the level of the twelfth dorsal vertebra, and divides, after a course of about $\frac{1}{2}$ inch, into three main trunks-the hepatic, splenic, and coronary or gastric arteries.

The superior mesenteric (level of disc between the twelfth Fig. xv., dorsal and the first lumbar vertebræ) follows 26. next, springing from the anterior aspect of the aorta immediately above the transpyloric plane. 
The renals (level of the first lumbar vertebra) pass out. Fig. $x v$., wards from the lateral aspect of the aorta 27. immediately below the level of the transpyloric plane.

The inferior mesenteric (level of the third lumbar Fig. xv., vertebra) arises from the left side of the main 28.

trunk at about the level of the subcostal plane.

The common iliac artery corresponds to the upper third Fig. $x v$., of a line drawn from a point $\frac{1}{2}$ inch below and 29. to the left of the umbilicus to a second point situated half-way between the anterior superior iliac spirie Fig. xv., and the symphysis pubis. The external iliac 31. artery corresponds in direction to the lower two-thirds of this line.

The deep epigastric artery is given off from the external Fig. xx., iliac just as that vessel passes under Poupart's 20. ligament half-way between the anterior superior iliac spine and the symphysis pubis. The epigastric artery then passes upwards and inwards along the inner side of the internal abdominal ring towards a point situated $\frac{1}{2}$ inch to I inch outside the umbilicus, entering the rectus sheath at the level of the semilunar fold of Douglas.

This vessel forms the outer boundary of Hesselbach's Fig. xx., triangle, the inner boundary of this space being 16. formed by the linea semilunaris of the same side, and the base by Poupart's ligament. Each triangle is vertically subdivided into two parts by the obliterated hypogastric artery, on either side of which herniæ may protrude.

The inferior vena cava is formed by the junction of the two common iliac veins on the right side of the body of the fifth lumbar vertebra, about $I$ inch below and $\frac{1}{2}$ inch 
FIG. $X X$.

1, I. The diaphragm.

2. The liver.

3. The gall-bladder.

4. The ligamentum teres.

5. The receptaculum chyli.

6. The thoracic duct.

7. The venous termination of the dict

8. The internal mammary artery.

9. The superior epigastric artery.

10. The musculo-phrenic artery.

II. The rectus abdominis muscle.

I2, I2. The linæ semilunares.

13, 13, 13. The lina transversie.

I4. The semilunar fold of Douglas.

I5. The urachus.

i5. Hesselbach's triangle.

17, 17. The internal abdominal ring.

I8, 18. The external abdominal ring.

19, 19. The inguinal canal.

20. The deep epigastric artery. 
THE INER, ANTERIOL ABDOMINAL WALL, ETC.

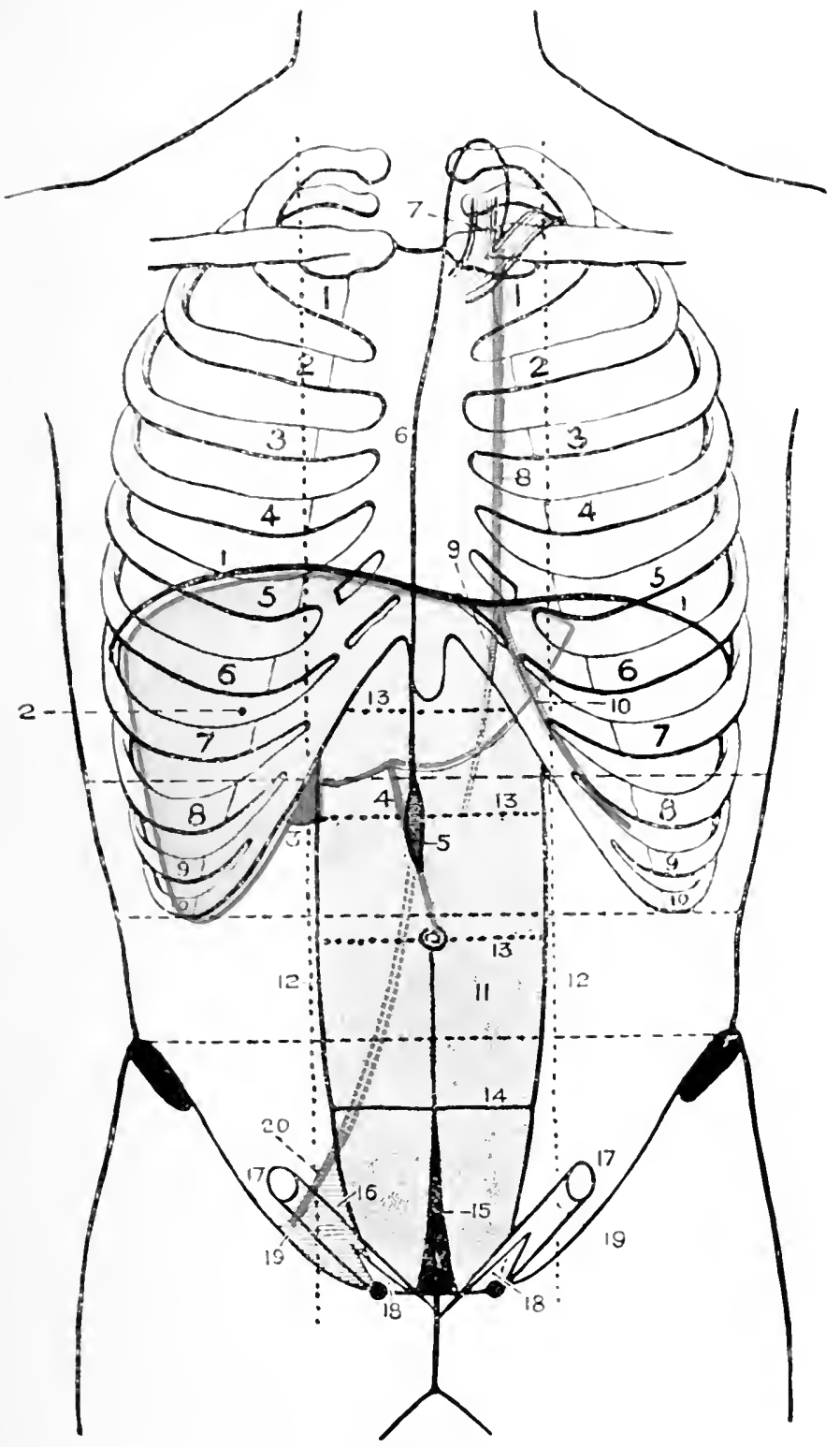

FIC. I. 

to the right of the umbilicus. The vein passes upwards Fig. $\mathbf{x v}$., to pierce the quadrate opening of the diaphragm 23. at the level of the eighth dorsal vertebra, entering the right auricle of the heart opposite the fifth right interspace and the adjoining part of the sternum.

\section{Tile Liver.}

The anterior border can be mapped out by drawing a Fig. $\times x ., 2$. curved line from a point in the fifth left position of the apex of the heart), the line cutting the left costal margin at the tip of the eighth costal cartilage and the right costal margin at the tip of the ninth costal cartilage. Between these two latter points, the anterior border of the liver crosses the middle line half-way between the umbilicus and the sterno-xiphoid junction (=transpyloric plane), whilst a notch to the right of the middle Fig. $\times x ., 4$. igamentum teres, which passes from that notck line indicates the hepatic attachment of the downwards and inwards to the umbilicus.

Beyond the tip of the ninth right costal cartilage the anterior border of the liver follcws the lower limit of the costal arch, descending sometimes even below that level, Fig. xvii., and after cutting across the twelfth rib, ascends 12. towards the level of the eleventh dorsal spine.

The upper limit of the liver is indicated by a line starting Fig. $x \times$. as before in the fifth left interspace $3 \frac{1}{2}$ inches from the middle line, and ascending slightly as it passes to the right. This line cuts across the sixth Fig. xvii., right chondro-sternal articulation, the upper 12. border of the right fifth costal cartilage in the right lateral vertical plane, the sixth rib in the mid-axillary 
line, sweeping thence just below the angle of the scapula towards the eighth dorsal spine.

The gall-bladder.-The fundus projects from under the Fig. xx., 3. the tips of the ninth and tenth costal cartilages and the outer border of the rectus abdominis muscle.

The diaphragm.-On ordinary inspiration the right dome of the diaphragm corresponds in level to the Fig. xx., 1. lower part of the fourth right interspace, whilst the left dome ascends to the lower part of the fifth left rib and costal cartilage.

\section{The Common Bile-duct, etc.}

The gastro-hepatic omentum, passing upwards from the Fig. xix., lesser curvature of the stomach to the trans16. verse fissure of the liver, presents a free edge, which looks downwards and to the right, and which forms the anterior boundary of the foramen of Winslow, the Fig. xix., channel of communication between the greater

17. and the lesser peritoneal sacs. The free edge of this omentum further contains (between its two layers of peritoneum) three important structures :

r. The common bile-duct to the right.

2. The hepatic artery to the left.

3. The portal vein behind and between the two former structures.

In mapping out any of these structures, it is, therefore, advisable to first draw in the lesser curvature of the stomach, the pylorus, the three parts of the duodenum, and the pancreas. The pylorus occupies such a definite position in the transpyloric plane that all these structures are easily and quickly drawn in. The free margin of the lesser omentum should be represented as a curved line 
passing upwards and to the right for $1 \frac{1}{2}$ to 2 inches from the duodeno-pyloric junction. The portal vein is formed behind the head of the pancreas by the union of the superior mesenteric and splenic veins, and passes upwards to the transverse fissure of the liver behind the first part of the duodenum, and in the free edge of the lesser omentum.

The lepatic artery, a branch of the cœliac axis, passes upwards from the upper border of the first part of the duodenum, in the free edge of the lesser omentum, to the transverse fissure of the liver.

The common bile-duct is 3 inches long, and is formed Fig. xix., by the union of the hepatic and cy'stic ducts.

18. It passes downwards in the free edge of the gastro-hepatic omentum, behind the first part of the duodenum, behind the head of the pancreas, and opens on the inner and posterior aspect of the second or descending part of the duodenum.

\section{The Spleen.}

The long axis of the spleen corresponds to the tenth Fig. xvii., rib, and the viscus extends upwards to the

9 . upper border of the ninth rib, and downwards to the lower border of the eleventh rib. The upper and inner pole lies $I_{2} \frac{1}{2}$ to 2 inches away from the tenth dorsal spine, whilst the lower or anterior pole reaches as far forwards as the mid-axillary line.

\section{The Spinal Cord.}

The spinal cord extends from the foramen magnum to Fig. vii., 5. the lower border of the first lumbar vertebra Fig. xvii, (transpyloric plane). The cord follows the 2. curves of the vertebral column, and presents 
also two enlargements, the intumescentia cervicalis and lumbalis. The former swelling lies between the third cervical and second dorsal vertebræ, the latter between the ninth and twelfth dorsal vertebræ. Near its termination the cord tapers away as the conus medullaris.

The filum terminale, the prolongation of the cord, is

Fig. vii,, 7. Fig. xvii.,

3.

continued onwards from the lower part of the body of the first lumbar vertebra to near the tip of the coccyx, at which level it blends with the periosteum lining that bone.

The theca vertebralis, or dural sheath, extends as low Fig. vii, 6. as the third sacral vertebra, at which level it is Fig. xvii., 1,1 . pierced by the filum terminale.

A line unitıng the two posterior superior iliac spines Fig. vii., 10. cuts across the second sacral spine, and the Fig. xvii., dural sac, therefore, terminates about $\frac{1}{2}$ inch 15.

below the level of this interspinous line. At the third month of intra-uterine life the cord extends the whole length of the vertebral canal, whilst at birth it reaches as low down as the third lumbar vertebra.

A reference to Fig 7 will show that cerebro-spinal fluid might be withdrawn from the thecal canal anywhere between the termination of the cord at the level of the transpyloric plane and the base of the sacrum. A line drawn across the back, at right angles to the long axis of the body, at the level of the highest part of the iliac crests, cuts across the median posterior line at the level of the interspace between the laminæ of the second and third or third and fourth vertebræ. It is at this point, or rather to one side of this point, that lumbar puncture is carried out. 


\section{THE PERINEUM.}

A brief account only will be given, as, though the landmarks are most important, the tendency is great to drift into the question of surgical applied anatomy, a pitfall which the writer is most anxious to avoid.

The perineum is, in shape, roughly quadrilateral, the lateral boundaries being formed in front by the diverging rami of the pubis and ischium, and behind by the ischial tuberosity and the gluteus maximus muscle. The anterior and posterior angles of the space are formed respectively by the symphysis pubis and the tip of the coccyx. The subpubic angle is obtuse in the female and acute in the male. In the female, also, the ischial tuberosities are further apart and slightly everted. The perineum is divided into two areas by a line drawn between the anterior part of the ischial tuberosities, thus forming-

(a) The genital area.

(b) The rectal area.

This transverse line passes about I inch in front of the anus, and represents the level of the two transverse perinei muscles, the posterior border of the triangular ligament, and the line along which Colles's fascia is reflected round the posterior border of the two transverse perinei muscles to become continuous with the posterior border of the triangular ligament. The "central tendinous point of the perineum" corresponds to the middle of this line, and forms the point of attachment of several muscles.

(a) The genital area.- In the male, this area is divided into two lateral triangles by the median antero-posterior prominence of the bulb of the penis (corpus spongiosum). The two crura of the penis (corpora cavernosa) diverge as 
they pass backwards towards the tuberosity of the ischium, and the main pudic vessels lie under cover of these erectile organs. The triangle is completed behind by the transversus perinei muscle. All the above-mentioned erectile structures and muscles lie superficial to the triangular ligament.

In the female, this area is practically cut into two lateral triangles by the orifice of the vagina, each side of which lies the bulb of the vestibule, an organ of erectile tissue, corresponding developmentally to the male corpus spongiosum. More superficially, the two labia majora converge towards the mons veneris in front, whilst, on the mesial aspect of the labia majora, the labia minora converge towards the clitoris, between which body and the vaginal margin a smooth triangular space exists, the vestibule. At the junction of the vagina and the vestibule the urethra opens.

Vaginal examination.-Passing along the posterior vaginal wall the finger enters the superior fornix, the upper part of which is in direct relation with the peritoneal cavity (Douglas's pouch). Along the anterior wall the smaller anterior fornix is first encountered, this cul-de-sac not being directly related to the peritoneal cavity, and immediately above this the os uteri may be examined. Bimanually, much information can usually be gained with regard to the size and position of the uterus, the condition of the uterine appendages, the contents of Douglas's pouch, etc.

(b) The rectal area.-This arca is divided into two lateral parts by a line drawn from the "central point of the perineum " to the tip of the coccyx, and the examining fingers may, in thin subjects, be made to sink deeply into each lateral recess (the ischio-rectal fossæ), being 
then in relation with the rectum and levator ani muscle on the inner side, the ischial tuberosity and the obturator internus muscle on the outer side, the transverse perinei muscle in front, and the gluteus maximus and great sacrosciatic ligament behind.

Rectal examination.-If the forefinger be gently inserted into the rectum, definite resistance is offered by the external and internal sphincters, the latter aided by contraction of the levator ani muscle Further on the finger enters the dilated ampullary portion of the rectum, meeting, perhaps, further obstruction from Houston's valves. When insinuated as far as possible, the palmar aspect of the distal phalanx will, in the male, be in contact with the vasa deferentia and the vesiculæ seminales, the middle phalanx with the prostate gland, and the proximal phalanx with the sphincters, which intervene between the finger and the triangular ligament and the spongy and membranous parts of the urethra. Posteriorly, the hollow of the sacrum and the coccyx can be fully explored. It is most important to bear in mind that the peritoneum is reflected from the rectum on to the upper third of the vagina in the female, and on to the vesicule seminales, about I inch above the upper limit of the prostate gland, in the male.

In children, since the true pelvis is but little developed and the later pelvic viscera are practically abdominal, a rectal examination enables one to explore all the lower abdominal viscera, including the bladder. 


\section{CHAPTER V}

\section{THE LOWER EXTREMITY}

THE pubic spine, the iliac crest, the anterior and pas. terior superior iliac spines, and the iliac tubercles have all been previously alluded to and located. It has also been stated that a line uniting the two posterior superior iliac spines cuts across the spine of the second sacral vertebra. Below this line the remaining sacral spines and the coccyx Fig. xxi., are easily felt, though the coccyx itself is more 4,5 readily verified by inserting the forefinger into the rectum whilst the thumb is placed over the bone externally.

The region of the hip.-(a) Posterior and external aspect. The great trochanter of the femur and the ischial tuberosity must now be examined. The latter process Fig. xxi., 7. lies under cover of the lower part of the gluteus
maximus muscle, whilst the trochanter is subcutaneous in its lower part, and covered over in front and above by the insertion of the gluteus medius muscle.

The trochanter is more or less quadrilateral in shape, Fig. xxi., 9. fading off into the shaft of the femur below, Fig. xxiii., 6 . and presenting a well-marked posterior border; the highest point of the trochanter corresponds to the posterior superior angle of the quadrilateral. When the body is in the erect position, there is a well-marked depression situated above and behind the great trochanter, 
FIG. XXI.

I. The iliac crest.

2. The posterior superior iliac spine.

3. The sacrum.

4. The second sacral spine.

5. The coccyx.

6. The pyriformis muscle.

7. The ischial tuberosity.

S. The sciatic artery and the ischial spine.

9. The great trochanter of the fenur.

I0, The gluteal artery.

II. Nélaton's line.

12. The great sciatic nerve.

13. The internal popliteal nerve.

I4. The external popliteal nerve.

I5. The biceps tendon.

16. Thie seminembranosus muscle.

17. The semitendinosus muscie.

18. The outer head of the gastrocnemius muscle

19. The inner head of the gastrocnemius muscle.

20. The posterior tibial artery and nerve.

2I. The external saphenous vein. 
THE B.CK OF THE THIGH AND IEC

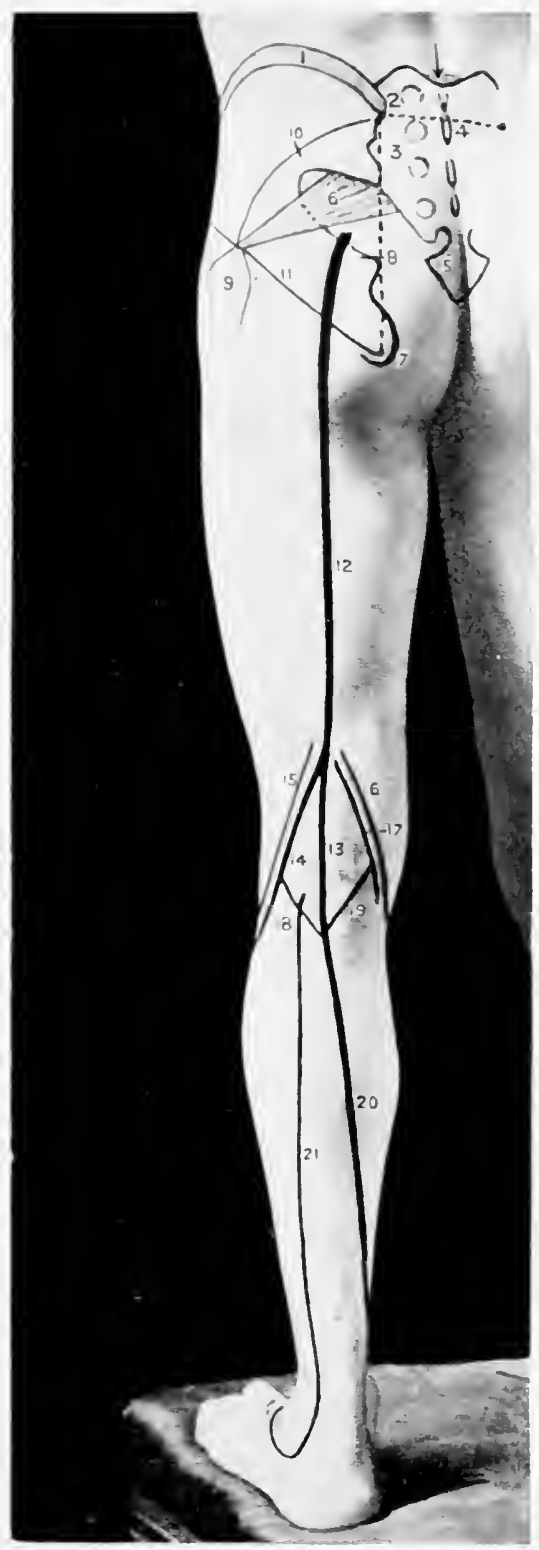

FIG. XXI. 




\section{FIG. XXIL.}

I. The iliac crest.

2. The pubic spine.

3. Poupart's ligament.

4. The anterior crural nerve.

5. The common femoral arterv.

6. The common femoral vein.

7. The crural canal.

8. The superficial femoral artery.

9. Vastus externus.

ro. Vastus internus.

II. The upper limit of the synovial membrane of the knee-joint.

I2. The patella.

13. The ligamentum patellæ.

I4. The tubercle of the tibia.

15. The internal tuberosity of the tibia.

16. The external tuberosity of the tibia.

17. The head of the fibula.

I8. The internal saphenous vein.

19. 'The anterior tibial artery.

20. The anterior tibial nerve.

21. The musculo-cutaneous ner:3.

22. The dorsalis pedis artery.

23. The dorsal venous arch. 
THE FRONT OF THE THIGH IND LEG

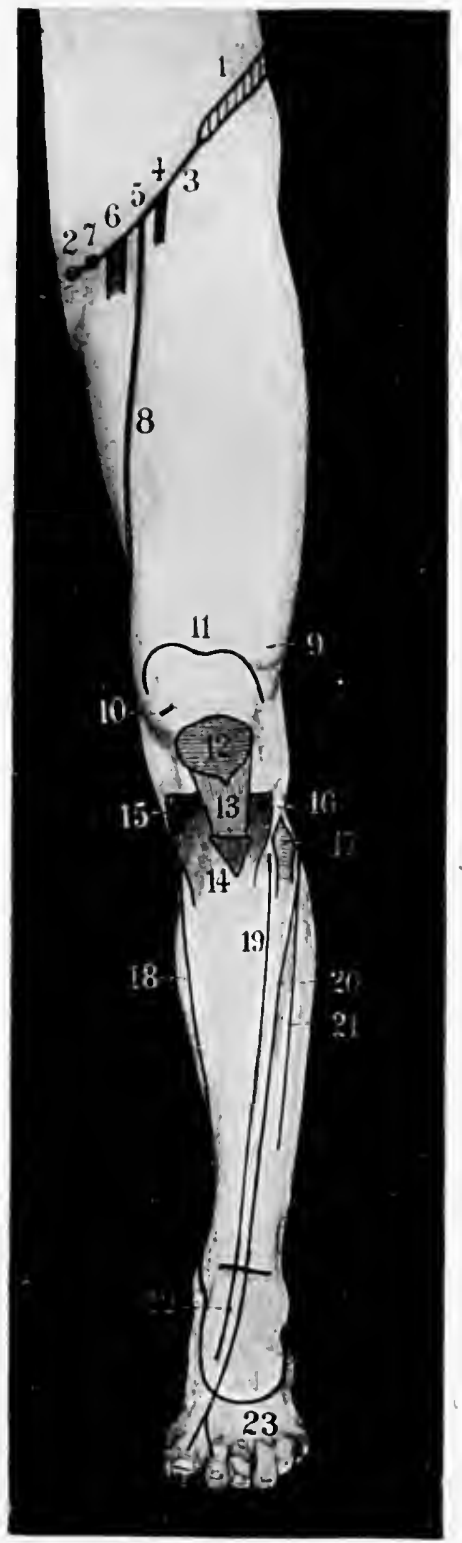

FIG. XXII. 

which becomes less marked when, as the result of discase or disuse, the gluteus maximus undergoes atrophic changes. The fold of the nates does not correspond to Fig. $x x i$. the lower border of the gluteus maximus muscle, as it crosses almost transversely the lower oblique fibres of that muscle. This fold also becomes less distinct when the glutei muscles degenerate. The head and neck of the femur form with the shaft of that bone an angle of 125 to I 30 degrees.

Nélaton's line.- "If in the normal state you examine Fig. $x x i$, 11. the relation of the great trochanter to the other Fig. $\times$. that the top of the great trochanter corresponds to a line drawn from the anterior superior iliac spine of the ilium to the most prominent point of the tuberosity of the ischium. This line also runs through the centre of the acetabulum. The extent of displacement in dislocation or in fracture is marked by the projection of the trochanter behind and above this line" (Nélaton).

Bryant's triangle. - When the patient is in the dorsal Fig. xxiii., recumbent position, draw a line round the 4. body at the level of the anterior superior iliac spine, and from this line drop a perpendicular to the top of the great trochanter. To complete the triangle, draw a line from the anterior superior iliac spine to the top of the trochanter. When the trochanter is displaced upwards the perpendicular line is diminished in length as compared with the sound side, and when it undergoes a backward displacement the spino-trochanteric line is relatively increased in length.

(b).--Anterior and internal aspect. The lower extremity is demarcated from the abdomen by a well-marked furrow, the inguinal groove. This corresponds to the situation 
of Poupart's ligament, the recurved lower border of the obliquus externus abdominis muscle. This ligament, as it passes from the anterior superior iliac spine to the pubic spine of the same side, forms the upper boundary of Scarpa's triangle, a space which is best demonstrated Fig. $x \times v$, when the thigh is flexed, abducted, and everted. 3,4 . The sartorius muscle is then thrown into action and the outer boundary of the space so shown. If the hand be now placed on the upper and inner aspect of the thigh and the limb be sharply adducted, a rounded tendon at once becomes noticeable. This is the adductor longus, which forms the inner boundary of Scarpa's triangle.

The outwardly directed adductor longus and the inwardly curving sartorius converge to form the apex of the triangle.

The floor of the space is formed from without inwards by the iliacus, psoas, pectineus and adductor longus muscles. In the superficial fascia which overlies this region, numerous lymphatic glands are situated, and it will here be convenient to briefly discuss their gencral arrangement. The superficial lymphatic glands are placed in three main groups:

(I) The oblique or inguinal glands, running parallel to and below Poupart's ligament, and draining the anterior aspect of the abdomen below the level of the umbilicus, the lower half of the side and back, the gluteal region, and the upper and outer part of the thigh.

(2) The vertical or femoral glands, running with the long internal saphenous vein, and draining the greater part of the inner aspect of the foot, leg, and thigh.

(3) The pubic glands, situated below and external to the pubic spine, and draining mainly the external genitals, perineum, and anus. 
The deep fascia presents an opening, the saphenous Fig. xxii., 8. "pening, for the transmission of the long Fig. xxiv., 9. saphenous vein to the common femoral vein. This foramen is oval in shape, being $I$ inch long and $\frac{1}{2}$ to 3 inch broad, the long axis vertical. The central point of the opening is situated $\mathrm{I}_{2}^{\frac{1}{2}}$ inches below and $\mathrm{I}_{2} \frac{1}{2}$ inches external to the pubic spine.

Beneath the deep fascia overlying Scarpa's triangle, certain important structures are situated, such as the common, superficial femoral, and profunda femoris arteries, the corresponding veins, and the anterior crural nerve. These will all be dealt with later, the femoral ring alone needing here further definition.

The femoral ring, through which a femoral hernia Fig. xxii., 7. commonly escapes from the abdominal cavity, Fig. xxiv., 8. lies below the inner part of Poupart's ligament, and external to the pubic spine. A good way to define the ring with precision is that recommended by Holden: "Feel for the pulsation of the common femoral artery, allow $\frac{1}{2}$ inch on the inner side for the femoral vein, then comes the femoral ring." The crural or femoral ring presents the following boundaries: To the inner side is Gimbernat's ligament; to the outer side is the femoral vein; in front is Poupart's ligament; behind is the pectineus muscle and the horizontal ramus of the os pubis.

Hunter's canal, a more or less triangular muscular Fig. xxiv., channel for the transmission of the superficial 12. femoral artery, occupies the middle third of the antero-internal aspect of the thigh. During forcible contraction of the thigh muscles, Scarpa's triangle may be seen to be continued downwards as a shallow depression between the extensor and adductor muscles, this furrow 
corresponding to the position of the canal in question. The anatomical boundaries of the canal are (I) vastus internus externally, (2) adductor longus and magnus behind, (3) sartorius and a strong fascial band hetween the adductors and vastus internus in front and internal.

The canal transmits the superficial femoral vein and artery, the long internus saphenous nerve (anterior crural), and the nerve to the vastus internus (anterior crural).

In order to compare the length of the lower extremities the limbs should be placed parallel to one another, and the tape-measure carried from the anterior superior iliac spine to the tip of the internal malleolus of the tibia of Fig. xxiv., the same side. The distance between these 16. two points may be subdivided, if necessary, by marking out, on the inner aspect of the knee, the transFig. xxiv., verse line which indicates the level of the 17. femoro-tibial articulation. The lengths of the femur and of the tibia are thus separately estimated.

The region of the knee.-The biceps tendon forms the Fig. xxi., 15. upper and outer boundary of the popliteal space, and under cover of this tendon, on its inner or popliteal aspect, a cord-like structure is felt, the external popliteal or peroneal nerve. This intimate relation of tendon and of nerve must be remembered in Fig. $x$ xi., 14. the operation of tenotomy of the biceps tendon Fig. xxiii., 11. If the biceps tendon be now traced downwards the head of the fibula is reached, this process lying below, external, and on a posterior plane to the outer tuberosity Fig.xxiii., 8 of the tibia. The styloid process of the head Fig.xxiii., $\boldsymbol{9}$. of the fibula projects upwards from the posterior part of the head, and in front of this the rounded long external lateral ligament of the knee-joint can be traced upwards to its femoral attachment. In front of 

FIG. XXIII.

3. The iliac crest.

2. The anterior superior iliac spine.

3. Poupart's ligament.

4. Bryant's triangle.

5. Nélaton's line.

6. The great trochanter.

7. The ilio-tibial band.

8. The outer tibial tuberosity.

9. The head of the fibula.

10. The biceps tendon.

II. The peroneal nerve.

12, 12. The anterior tibial nerve.

13. The musculo-cutaneous nerve.

I4, I4. The anterior tibial artery.

15. The dorsalis pedis artery.

16. 'The external saphenous veit.

I7. The venous arch. 
THE SIDE OF THE THIGH ANI) LEG

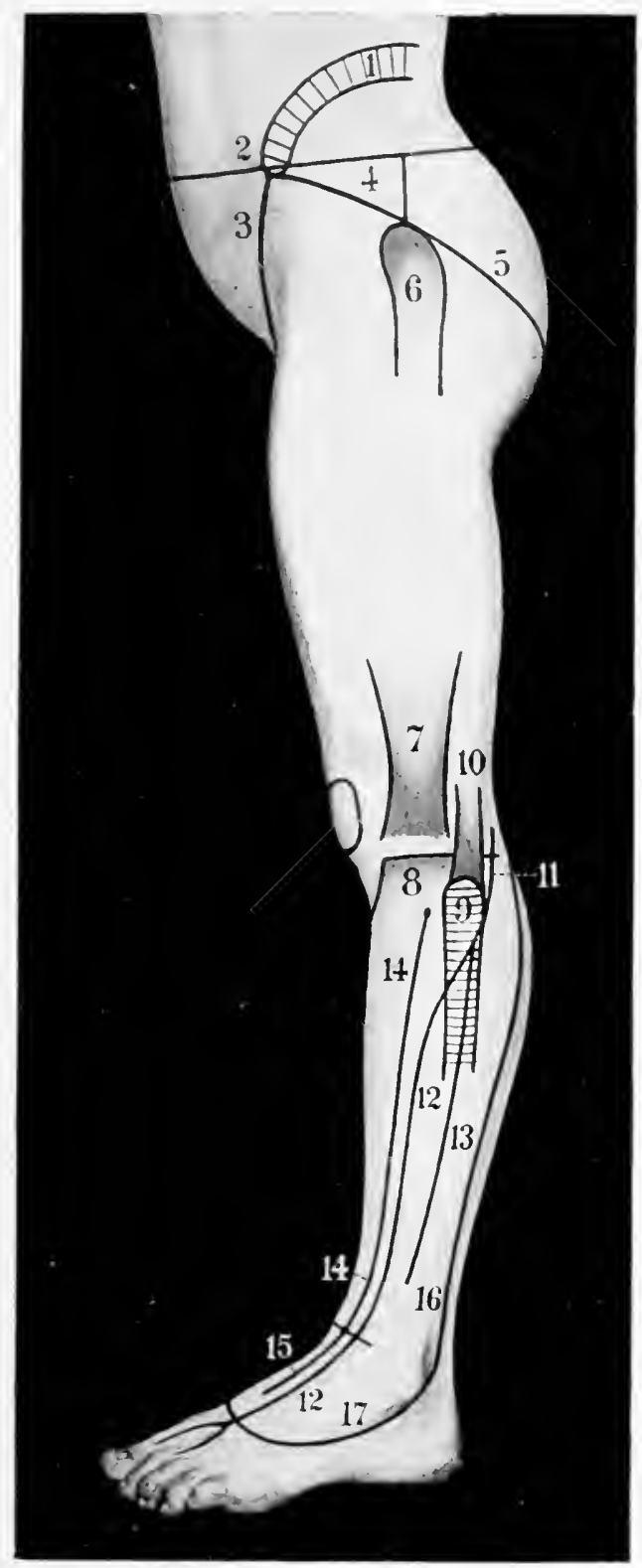

FIG. XXIII. 


HIG. XXIV.

1. The anterior superior iliac spine

2. The pubic spines.

3. The sartorius muscle.

4. The adductor longis muscle.

5. The anterior crural nerve.

6. The comiuion femoral artery.

7. The common femoral vein.

8. The iemoral ring.

9. The saphenous opening.

Io, Io, Is. The internal or long saphenous vein.

I1. The profunda femoris artery.

12. The superficial femoral iu Scarpa's triangle.

13. The superficial femoral in Hunter's canal.

14. The adductor magnus tendon.

15. The adductor tubercle.

16. The lower epiphysial line of the femur.

17. The line of the knee-joint.

I8. The gracilis, sartorius, and semitendinosus muscles.

19. The internal saphenous nerve.

20. The posterior tibial artery.

2I. The internal plantar artery.

22. The external plantar artery.

23. The anterior tibial nerve. 
THE SILE () THE THLGI ANH) LEC

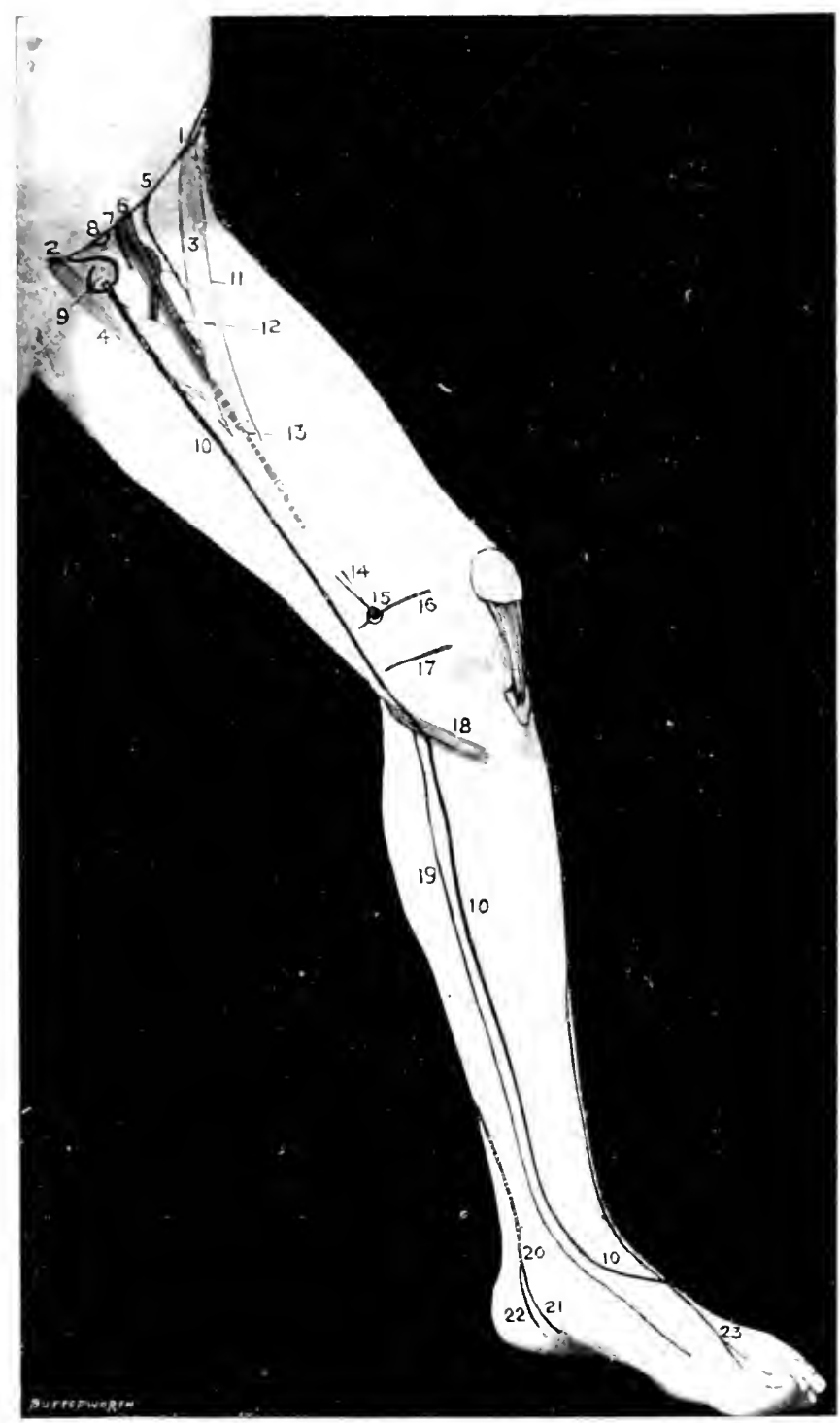

FIG XXIV. 

the biceps tendon there is a depression which is bounded Fig xxiii, 7. anteriorly by the broad ilio-tibial band. Two well-marked tendons bound the popliteal space on the upper and inner side, the semimembranosus and semitendinosus. The latter is the more external, the Fig. xxi., more superficial, and the narrower, and the 16, 17. long rounded tendon can be traced some distance up into the thigh. The semimembranosus tendon lies to the inner side of the semitendinosus and on a deeper plane. The broad tendon can be traced downwards to its insertion into the inner and posterior aspect of the internal tuberosity of the tibia. On the inner aspect of the knee the tendon of the gracilis muscle and the lower part of the sartorius muscle form a fairly well-marked prominence, the individual muscles being, however, usually incapable of clear definition owing to their flattened shape. Between these tendons and the prominent vastus internus muscle a depression exists, and Fig. xxiv., by deep palpation the adductor magnus tendon 14. may be felt lying under cover of the inner margin of the vastus internus muscle. By tracing this Fig. xxiv., tendon downwards to its insertion the adductor 15. tubercle is reached. This tubercle corresponds 16. also to the level of the lower epiphysial line of the femur.

The sartorius and gracilis muscles, though not easily defined on the inner side of the knee, form, together with Fig. xxiv., the semitendinosus muscle, a fairly well-marked 18. elevation below the internal tuberosity of the tibia, which is directed downwards, forwards, and outwards.

The ligamentum patellæ narrows off as it passes from Fig. xxii, the inferior border of the patella to the tibial 13. tuberosity, and on each side of the ligament 
depressions exist, in the lower part of which the inner and outer tuberosities of the tibia are readily felt.

The prepatellar bursa extends from the middle of the patella to the tibial tubercle. Laterally, the bursa falls just short of the patellar border.

The synovial membrane of the knee-joint extends upwards Fig. xxii., about three fingers' breadth above the upper

11. border of the patella when the leg is in the extended position, reaching up under the vastus internus to a slightly higher level than on the other side. Laterally, the synovial membrane extends to near the inner and outer margins of the femoral condyles, whilst the lower limit is situated just above the tubercle of the tibia. When the joint is distended with fluid the outline of the joint cavity becomes marked, and the depressions which normally exist each side of the patellar ligament become obliterated.

The ankle and foot.-The external malleolus projects Fig. xxvii., about $\frac{1}{2}$ inch below the internal, and also lies 1,2. on a more posterior plane. The ankle-joint corresponds in level to a point about $\frac{1}{2}$ inch above the tip of the internal malleolus.

About $\mathrm{I}$ inch below and $\frac{1}{2}$ inch in front of the styloid process of the external malleolus is the peroneal tubercle, Fig. $x x v$., which separates the peroneus brevis above from 20. the longus below. The two peronei tendons, when traced upwards, are found to pass behind the external malleolus. About $I$ inch in front of the peroneal iubercle is the prominent styloid process of the base of Fig. $x \times v$., the fifth metatarsal bone, to which the pero17. neus brevis is attached. Between the peroneal tubercle and the base of the fifth metatarsal bone the cuboid bune may be felt, grooved on its outer and under 

FIG. XXV.

\section{INTERNAL, ASPECT OF FOOT AND ANKI,}

I. The tibialis anticus.

2. The internal malleolus.

3. The tibialis posticns.

4. The tubercle of the scaploid.

5. The flexor longus digitorum.

6. The sustentaculum tali of the os calcis.

7. The flexor longus hallucis.

8. The tendo Achillis.

9. The head of the astragalus.

Io. The joint between the scaphoid and the internal cuneiform.

II. The joint between the first metatarsal bone and the internal cuneiform.

12. The metatarso-phalangeal joint.

Eixternal Aspect of Foot and ANKLE.

13. The external malleolus.

I4. The head of the astragalus.

15. The head of the os calcis.

16. The peroneus tertius.

17. The base of the fifth metatarsal bone.

I8. The peroneus brevis.

I9. The peroneus lougus.

2o. The peroneal tubercle of the os calcis.

2I. The tendo Achillis.

22. The extensor longus digitorum. 


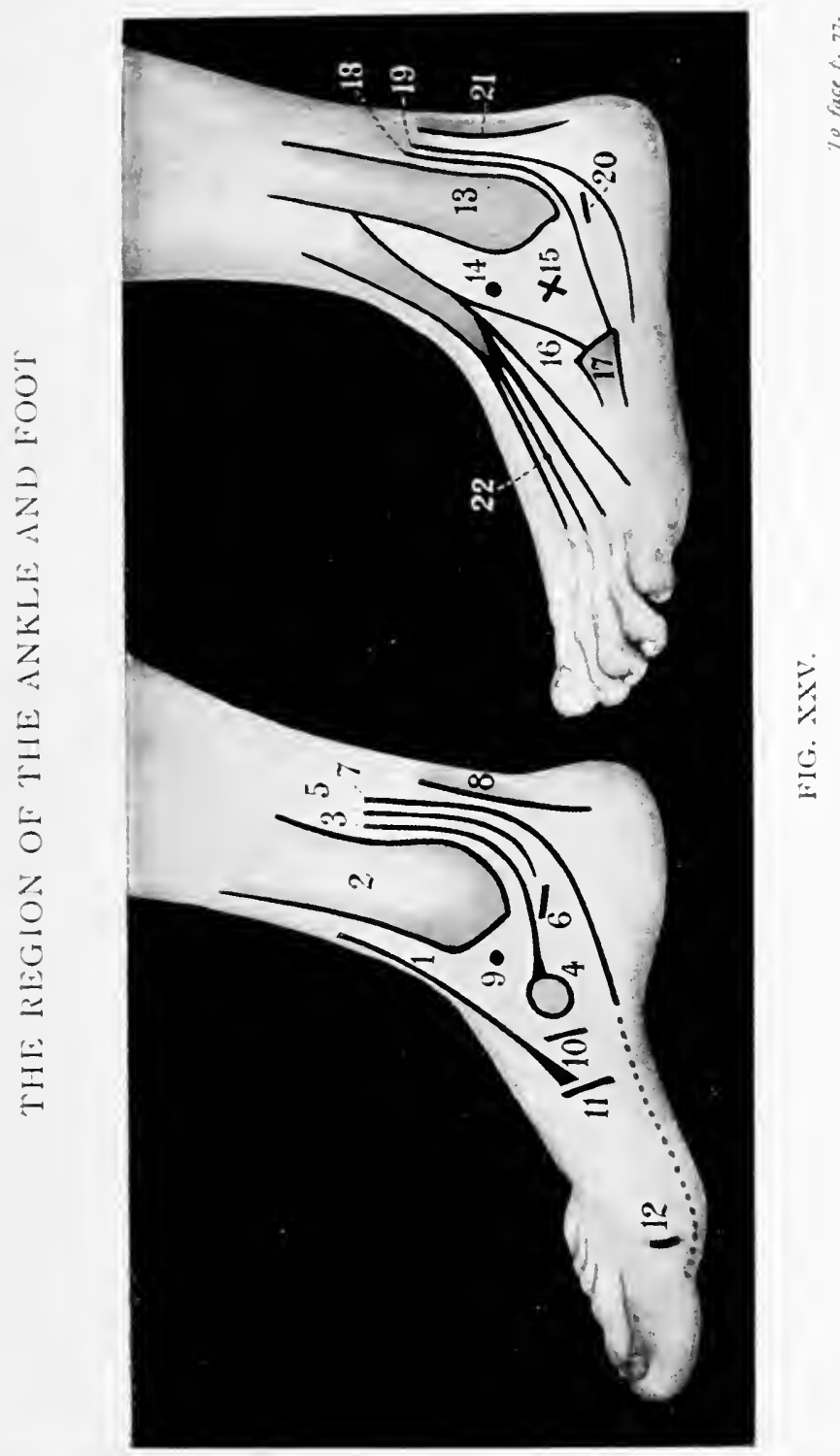



aspect by the peroneus longus tendon. The tendon crosses the plantar aspect of the foot in a forward and inward direction, to be inserted into the outer aspect of the base of the first metatarsal bone. Immediately in front of the external malleolus there is a well-marked Fig. xxv. depression, which is bounded in front by a prominence due to the fleshy mass of the extensor brevis digitorum, and above by the tendon of the peroneus tertius.

Fig. $x \times v ., 14$ If the floor of this depression be examined, the head of the astragalus will be felt above and to the inner side, and the head of the os calcis Fig. xxv., 15. below and to the outer side.

Between the two malleoli in front of the ankle-joint four tendons can be felt. The most prominent and the innermost is the tendon of the tibialis anticus Fig. $x \times v ., 1$. muscle. External to this follow the extensor longus hallucis, the extensor longus digitorum Fig. $x \times v$. and the peroneus tertius. When the foot is well extended, the head of the astragalus can also be identified lying under cover of the extensor tendons.

Immediately below the internal malleolus is the sustenFig. $\times \times v$., 6. taculum tali, grooved on its under aspect by the Fig. xxv., 7. flexor longus hallucis tendon, and between the Fig. $x \times v$., sustentaculum and the internal malleolus the 3, 6. tibialis posticus and flexor longus digitorum pass.

The tibialis posticus tendon can be traced upwards behind the internal malleolus and downwards Fig. $x \times v ., 3$. to the scaphoid tuberosity, to which process the tendon gains its main attachment. In Fig. axv., 4. front of the internal malleolus there is another depression, which lies below the line of the tibialis 
anticus tendon, and here the head of the astragalus can again be felt, especially prominent when the Fig. $x \times v$., 1. foot is well everted. About $\mathbf{I}$ inch below Fig. xxv., 9. and in front of the internal malleolus the Fig. xxv., 4. tuberosity of the scaphoid bone forms the most prominent bony point on the inner side of the foot, and a line which joins the tip of the internal malleolus, the head of the astragalus, and the scaphoid tubercle, normally presents a slight upward convexity.

In flat-foot, the head of the astragalus undergoes a downward displacement, and the line uniting the three bony points becomes straight, or even downwardly convex.

A line drawn almost transversely across the foot from a point just behind the scaphoid tubercle indicates the level of the mid-tarsal joint.

Fig. $x \times v$., $10,11$.

Fig. $x \times v$, $11,12$.

In front of the scaphoid tuberosity, the internal cuneiform and the first metatarsal bones may be located and verified.

Behind the ankle-joint, the tendo Achillis is placed, Fig. xxv., the tendon being at its narrowest at a point 8, 21. about $I_{\frac{1}{2}}$ inches above its insertion into the posterior part of the os calcis. When distended with fluid, the synovial membrane of the ankle-joint bulges outwards, so as to obliterate the depressions that normally lie between the tendo Achillis and the two malleoli.

The anterior anmular ligament of the ankle.-The upper portion of this ligament, about $I$ inch broad, Fig. xxvi., 3. extends transversely across the ankle from tibia to fibula. It presents two compartments only, one for the tibialis anticus, and one for Fig. xxvi., 6. the remaining extensor tendons. The former tendon alone possesses a synovial sheath. 
THE REGION OF THE ANKLE AND FOOT

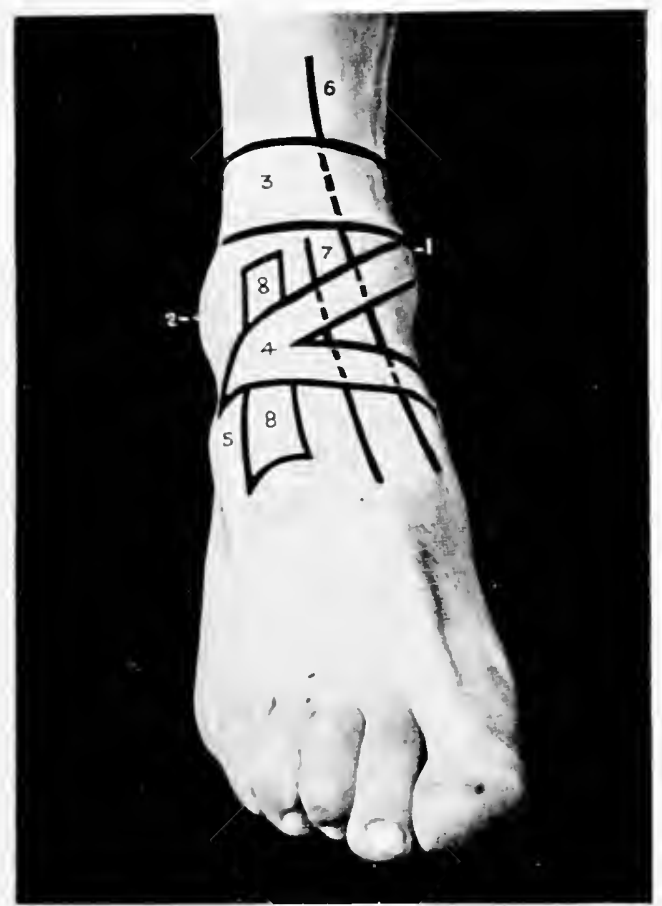

FIG. XXI.

1. The internal malleolus.

2. Tlie external malleolus.

3. The iransverse band of tlie anterior annular liganuent.

4. 'The $Y$-shaped hand of the anterior annular ligantent.

5. The heal of the os calcis and the extensor brevis digitorum.

6. The tibialis anticus synovial slieath.

7. The extensor longus liallucis synovial sheath.

S. The extensor longus digitorum and peroneus tertius synovial sheatl. 

<smiles>C1CCC1</smiles> 


\section{THE REGION OF THE ANKLE AND FOOT}

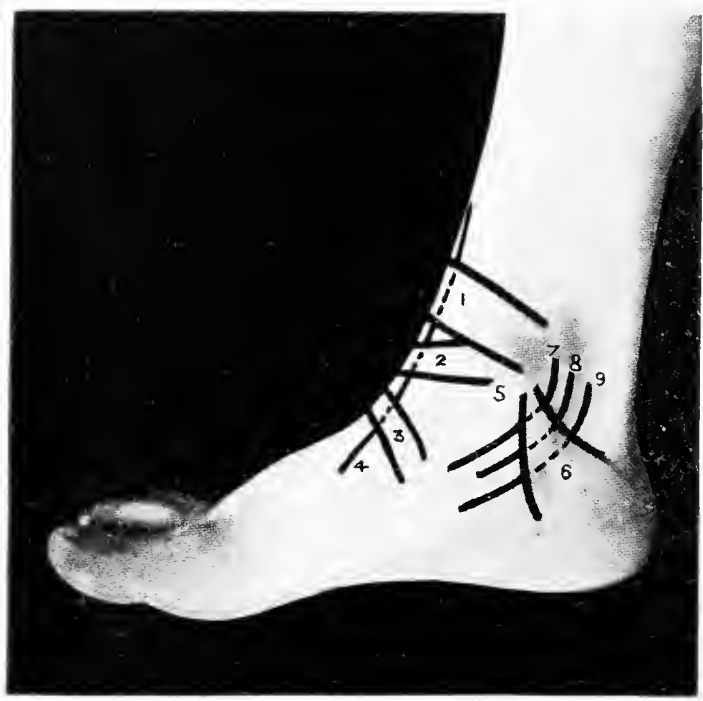

FIG. XXVII.

1. The transverse band.

2, 3. The upper and lower limbs of the $Y$-shaped part of the anterior annular ligament.

4. The tibialis anticus synovial sheath.

5. The internal malleolus.

6. The internal annular ligament.

7. The tibialis posticus synovial sheath.

S. The flexus longus digitorum synovial sheath.

9. The flexor longus hallucis synovial sheath. 
The lower portion of the ligament is $\mathrm{Y}$-shaped, the Fig. xxvi., 4. single limb arising from the upper and outer Fig. xxvi., 5. aspect of the head of the os calcis in close connection with the origin of the extensor brevis digitorum muscle. The upper limb of the divided portion becomes attached to the internal malleolus, whilst the lower limb sweeps over to the scaphoid tuberosity and to the inner side of the foot. The extensor communis digitorum and Fig. xxvi., the peroneus tertius pass under the single 8. 8. undivided limb, and possess in this situation a common synovial sheath; whilst the extensor longus Fig. xxvi., hallucis and the tibialis anticus pass through 6, 7. separate compartments in each limb of the divided portion of the ligament, and each tendon in so doing is surrounded by a synovial sheath, that enveloping the tibialis anticus tendon being continuous with the sheath already alluded to as enclosing the tendon under the transverse portion of the ligament.

The internal annular ligament is triangular in shape, the Fig. xxvii., apex being attached to the internal malleolus, 6. and the base to the lower margin of the os calcis. From the deep aspect of the ligament septa are given off which form separate compartments for the Fig. xxvii., passage of the tendons of the tibialis posticus, $\cdot 7,8,9$. flexor longus digitorum, and flexor longus hallucis muscles, each tendon having its own synovial sheath. These three sheaths extend for about I inch above the upper limit of the annular ligament; and although the sheath enveloping the tibialis posticus reaches almost as far forwards as the scaphoid tuberosity, the other two sheaths usually terminate about $\frac{1}{2}$ inch Fig. xxix., below the inferior margin of the ligament. $\mathbf{3}, \mathbf{3}, \mathbf{3}, \mathbf{3}$. The flexor longus hallucis and flexor longus 
digitorum have, again, distinct synovial sheaths just before their insertion into the distal phalanges of the toes, these sheaths, however, being very variable, and rarely extending further backwards than the heads of the metatarsal bones.

The external anmular ligament is less definite in shape, and can only be described as a broad band passing from the external malleolus to the lower margin of the os calcis. Fig. xxviii., Beneath it two tendons pass, the peroneus 4, 6, 6. longus and brevis. These two tendons possess a common synovial sheath, which extends upwards 2 to 3 inches above the tip of the external malleolus, and downwards as far as the "peroneal tubercle," where the sac divides into two, one part accompanying the peroneus brevis to near the base of the fifth metatarsal bone, the other extending forwards to the outer and under aspect of the cuboid bone. The peroneus longus is also usually enclosed in a synovial sheath in the last inch or so of its course, previous to its insertion into the outer aspect of the base of the first metatarsal bone.

\section{The Vessels and Nerves of The Lower Extremity.}

The gluteal artery emerges from the great sacro-sciatic notch, above the pyriformis muscle, at the
Fig. $x$ i., 10. junction of the inner and middle thirds of a line drawn from the posterior superior iliac spine to the top of the great trochanter of the femur of the same side.

The sciatic artery may be ligatured at a point which lies just external to the junction of the middle and
Fig. xxi., 8. lower thirds of a line drawn from the posterior superior iliac spine to the outer part of the ischial tuberosity of the same side. This line also cuts across 

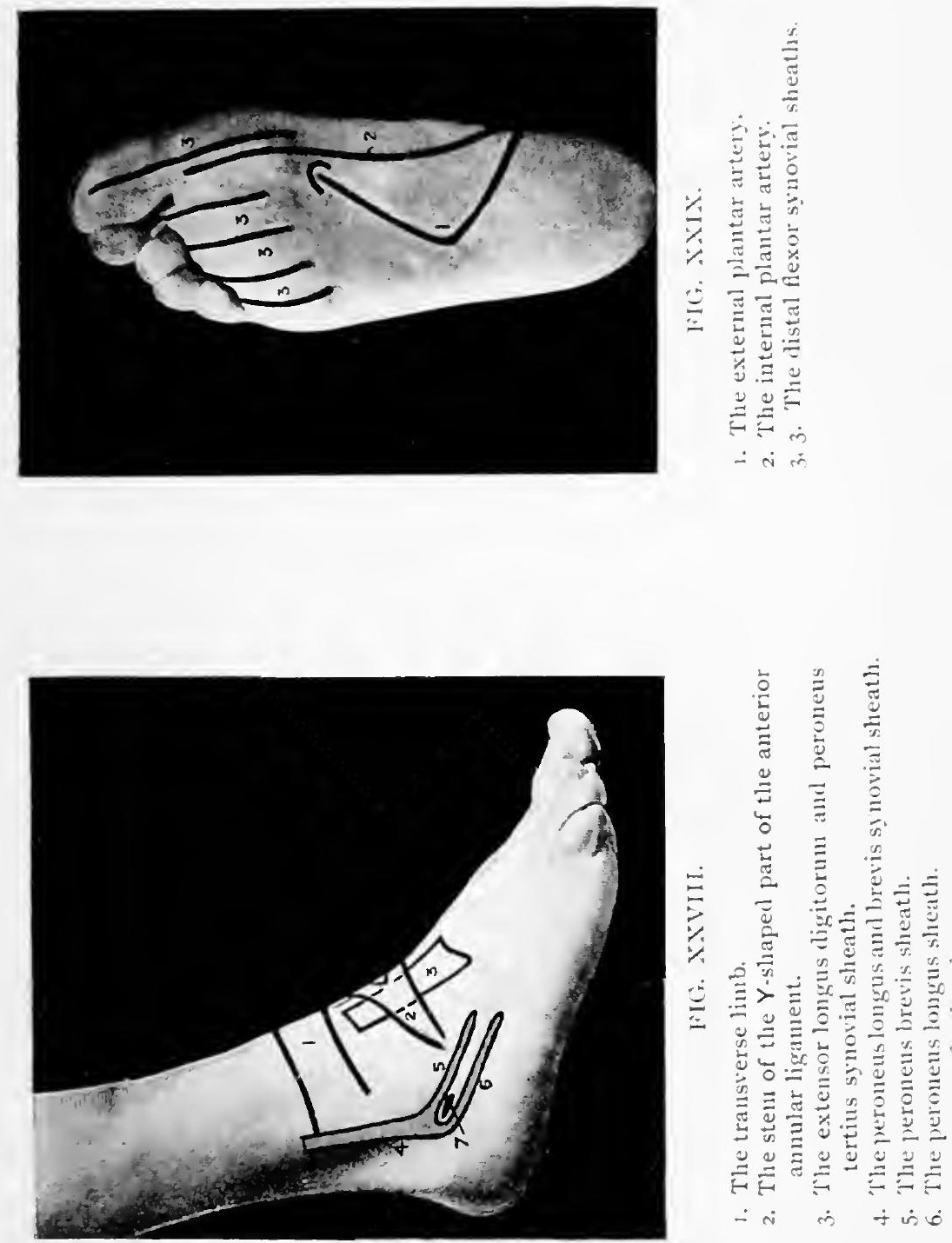

the posterior inferior iliac spine and the tip of the ischial spine, whilst the internal pudic artery lies immediately internal to the seat of election for ligation of the sciatic artery.

The common and superficial femoral arteries. - With the Fig. $x \times$ iv. thigh flexed, everted, and slightly abducted, drawn from a point midway between the anterior superior iliac spine and the symphysis pubis to the adductor tubercle of the femur below.

Fig xxiv.,

The upper $\mathrm{I} \frac{1}{2}$ inches of this line $=$ the common

6. femoral artery.

Fig. xxiv., The upper third=the common and super6, 12. ficial femoral arteries in Scarpa's triangle.

Fig. xxiv., The upper two-thirds $=$ the complete common 6, 12, 13. and superficial femoral arteries.

Fig. xxiv., The middle third $=$ the superficial femoral 13. artery in Hunter's canal.

The popliteal artery enters the upper angle of the popliteal space (from the inner side) by passing between the femur and the adductor magnus tendon. The vessel at first passes obliquely outwards and downwards to the mid-point of the space, and then changes direction by passing vertically downwards as far as the lower border of the popliteus muscle, at which level it bifurcates into anterior and posterior tibial arteries. The point of bifur. cation corresponds to the level of the tubercle of the tibia.

The anterior tibial artery. - The course of this vessel Fig. xxii., may be indicated by a line drawn from a point 19. $x$ iii., just below the level of the tibial tubercle, and 14, 14. midway between the outer tuberosity of the tibia and the head of the fibula, to a second point in front of the ankle midway between the two malleoli, at which 
level the artery lies between the tendons of the extensor longus hallucis and longus digitorum muscles.

Fig.xxii., The anterior tibial artery is continued onFig. 22 xiii., wards as the dorsalis pedis as far as the base of 15. the first interosseous space.

The posterior tibial artery starts at the lower border of Fig. xxi., the popliteus muscle as one of the terminal 20. branches of the popliteal artery. It can be represented by a line which starts at the inferior angle of the popliteal space, on a level with the tubercle of the tibia, and which passes downwards and inwards to the mid-point between the posterior border of the internal malleolus and the inner border of the os calcis. At this level it lies under cover of the internal annular ligament, and bifurcates in this situation into the internal and Fig. xxiv., external plantar arteries. Behind the internal 20.22. malleolus the posterior tibial artery lies between the tendons of the flexor longus hallucis and longus digitorum muscles, but on a slightly superficial plane.

The internal plantay artery passes forwards to the cleft between the first and second toes, whilst
Fig. xxix., 2. the more important external plantar artery is first directed forwards and outwards towards the base of the fifth metatarsal bone, and then, changing direction, passes forwards and inwards to the base of the Fig. xxix., 1. first interosseous space, forming in this latter part of its course the deep plantar arch. It anastomoses with the dorsalis pedis artery, which dips downwards between the two heads of the first dorsal interosseous muscle.

The external saphenous vein arises from the outer side of Fig. xxiii., the venous arch on the dorsum of the foot, 16, 17. passing upwards behind the external malleolus and along the outer and back part of the leg to the middle 
of the popliteal space, where it pierces the deep fascia to Fig. xxi., open into the popliteal vein. It is accompanicd 21. in the greater part of its course by the extermal saphenous nerie, which extends forwards on the outer side of the foot as far as the tip of the little toe.

The internal saphenous iein arises from the inner side of Fig. xxiv., the venous arch found on the dorsum of the 10, 10, 10. foot. It passes upwards in front of the internal malleolus, along the inner side of the leg and knee, behind the internal condyle of the femur, and its further upward course in the thigh is indicated by a line drawn from the adductor tubercle to the saphenous opening. Attention has previously been drawn to the elevation below the internal tuberosity of the tibia which is formed by the sartorius, gracilis and semitendinosus muscles, and below this prominence the saphenous vein is accompanied by the internal saphenous nerve, a branch of the deep division of the anterior crural. The saphenous nerve runs down the leg with the vein, in front of the internal malleolus of Fig. xxiv., the tibia, and extends as far forwards as the 19. ball of the great-toe. In the thigh the nerve crosses in front of the superficial femoral artery from without inwards, and accompanies that artery throughout the whole length of Hunter's canal.

The anterior crural nerve emerges from under cover of Poupart's ligament, about half-way between Fig.xxiv., 5. the anterior superior iliac spine and the pubic spine. The nerve lies nearly $\frac{1}{2}$ inch external to the common femoral artery, and the same distance external to the femoral sheath.

The great sciatic nerve makes its exit from the pelvis Fig. xxi., 12 the pyriformis muscle. The nerve emerges 
from under cover of the lower border of the gluteus maximus muscle just to the inner side of the mid-point between the ischial tuberosity and the great trochanter of the femur. The nerve corresponds in direction to the upper two-thirds of a line drawn downwards from the above point to the middle of the popliteal space below. At the junction of the middle and lower thirds of the thigh the great sciatic nerve divides into its two terminal branches, internal and external popliteal.

The small sciatic nerve lies in the same line as the great sciatic, but extends downwards as far as the inferior angle of the popliteal space.

The internal popliteal nerve crosses the popliteal artery Fig. $x x i ., 13$ superficially from without inwards; its onward continuation, the posterior tibial nerve, and the two terminal branches of the posterior tibial nerve, the internal and external plantars, all have the same surface marking as the corresponding arteries. Two
points, however, need to be borne in mind: first, the posterior tibial nerve crosses the corresponding artery superficially from within outwards and downwards and, secondly, the internal plantar nerve is relatively much more important than the corresponding artery.

The external popliteal or peroneal nerve was last seen to lie Fig. xxi., under cover of the biceps femoris tendon at the Fig. xxiii., upper and outer boundary of the popliteal space. 10., 11. The nerve follows the tendon downwards to the head of the fibula, and curls round to the antero-external Fig. xxiii., aspect of the leg about I inch below the head 12, 13. of that bone, dividing there into its two terminal branches, anterior tibial and musculo-cutaneous.

The anterior tibial nerve passes downwards and inwards to join the corresponding artery, lying external to the 
upper third of the artery, superficial to the middle third, Fig. xxii., and external again to the lower third. The 20. nerve extends forwards along the outer side Fig. xxiii., of the dorsalis pedis artery as far as the cleft 12. between the first and second toes, the con. tiguous sides of which toes it supplies.

The musculo-cutaneous nerve, running down in the sub. Fig. xxii., stance of the peronei muscles, becomes cuta21. . neous below the middle of the leg. It then 13. passes obliquely downwards and inwards across the anterior annular ligament, to be distributed to the greater part of the dorsum of the foot. 


\section{APPENDIX}

\section{THE LENGTH OF VARIOUS PASSAGES, TUBES, ETC.}

THE spinal cord, I6 to 18 inches.

The trachea, $4 \frac{1}{2}$ inches.

The right bronchus, I inch.

The left bronchus, $\mathrm{I} \frac{1}{2}$ to 2 inches.

The pharynx, $4 \frac{1}{2}$ inches.

The œsophagus, 9 to Io inches.*

The stomach :

Capacity, about 2 pints.

Length, Io inches.

Width, 4 to 5 inches.

Duodenum, 8 to ro inches.

Bile-duct, 3 inches.

Small intestine, 23 feet.

Jejunum, upper two-fifths.

Ileum, lower three-fifths.

Appendix, 3 to 4 inches.

Cæcum, $2 \frac{1}{2}$ inches.

Ascending colon, 8 inches.

Transverse colon, 20 inches.

Descending colon, 4 to 6 inches.

* The distance from the teeth to the cardix orifice of the stomach is about 16 to 17 inches. 
Iliac colon, 5 to 6 inches.

Pelvic colon, $\mathrm{I} 6$ to $\mathrm{I} 8$ inches.

Rectum, 5 to 6 inches.

Anal canal, I to $\mathrm{I} \frac{1}{2}$ inches.

Crural canal, $\frac{1}{2}$ inch.

Inguinal canal, $\mathrm{I}_{2} \frac{1}{2}$ inches.

Receptaculum chyli, $\mathrm{I}$ to 2 inches.

Thoracic duct, I6 to 18 inches.

Kidney, $4 \frac{1}{2}$ inches by $2 \frac{1}{2}$ inches by $I \frac{1}{2}$ inches

Ureter, Io inches.

Male urethra, 8 to Io inches.

Prostatic, I to $\mathrm{I} \frac{1}{2}$ inches.

Membranous, anterior wall, $\frac{3}{4}$ inch. posterior wall, $\frac{1}{2}$ inch.

Spongy and penile, 6 to 8 inches.

Testis, I $\frac{1}{2}$ inches by $I$ inch by $\frac{3}{4}$ inch.

Seminiferous tubules, 2 to 3 feet.

Canal of the epididymis, rg to 20 feet.

Vas deferens; 16 to 18 inches.

Ovary, I inch by $\frac{1}{2}$ inch.

Fallopian tubes, 4 to $4 \frac{1}{2}$ inches.

Uterus, 3 inches by 2 inches by $\mathrm{I}$ inch.

Vagina, anterior wall, 3 inches.

, posterior wall, 4 inches.

Female urethra, I to $I \frac{1}{2}$ inches. 


\section{THE WEIGHT OF SOME ORGANS.}

The brain: Male, 50 ounces; female, 45 ounces.

The lungs: Together, 42 ounces; right, 22 ounces; left, 20 ounces.

The heart: Male, ro to I2 ounces; female, 8 to Io ounces.

The liver, 50 to 60 ounces.

The kidneys, $4 \frac{1}{2}$ ounces.

The suprarenals, I to 2 drachms.

The prostate, 6 drachms.

The testis, 6 to 8 drachms.

The ovary, I to 2 drachms.

The spinal cord, I $\frac{1}{2}$ ounces.

The prncreas, 2 to 4 ounces.

The spleen, 7 ounces. 
THE OSSIFICATION AND EPIPHYSES OF THE BONES OF THE UPPER AND LOWER EXTREMITIES.

Certain epiphyses and epiphysial lines have been alluded to in the text, and the following table, compiled from Gray's "Anatomy," has consequently been appended

(a) THE UPPER EXTREMITY :

The clavicle':

I centre for the shaft (in membrane) in the fourth to fifth week (i.u.l.).*

I centre for the sternal end in the eighteenth to twentieth year.

Union between the two in the twenty-fifth year.

The scapula:

I centre for the body in the eighth week (i.u.l.).

I centre for the coracoid process in the first year.

I centre for the base of the coracoid process

2 centres for the acromial process

I centre for the vertebral border

I centre for the inferior angle

between the fifteenth and eighteenth years.

The humerus:

I centre for the shaft in the eighth week (i.u.l.).

I centre for the head in the first year.

I centre for the great tuberosity in the thira year.

I centre for the small tuterosity in the fourth year.

Head and tuberosities unite together in the fifth yeas and with the shaft in the twentieth year.

I centre for the internal condyle in the fifth year.

I centre for the trochlear in the twelfth year.

I centre for the capitellum in the second year.

I centre for the external condyle in the thirteenth year.

The last three unite together to form an epiphysis, which unites with the shaft in the seventeenth year, the internal condyle juining separately in the eighteenth year.

The radius and $u \ln a$ :

I centre for the shaft of the radius in the eighth week (i.u.l.).

I centre for the shaft of the ulna in the eighth week (i.u.l.).

- i.u.L $=$ intra uterine life 
I centre for the lower end of the radius in the second year - union at twenty.

I centre for the lower end of the ulna in the fourth yearunion at twenty.

I centre for the upper end of the radius in the fifth yearunion at sixteen.

I centre for the upper end of the ulna in the tenth yearunion at sixteen.

The carpus:

All the bones are cartilaginous at birth. The first centre of ossification appears in the os magnum and the last in the pisiform.

The metacarpus and phalanges:

I centre for the shaft of the metacarpal and the shaft of the phalanx in the eighth week (i.u.l.).

I centre for the head of the metacarpal bone and the base of the phalanx in the third year.

Union between diaphyses and epiphyses in the twentieth year.

The thumb metacarpal is an exception to the rule, a well-marked epiphysis always appearing at the base. This bone, therefore, resembles a phalanx in its mode of ossification, though an epiphysis is not infrequently seen at the head of the bone also.

\section{THE LOWER EXTREMity:}

The os innominatum:

Three main primary centres for ilium, ischium, and pubis, appearing respectively in the second, third, and fourth months (i.u.l.). The three parts of the bone are separated at first by the $\mathbf{Y}$-shaped acetabular cartilage.

Five secondary centres appear about puberty for the crest, symphysis pubis, anterior inferior iliac spine, ischial tuberosity, and the acetabular cartilage. These unite at about the twenty-fifth year.

\section{The fernur :}

I centre for the shaft in the fifth week (i.u.l.).

I centre for the lower end in the ninth month (i.u.l.)union with shaft in the twentieth year.

I centre for the head in the first year-union with shaft in the eighteenth year.

I centre for the great trochanter in the fourth year.

I centre for the small trochanter in the fourteenth year.

\section{The patella :}

I centre in the third year. 
The tibia and fibula :

I centre for the shaft of the tibia in the seventh week (i.u.l.).

I centre for the shaft of the fibula in the eighth week (i.u.l.).

1 centre for the upper end of the tibia in the first yearunion at twenty.

J centre for the upper end of the fibula in the fourth year -union at twenty-five.

1 centre for the lower end of the tibia in the second year -union at eighteen.

I centre for the lower end of the fibula in the second year-union at twenty.

The tarsus:

The os calcis, astragalus and cuboid alone have centres of ossification at birth, these appearing respectively in the sixth, seventh, and ninth months. The os calcis possesses a secondary centre, appearing about the tenth year, for its posterior surface.

The metatarsus and phalanges:

Centres appear as in metacarpus, etc. 


\section{N D EX}

A BDOMINAL, AORTA, 61 planes, 50

regions, 5 I

Acromial spine and process, 19, 20

Acromio-clavicular joint, 19

Adductor magnus tendon, 75 tubercle, 75

Anal canal, length of, 87

"Anatomical snuff-box," 27, 28, 29

Ankle region, 76

Antecubital space, 24

Anterior annularligament(ankle), 78

Anterior annular ligament (wrist), 25,26

Anterior crural nerve, 83

tibial artery, 8I

tibial nerve, 84

triangle of neck, I2

Antrum of Highmore, II

Aortic arch, 38

intercostals, 40

valve, 37

Apex beat, 36

Apices of lung, 45

Appendix, 57 length of, 86

Ascending aorta, 38 colon, 57 length of, 86

Astragalus, 77

Auricular area, 37

Auriculo-temporal nerve, I5

Axilla, 21

Axillary artery, 20, 29 lymphatics, 22

Base of brain, 4

Basic fossæ, 8

Basilic vein, 24

Biceps femoris, 74

hunieri, 21, 24

Bicipital fascia, 24

groove, 2 I

sulci, 24

Bile-duct, 64 length of, 86

Bony points of elbow, 23

Brachial artery, 24, 29 plexus, I7
Bregma, 2

Broca's area, 6

Bronchi, 46

length of, 86

Bryant's line and triangle, 7 I

Bulb of penis, 67 of vestibule, 67

Cæcиm, 56

length of, 86

Canal of epididymis, 87

Cardiac orifice, 54

Carotid arteries, 13

triangle, 13

tubercle, $\mathrm{r} 3$

Central point, $5^{\circ}$ tendinous point of perineum, 67,68

Cephalic vein, 24, 25

Cerebellum, 5

Cerebrum, 4

Cervical sympathetic, 16

Circumflex 11erve and arters, 30

Clavicle, 19

Clitoris, 68

Cœliac axis, 6r

Colles's fascia, 67

Common bile-duct, 64,65 carotid artery, 38 femoral artery, $8 \mathbf{r}$ iliac artery, 62

Conus medullaris, 66

Coraco-brachialis fold, 22, 29

Coracoid process, 20

Coronal suture, 2

Coronary artery, 6r

Creases of palm and fingers, 33 of wrist, 25

Cricoid cartilage, 18,47

Crura of penis, 67

Crural canal, 73 length of, 87

Cuboid bone, 76

Cuneiform bone, 26

Curvatures of stow1ach, $5^{6}$

Deep cardiac dulness, 45 epigastric artery, 62 palmar arch, 30 plantar arch, 82 
Deltoid, 20

Descending aorta, 38 colon, 58

Diaphragm, 64 length of, 87

Digital arteries, 30

Dorsalis pedis artery, $\$ 2$

Douglas's fold, 43, 53 pouch, $6 \mathrm{~S}$

Duodeno-jejunal fold, 55

Duodenum, 55 length of, 86

Dura mater, 59, 66

Elbow region, 23

Epiglottis, 18

Epiphyses, 89

Epiphysial line of humerus, 21, 23 of femur, 75

Epitrochlear gland, 25

Extensor tendons of foot, 64 of wrist, 28

External abdominal ring, 54 angular frontal process, 3 annular ligament (foot), 80 carotid artery, to

iliac artery, 62

jugular vein, 15

lateral ligament (knee), 74 parieto-occipital fissure, 6

plantar artery and nerve, 82 , 84

popliteal nerve, 74,84

saphenous vein and nerve, $\mathrm{S}_{2}, 83$

Facial artery, 14

nerve, 9. 10

Fallopian tubes, length of, 87

False ribs, 34

Falx cerebri, 2

Female urethra, lengtli of, 87

Femoral canal and ring, 73

Fibula, 74

Filum terminale, 66

First costal cartilage and rib, 34

First interspace, 34

Fissures of lung, 44

Flexor carpi radialis, 25, 29 ulnaris, 25

sublimis, 25,26

synovial sheaths, 26,27

Floating ribs, 34

Fontanelle, anterior, 2 posterior, 2

Foot region, 76

Foramen of Winslow, 64

Fornices of vagina, 68

Frontal sinus, 11

Gall-bladder, 64

Gastro-hepatic omentum, 64
Genital area, 67

Gluteal artery, 60

Gluteus maximus, 70

Gracilis, 75

Great auricular nerve, 17

occipital nerve, 14

sciatic nerve, $s_{3}$

Hamiltou's test, 20

Hand region, 25

Heart, 35

Hepatic artery, 61, 64, 65

flexure, 57

Hesselbach's triangle, 62

Hip region, $70,7 \mathrm{I}$

Houston's valves, 68

Humierus, head of, 20,22

Hunter's canal, 73

Ileo-cæcal valve, 56

Iliac colon, 58 length of, 87

crest, $5^{2}$

spines, 52, 53

tubercles, 53

Ilio-pelvic colon, 58 length of, 87

Ilio-tibial band, 75

Inferior dental nerve and artery, 10

mesenteric artery, 62

temporal crest, 3,4

vena cava, 40,62

Infraclavicular space, 20

Infra-orbital foranten, if

Inguinal canal, 54 length of, 87

groove, 71

Inion, I

Innominate artery, 38 veins, 39,40

Intercostal space, 35

Internal abdominal ring, 54

annular ligament (foot), 79

carotid artery, I3

jugular vein, 16

mammary artery, 39

plantar artery and nerve, 82 , 84

popliteal nerve, 84

pudic artery, $8 \mathrm{r}$

saphenous nerve, 83 vein, $\mathrm{S}_{3}$

Intertubercular plane, 50,53

Ischial spine, $8 \mathrm{I}$

tuberosity, 70

Ischio-rectal fosse, 68

Island of Reil, 5

Kidney, 59

lengtli and weight of, 87 
Kuee region, 74

Kuuckles, 33

Labia majora and minora, 67

Lachrymal sac, ro

Lambda, 2

Lambdoid suture, 2

Larynx, i8

Lateral sinus, 2, 4, 5, 9 ventricles, 8 vertical plane, 49

Length of femur and tibia, 74 of humerus, 2 I

Ligamentum patellæ, 75 teres, 63

Lineæ semilunares, $5^{2}$ transversæ, 52

Lingual artery, 14

Liver, 63 weight of, 88

Ludwig's angle, 35 plane, $5 \mathrm{I}$

Lumbar puncture, 66

Lungs, 42 weight of, 89

Macewen's triangle, 4, 8

Malar tubercle, 3

Mamma, 3.4

Masseter muscle, 9

Mastoid antrum, 8

McBurney's point, 57

Median nerve, 24, 32 vertical plane, 49

Mental foramen, I I

Mesentery of small intestine, 56

Mesial fissure of brain, I

Metacarpo-phalangeal joint, 33

Metopic suture, 2

Middle cerebral artery, 5 meningeal artery, 6,7

Mid-tarsal joint, 78

Mitral valve, 37

Mons veneris, 67

Morris's quadrilateral, 60

Muscular triangle, I 2

Musculo-cutaneous nerve (arm), 3 I (1eg), 85

Musculo-phrenic artery, 39

Musculo-spiral nerve, 24, 3 I

Nasal duct, Io

Nasion, I

Natal fold, 7I

Nélaton's line, 7 I

Ninth costal cartilage, $35,50,59$

Nipple, 35

Obelion, 2

Occipital artery, 14 nerve (great), I4 (small), 17
Eisophagus, 47

Olecranon, 23

Omo-hyoid muscle, ra

Orbit, boundaries of, 10

Os calcis, 77

Os uteri, 68

Ovary, $6 \mathrm{I}, 87,88$

Palmar fascia, 33

Palmaris longus, 32

Pancreas. 56 weight of, 88

Paracentesis of pericardium, 46

Paracentral point, 50

Parietal eminence, 2

Parieto-occipital sulcus, 6

Parotid gland, 9

Pectoralis major and fold, 21 minor, 29 ।

Pelvic colon, 58 length of, 87

Pericardium, 46

Perineum, 67

Peroneal nerve, 74,84 tendons, 76,80 tubercle, 76 , 8o

Petit's triangle, 54

Pharynx, I I length of, 86

Phrenic nerve, 16

Pisiform bone, 25, 26

Plantar arch, 82

Pleura, 4I :

Popliteal artery, 8I space, 74

Portal vein, 64

Posterior annular ligament (wrist), 28 auricular artery and nerve, I4 inferior iliac spine, 81 interosseous nerve, 24,32 superior iliac spine, 53 tibial arteryland nerve, $82, S_{4}$ triangle, I3

Poupart's liganient, 7 I

Prepatellar bursa, 76

Prostate gland, 53 weight of, 88

Pubic spine, 53

Pudic vessels, 67

Pulmonary artery, 39 valve, 37

Pylorus, 55

Pyriformis muscle, 80

Radial artery, 25, 28, 29 nerve, 24,3 I tubercle, 28

Radius, 23

Receptaculum chyli, 47,87

Rectal area, 67, 68 examination, 69 
Rectum, $5^{8}$ length of, 87

Reid's base line, 5

Renal artery, 62

Rima glottidis, 18

Rolandic area, 6 fissure, 6

Roots of lung, 45

Sagittal suture, 2

Saphenous opening, 73

Sartorius, 75 .

Scaleuus anticus, I5

Scaphoid bone (carpus), 25 (tarsus), 77,78

Scarpa's triangle, 72

Sciatic artery, 80 nerve (great), 83 (small), $8_{4}$

Semilunar fold of Douglas, 52

Semimembranosus, 75

Seminiferous tubules, length of, 87

Semitendinosus, 75

Shoulder region, I9

Sinuses of nose, 12

Small intestine, $5^{6}$ occipital nerve, 17 sciatic nerve, $S_{4}$

Sphenoidal siuus, I2

Spinal accessory nerve, 16 cord, 65 length and weight, 86, 88

Spinous plane, 52

Spleen, 65

Splenic artery, 61 flexure, 57

Stenson's duct, 9

Sterno-mastoid, I 2

Sterno-xiphoid plane, 52

Stomach, 54

Styloid process of radius and ulna, 27

Subclavian artery, 15, 39 triangle, I3

Subcostal plane, 52

Suburaxillary gland and triangle, 12

Subpubic angle, 67

Superficial cardiac dulness, 45 cervical plexus, 17

femoral artery, $8 \mathrm{I}$

lymphatics of arm, 22 of leg, 72

palmar arch, 30

temporal artery, 15

Superior epigastric artery, 39

longitudinal sinve, 2

mediastinum, 39

mesenteric artery, 61

temporal crest, 3,6
Superior thyroid artery, 13

vella cava, to

Supra-acronilal nerve, 17

Supraclavicular nerve, 17

Siprameatal crest and spine, 3, 8 fossa, $\mathrm{S}$

Supra-orlital foramen, iI

Suprarenals, weiglit of, ss

Suprasterual nerve, I7

plane, 52

Sustentaculum tali, 77

Sylvian fissure, 5

point, 5

Sympathetic chain and ganglia, 16

Symphysis pubis, 53

Synovial membrane of knee, 76 sheaths of ankle, 78,79

of wrist (extensor), 28

(flexor), 26

Tegmen antri, 9

Teuporo-sphencillal sulcus, 6

Tendo Achillis, 78

oculi, ro

Tendons of ankle region, 76 of wrist, 25

Tentorium cerebelli, 5

Testis, length and weight, $87, S 6$

Theca vertebralis, 66

Thoracic aorta, $3^{8}$

duct, 47

plane, 50

Thyroid isthmus, 18

Tihial tuberosities, 74

Tibialis anticus, 77 posticus, 77

Tonsil, 10

Trachea, I8

Transpyloric plane, 50, 55

Transverse cervical nerve, I7 colon, 57,86

creases of palm, 33 of wrist, 25

facial artery, 9

Transversus perinei, 67 prucess of atlas, 16

Trapezium, 25

Triangles of neck, 12

Triangular ligament, 67

Tricuspid valve, $3^{8}$

Trochanter of femur, 70

True ribs, 34

Tuberosities of humerus, 20 of tibia, 74

Ulnar artery, 24, 30 nerve, 32

Umbilical plane, 52

Umbilicus, 52

Unciform bone, 26

Urachus, 6I 


\section{INDEX}

Ureter, 60,87

Urethra, male, 87

female, 87

Uterus, dimeusions of, 87

Vagina, examination of, 68 dimensions of, $\mathrm{S}_{7}$

Vagus nerve, 16

Valves of heart, 37

Veins of elbow, 24

Vena azygos major, 40

Ventricular area, 36

Vermiform appendix, 57

Vestibule, 68

Vocal cords, 18

Wrist-joint, 25

Wrist region, 25

Zygomatic process, 3

H. K. LEWIS \& CO. LTD., 136, GOWER STREET, LONDON, W.C. 




\section{PLEASE DO NOT REMOVE}

CARDS OR SLIPS FROM THIS POCKET

\section{UNIVERSITY OF TORONTO LIBRARY}

BioMed 
